3.5

Sa

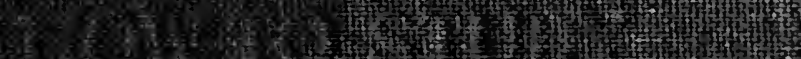

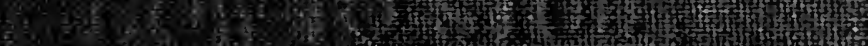
3ut 筑

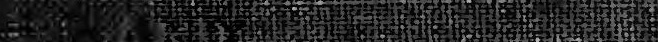
ato

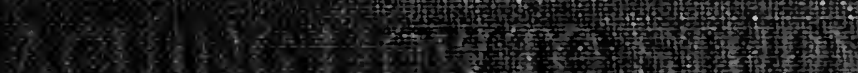

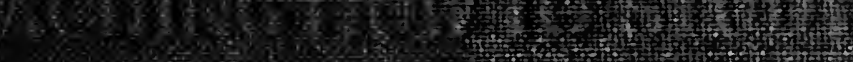
P

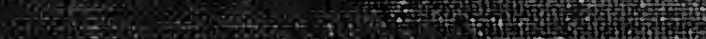

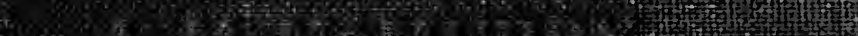

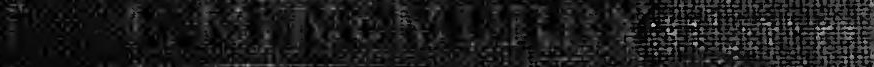
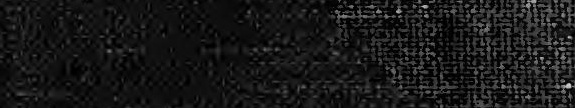


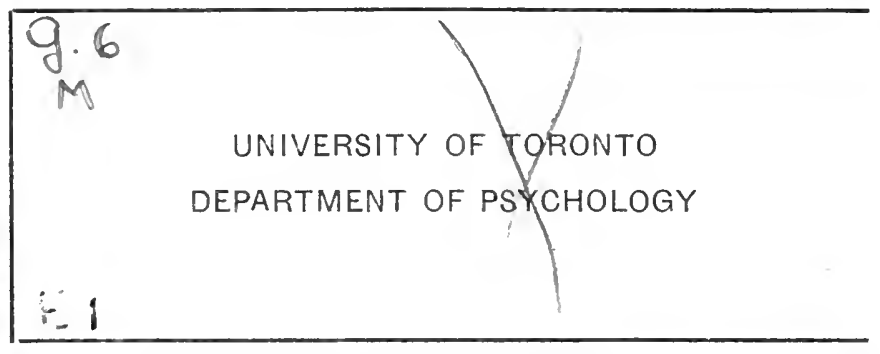




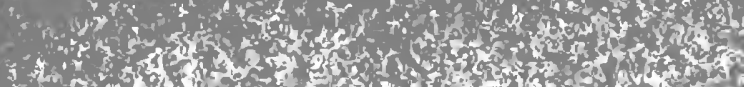

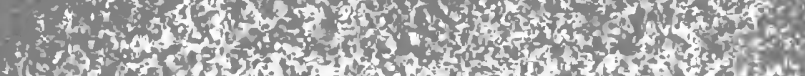

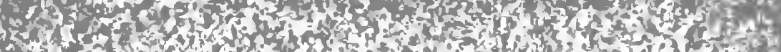

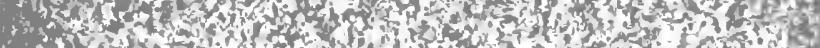

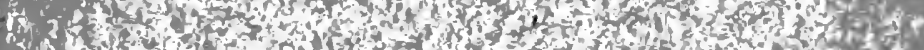

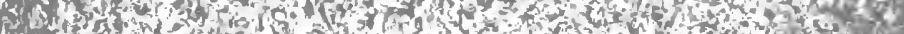

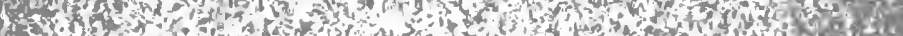

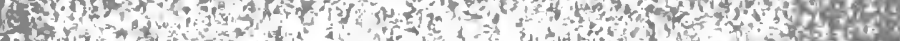

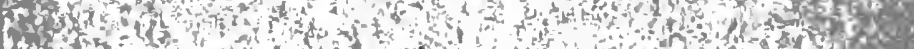
Atwan -

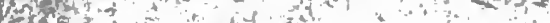

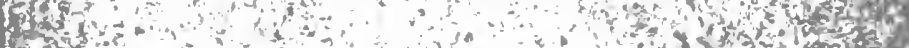
Buthe

de

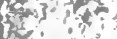

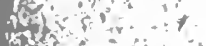

Ift

tas is

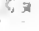

L 130

$x+2=$

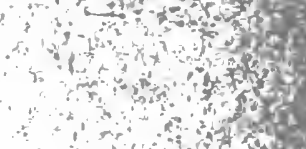

the

$\because n$

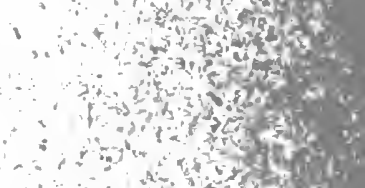

सt:

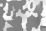

सी

consinis

s.

os:

tipi:

$1+\sin$

$\int_{1}$

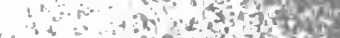

$\because \therefore ;$ inf

(5)

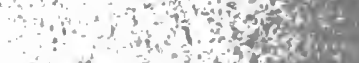

$B=1^{\text {th }}=0$

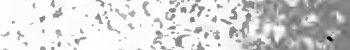

is:

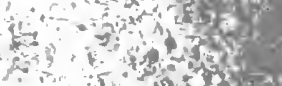

siv:

$8=3 \frac{3}{4}$

$=5$

(3)

$x^{2}+x^{2}$

ist

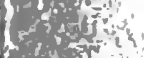

Cin $10 x+2$

$1+\because \cdots+1,1$

to: $:$ की मों

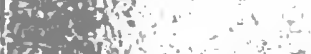

,

Afer

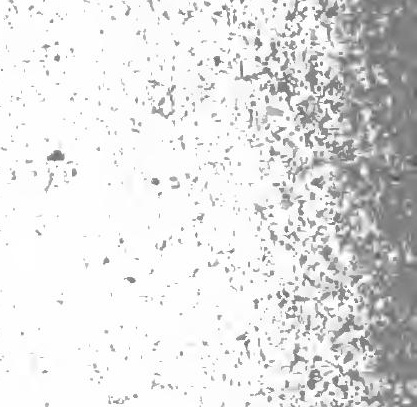




\title{
HOW TO STUDY AND \\ TEACHING HOW TO STUDY
}

\author{
BY \\ F.' M. MCMURRY
}

PROFESSOR OF ELEMENTARY FDOCATION IN TEACHERS COLLEGE, COLUMBLA UNIVERSITY

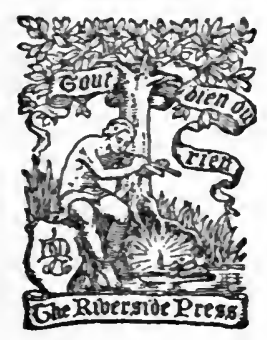

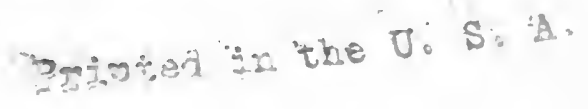

BOSTON NEW YORK CHICAGO SAN FRANCISCO

HOUGHTON MIFELIN COMPANY cbe tuberside fress Cambrioge 
COPYRIGHT, 1909, BY F. M. MCMURRY

ALL RIGHTS RISERVED

SIXTEENTH IMPRESSION

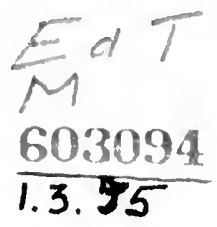

Che Rlberside Press CAMBRIDGR . MASSACIUSETTS

PRINTRD IN TIIR $U, S$. A 
TO MY FRIEND

ORVILLE T. BRIGHT

THIS VOLUME IS DEDICATED, AS A TOKEN OF WARM AFFECTION .

AND PROFESSIONAL

INDEBTEDNESS 
Digitized by the Internet Archive in 2007 with funding from Microsoft Corporation 


\section{PREFACE}

Some seven or eight years ago the question of how to teach children to study happened to be included in a list of topies that I hastily prepared for discussion with one of my classes. On my later examination of this problem I was much surprised, both at its difficulty and scope, and also at the extent to which it had been neglected by teachers. Ever since that time the two questions, How adults should study, and How children should be taught to study, have together been my chief hobby.

The following ideas are partly the result of reading; but since there is a meagre quantity of literature bearing on this general theme, they are largely the result of observation, experiment, and discussion with my students. Many of the latter will recognize their own contributions in these pages, for I have endeavored to preserve and use every good suggestion that came from them; and I am glad to acknowledge here my indebtedness to them.

In addition I must express my thanks for valuable criticisins to my colleague, Dr. George D. Strayer, and also to Dr. Lida B. Earhart, whose suggestive monograph on the same general subject has just preceded this publication.

Teachers College, May 6, 1909.

Tye Author. 



\section{CONTENTS}

\section{PART I}

PRESENT METHODS OF STUDY ; NATURE OF STUDY AND ITS PRINCIPAL FACTORS

I. Imdications that young People do not leari TO STUDY PROPERLY; THE SERIOUSNESI OF THE EnIL . . . . . . . . . . . . 5

II. The Nature of Studx, and its prixcipal FacTORS . . . . . . . . . . . 12

\section{PART If}

NATURE OF THE PRINCIPAL FACTORS IN STUDY, AND THEIR RELATION TO CHILDREN

III. Provision for specific perposes, as one Factor IN STUdY . • . . . . . . . . 31

IV. The supplementivg of Thought, as a second FACTOR IN STCDY . . . . . . . . 61

V. The Organization of Ideas, as a third Factor IN STUdY . . . . . . . . . . 85

VI. JUdGING OF THE SOCNDNESS AND GENERAL WORTH of Statemests, as a fotrth Factor Iy Study 135 
VII. Memorizing, as a fifth Factor in Study • 161

VIII. The using of Ideas, as a sixth Factor in Studt 192

IX. Provision for a tentative rather than a fixed

Attitude toward KNowledge, as a sevente

Factor in Study . . . . . . . . . 220

X. Provision for Individuatity, as aN eigmta FacTGR IN STUDY . . . . . . . . . . 246

\section{PART III}

\section{CONCLUSIONS}

XI. Full meaning of Study; Relation of Study to Children and to the School . . . . . 283

$\operatorname{INDEX} \ldots \ldots \ldots . \ldots . \ldots 313$ 


\section{PART I}

PRESENT METHODS OF STUDY; NATURE OF STUDY, AND ITS PRINCIPAL FACTORS 



\section{HOW TO STUDY}

\section{CHAPTER I}

INDICATIONS THAT YOUNG PEOPLE DO NOT LEARN TO STUDY PROPERLY; THE SERIOUSNESS OF THE EVIL

No doubt every one can recall peculiar methods of study that he or some one else has at some time followed. During my attendance at high school I often studied aloud at home, along with examples of several other temporary or permanent members of the family. I remember becoming exasperated at times by one of my girl companions. She not only read her history aloud, but as she read she stopped to repeat each sentence five times with great vigor. Although the din interfered with my own work, I could not help but admire her endurance; for the physical labor of mastering a lesson was certainly equal to that of a good farm hand, for the same period of time.

This way of studying history seemed extremely ridiculous. But the method pursued by myself and several others in beginning algebra at about the same time was not greatly superior. Our text-book contained several long sets of problems which were the terror of the class, and scarcely one of which we were able to solve alone. We had several friends, however, who could solve them, and, by calling upon them for help, we obtained the "statement" for each one. All 


\section{HOW TO STUDY}

these statements I memorized, and in that way I was able to "pass off" the subject.

A few years later, when a school principal, I had a fifteen-year-old boy in my school who was intolerably lazy. His ambition was temporarily aroused, however, when he bought a new book and began the study of history. He happened to be the first one called upon, in the first recitation, and he started off finely. But soon he stopped, in the middle of a sentence, and sat down. When I asked him what was the matter, he simply replied that that was as far as he had got. Then, on glancing at the book, I saw that he had been reproducing the text verbatim, and the last word that he had uttered was the last word on the first page.

These few examples suggest the extremes to which young people may go in their methods of study. The first instance might illustrate the muscular method of learning history; the second, the memoriter method of reasoning in mathematics. I have never been able to imagine how the boy, in the third case, went about his task; hence, I can suggest no name for his method.

While these methods of study are ridiculous, I am not at all sure that they are in a high degree excep-

Oolleotive tional. The most extensive investigation of examples of this subject has been made by Dr. Lida B. stady.

Earhart, ${ }^{1}$ and the facts that she has collected reveal a woeful ignorance of the whole subject of study. Among other tests, she assigned to eleven- and twelve-year-old children a short selection from a text-

1 Systematic Study in the Elementary Schools. A popular form of this thesis, entitled Teaching Children to Study, is published in the Riverside Educational Monographs. 
book in geography, with the following directions: "Here is a lesson from a book such as you use in class. Do whatever you think you ought to do in studying this lesson thoroughly, and then tell (write down) the different things you have done in studying it. Do not write anything else."1

Out of 842 children who took this test, only fourteen really found, or stated that they had found, the subject of the lesson. Two others said that they wound find it. Eighty-eight really found, or stated that they had found, the most important parts of the lesson; twentyone others, that they would find them. Four verified the statements in the text, and three others said that they would do that. Nine children did nothing; 158 "did not understand the requirements"; 100 gave irrelevant answers; 119 merely "thought," or "tried to understand the lesson," or "studied the lesson"; and 324 simply wrote the facts of the lesson. In other words, 710 out of the 842 sixth- and seventh-grade pupils who took the test gave indefinite and unsatisfactory answers. This number showed that they had no clear knowledge of the principal things to be done in mastering an ordinary text-book lesson in geography. Yet the schools to which they belonged were, beyond doubt, much above the average in the quality of their instruction.

In a later and different test, in which the children were asked to find the subject of a certain lesson that was given to them, 301 out of 828 stated the subject fairly well. The remaining 527 gave only partial, or indefinite, or irrelevant answers. Only 317 out of the

1 Ibid., Chapter 4. 
828 were able to discover the most important fact in the lesson. Yet determining the subject and the leading facts are among the main things that any one must do in mastering a topic. How they could have been intelligent in their study in the past, therefore, is difficult to comprehend.

It is, perhaps, unnecessary to collect proofs that young people do not learn how to study, because Teachers' teachers admit the fact very generally. In. and parents'
complaints
deed, it is one of the common subjects of about mothods of strdy. complaint among teachers in the elementary school, in the high school, and in the college. All along the line teachers condole with one another over this evil, college professors placing the blame on the instructors in the high school, and the latter passing it down to teachers in the elementary school. Parents who supervise their children's studies, or who otherwise know about their habits of work, observe the same fact with sorrow. It is at least refreshing to find one matter, in the much-disputed field of education, on which teachers and parents are well agreed.

How about the methods of study among teachers themselves? Unless they have learned to study propMethod of erly, young people cannot, of course, be exstudy among pected to acquire proper habits from them. teachers.

The most enlightening single experience I. have ever had on this question came several years ago in connection with a series of lectures on Primary Education. A course of such lectures had been arranged for me without my full knowledge, and I was unexpectedly called upon to begin' it before a class of some seventy-five teachers. It was necessary to commence 
speaking without having definitely determined my first point. I had, however, a few notes which I was attempting to decipher and arrange, while talking as best I could, when I became conscious of a slight clatter from all parts of the room. On looking up I found that the noise came from the pencils of my audience, and they were writing down my first pointless remarks. Evidently discrimination in values was not in their program. They call to mind a certain theological student who had been very unsuccessful in taking notes from lectures. In order to prepare himself, he spent one entire summer studying stenography. Even after that, however, he was unsuccessful, because he could not write quite fast enough to take down all that was said.

Even more mature students often reveal very meager knowledge of methods of study. I once had a class of some thirty persons, most of whom were men twenty. five to thirty-five years of age, who were college graduates and experienced teachers. One day I asked them, "When has a book been read properly?" The first reply came from a state university graduate and school superintendent, in the words, "One has read a book properly when one understands what is in it." Most of the others assented to this answer. But when they were asked, "Is a person under any obligations to judge the worth of the thought?" they divided, some saying yes, others no. Then other questions arose, and the class as a whole soon appeared to be quite at sea as to the proper method of reading books. Perhaps the most interesting thing was the fact that they seemed never to have thought seriously about the matter. 
Fortunately Dr. Earhart has not overlooked teachers methods of study in her investigations. In a questionnaire that was filled out by 165 teachers, the latter were requested to state the principal things that ought to be done in "thinking about a lesson." This was practically the same test as was given to the 842 children before mentioned. While at least twenty different things were named by these teachers, the most frequent one was, "Finding the most important points." 1 Yet only fifty-five out of the 165 included even this. Only twenty-five, as Dr. Earhart says, "felt, keenly enough to mention it, the necessity of finding the main thought or problem." Forty admitted that they memorized more often than they did anything else in their study. ing. Strange to say, a larger percentage of children than of teachers mentioned finding the main thought. and finding the more important facts, as two factors in mastering a lesson. Water sometimes appears to rise higher than its source.

About two-thirds of these 165 teachers ${ }^{2}$ declared that they had never received any systematic instruction about how to study, and more than half of the remainder stated that they were taught to memorize in studying. The number who had given any careful instruction on proper methods of study to their own pupils was insignificant. Yet these 165 teachers had had unusual training on the whole, and most of them had taught several years in elementary schools. If teachers are so poorly informed, and if they are doing so little to instruct their pupils on this subject, how can the latter be expected to know how to study?

'Ibid., Chapter 5. ' Ibid., Chapter 5. 
The prevailing definition of study gives further proof of a very meager notion in regard to it. Frequently during the last few years I have obtained from The prostudents in college, as well as from teachers, $\begin{gathered}\text { vailing } \\ \text { definition of }\end{gathered}$ brief statements of their idea of study. Fully stady. nine out of every ten have given memorizing as its nearest synonym.

It is true that teachers now and then insist that studying should consist of thinking. They even send children to their seats with the direction to "think, think hard." But that does not usually signify much. A certain college student, when urged to spend not less than an hour and a half on each lesson, replied, "What would I do after the first twenty minutes?" His idea evidently was that he could read each lesson through and memorize its substance in that time. What more remained to be done? Very few teachers, I find, are fluent in answering his question. In practice, memorizing constitutes much the greater part of study.

The very name recitation suggests this fact. If the school periods are to be spent in reciting, or reproducing, what has been learned, the work of preparation very naturally consists in storing the memory with the facts that are to be required. Thinking periods, as a substitute name for recitation periods, suggests a radical change, both in our employment of school time and in our method of preparing lessons. We are not yet prepared for any such change of name.

Consider finally the literature treating of study. Certainly there has never been a period when there was a more general interest in education than during the last twenty years, and the progress that has been 
made in that time is remarkable. Our study of the The litera- social view-point, of child nature, of appertare dealing ception, interest, induction, deduction, corof stady. relation, etc., has been rapidly revolutionizing the school, securing a much more sympathetic government of young people, a new curriculum, and far more effective methods of instruction. In consequence, the injuries inflicted by the school are fewer and less often fatal than formerly, while the benefits are more numerous and more vital. But, in the vast quantity of valuable educational literature that has been published, careful searching reveals only two books in English, and none in German, on the "Art of Study." Even these two are ordinary books on teaching, with an extraordinary title.

The subject of memorizing has been well treated in some of our psychologies, and has received attention in a few of the more recent works on method. Various other problems pertaining to study have also, of course been considered more or less, in the past, in books on method, in rhetorics, and in discussions of selection of reading matter. In addition, there are a few short bul notable essays on study. There have been practically, however, only two books that treat mainly of this subject, - the two small volumes by Dr. Earhart, already mentioned, which have been very recently published. In the main, the thoughts on this general subject that have got into print have found expression merely as incidents in the treatment of other themes - coming, strange to say, largely from men outside the teaching profession - and are contained in scattered and forgotten sources. 
Thus it is evident not only that children and teachers ure little acquainted with proper methods of study, but that even sources of information on the subject are strangely lacking.

The seriousness of such neglect is not to be overestimated. Wrong methods of study, involving much unnecessary friction, prevent enjoyment of seriousness school. This want of enjoyment results in of this evil. much dawdling of time, a meager quantity of knowledge, and a desire to quit school at the first opportunity. The girl who adopted the muscular method of learning history was reasonably bright. But she had to study very "hard"; the results achieved in the way of marks often brought tears; and, although she attended the high school several years, she never finished the course. It should not be forgotten that most of those who stop school in the elementary grades leave simply because they want to, not because they must.

Want of enjoyment of school is likely to result, further, in distaste for intellectual employment in general. Yet we know that any person who amounts to much must do considerable thinking, and must even take pleasure in it. Bad methods of study, therefore, easily become a serious factor in adult life, acting as a great barrier to one's growth and general usefulness. 


\section{CHAPTER II}

THE NATURE OF STUDY, AND ITS PRINCIPAL FACTORS

OUR physical movements ordinarily take place in response to a need of some sort. For instance, a person How the wishing to reach a certain point, to play a demand for study erises. certain game, or to lay the foundations for a house, makes such movements as are necessary to accomplish the purpose desired. Even mere physical exercise grows out of a more or less specific feeling of need.

The mental activity called study is likewise called forth in response to specific needs. The Eskimo, for example, compelled to find shelter and having only blocks of ice with which to build, ingeniously contrives an ice hut. For the sake of obtaining raw materials he studies the habits of the few wild animals about him, and out of these materials he manages by much invention to secure food, clothing, and implements.

We ourselves, having a vastly greater variety of materials at hand, and also vastly more ideas and ideals, are much more dependent upon thinking and study. But, as in the case of the Eskimo, this thinking and study arises out of actual conditions, and from specific wants. It may be that we must contrive ways of earning more money; or that the arguments for protective tariff seem too inconsistent for comfort; or that the reports about some of our friends alarm us. The occasions that call forth thought are infinite in number and kind. But the essential fact is that study does not normally 
take place except under the stimulus or spur of particular conditions, and of conditions, too, that are unsatisfactory.

It does not take place even then unless we become conscious of the strained situation, of the want of harmony between what is and what might be. For ages malarial fever was accepted as a visitation by Divine Providence, or as a natural inconvenience, like bad weather. People were not disturbed by lack of harmony between what actually was and what might be, because they did not conceive the possibility of preventing the disease. Accordingly they took it as a matter of course, and made no study of its cause. Very recently, on the other hand, people have become conscious of the possibility of exterminating malaria. The imagined state has made the real one more and more intolerable; and, as this feeling of dissatisfaction has grown more acute, study of the cause of the disease has grown more intense, until it has finally been discovered. Thus a lively consciousness of the unsatisfactoriness of a situation is the necessary prerequisite to its investigation; it furnishes the motive for it.

It has ever been so in the history of evolution. Study has not taken place without stimulus or motive. It has always had the practical task of lifting us out of our difficulties, either material or spiritual, and placing us on our feet. In this way it has been merely an instrument-though a most important one-in securing our proper adjustment or adaptation to our environment. ${ }^{1}$

2 For discussion of this subject, see Studies in Logical Theory. by John Dewey. See, also, Systematic Study in Elementary Schoola by Dr. Lida B. Earhart, Chapters 1 and 2. 
After we have becomc acutely conscious of a misfit somewhere in our experience, the actual study done to The variety right it varies indefinitely with the individual. of response The savage follows a hit-and-miss method of to the domand for study. investigation, and really makes his advances by happy guesses rather than by close application. Charles Lamb's Dissertation on Roast Pig furnishes a typical example of such accidents.

The average civilized man of the present does only a little better. How seldom, for instance, is the diet prescribed for a dyspeptic - whether by himself or by a physician - the result of any intelligent study! The true scientist, however, goes at his task in a careful and systematic way. Recall, for instance, how the cause of yellow fever has been discovered. For years people had attributed the disease to invisible particles which they called "fomites." These were supposed to be given off by the sick, and spread by means of their clothing and other articles used by them. Investigation caused this theory to be abandoned. Then, since Dr. J. C. Nott of Mobile had suggested, in 1848, that the fever might be carried by the mosquito, and Dr. C. J. Finlay of Havana had declared, in 1881, that a mosquito of a certain kind would carry the fever from one patient to another, this variety of mosquito was assumed by Dr. Walter Reed, in 1900, to be the source of the disease, and was subjected to very close investigation by him. Several men voluntarily received its bite and contracted the fever. Soon, enough cases wcre collected to establish the probable correctness of the assumption. The remedy suggested - the utter destruction of this particular kind of mosquito, including 
its eggs and larvæ - was so efficacious in combating the disease in Havana in 1901, and in New Orleans in 1905, that the theory is now considered established. Thus systematic study has relieved us of one of the most dreaded diseases to which mankind has been subject.

An extensive study, like this investigation, into the cause of yellow fever employs induction very plainly. It also employs deduction extensively, inasmul The principal much as hypotheses that have been reached factors in more or less inductively have to be widely stady. applied and tested, and further conclusions have to be drawn from them. Such a study, therefore, involving both induction and deduction and their numerous short cuts, contains the essential factors common to the investigation of other topics, or to study in general; for different subjects cannot vary greatly when it comes to the general method of their attack. An analysis, therefore, which reveals the principal factors in this study is likely to bring to light the main factors of study in general.

If the search for the cause of yellow fever were traced more fully, one striking feature discovered would be the fact that the investigation was never aimless. The need of unraveling the mystery 1. The find. was often very pressing, for we have had specifio purthree great epidemics of yellow fever in our pasctor in own country since 1790 , and scientists have stady. been eager to apply themselves to the problem. Yet a specific purpose, in the form of a definite hypothesis of some sort, was felt to be nacessary before the study could proceed intelligently. 
Thus, during the epidemic of 1793, the contagious ness of the disease was debated. Then the theory of "fomites" arose, and underwent investigation. Finally, the spread of the disease through the mosquito was proposed for the solution. And while books of reference were examined and new observations were collected in great number, such work was not undertaken by the investigators primarily for the sake of increasing their general knowledge, but with reference to the particular issue at hand.

The important question now is, Is this, in general, the way in which the ordinary student should work? Of course, he is much less mature than the scientist, and the results that he achieves may have no social value, in comparison. Yet, should his method be the same? At lcast, should his study likewise be under the guidance of specific purposes, so that these would direct and limit his reading, observation, and independent thinking? Or would that be too narrow, indeed, exactly the wrong way? And, instead of limiting himself to a collection of such facts as help to answer the few problems that he might be able to set up, should he be unmindful of particular problems? Should he rather be a collector of facts at large, endeavoring to develop an interest in whatever is true, simply because it is true? Here are two quite different methods of study suggested. Probably the latter is by far the more common one among immature students. Yet the former is the one that, in the main, will be advocated in this book as a factor of serious study.

Dr. Reed in this case went far beyond the discoreries of previous investigators. Not only did he con- 
ceive new tests for old hypotheses, but he posited new hypotheses, as well as collected the data that would prove or disprove them. Thus, while he no 2. The sapdoubt made much use of previous facts, of thought, he went far beyond that and succeeded in as a second enlarging the confines of knowledge. That study. is a task that can be accomplished only by the most mature and gifted of men.

The ordinary scholar must also be a collector of facts. But he must be content to be a receiver rather than a contributor of knowledge; that is, he must occupy himself mainly with the ideas of other persons, as presented in books or lectures or conversation. Even when he takes up the study of nature, or any other field, at first hand, he is generally under the guidance of a teacher or some text.

Now, how much, if anything, must he add to what is directly presented to him by others? To what extent must he be a producer in that sense? Are authors, at the best, capable only of suggesting their thought, learing much that is incomplete and even hidden from view? And must the student do much supplementing, even much digging, or severe thinking of his own, in order to get at their meaning? Or, do authors - at least the greatest of them - say most, or all, that they wish, and make their meaning plain? And is it, accordingly, the duty of the student merely to follow their presentation without enlarging upon it greatly?

The view will hereafter be maintained that any good author leaves much of such work for the student to do. Any poor author certainly leaves much more. 
The scientist would easily lose his way among the many facts that he gathers for examination, did he not carcfully select and bring them into order. He arranges 3. The or- them in groups according to their relations, laots ool. ${ }^{\text {anization }}$ recognizing a few as having supreme imlected, as a portance, subordinating many others to in stady. these, and casting aside many more because of their insignificance. This all constitutes a large part of his study.

What duty has the less mature student in regard to organization? Should the statements that he receives be put into order by him? Are some to be selected as vital, others to be grouped under these, and still others to be slighted or even entirely omitted from consideration, because of their insignificance? And is he to aetermine all this for himself, remembering that thorough study requires the neglect of some things as well as the emphasis of others? Or do all facts have much the same value, so that they should receive about equal attention, as is the case with the multiplication tables? And, instead of being grouped according to relations and relative values, should they be studied, one at a time, in the order in which they are presented, with the idea that a topic is mastered when each single statement upon it is understood? Or, if not this, has the reliable author at least already attended to this whole matter, making the various relations of facts to one another and their relative values so clear that the student lias little work to do but to follow the printed statement? Is it even highlily unsafe for the latter to assume the responsibility of judging relative values? And would the neglect or skipping of many supposedly 
little things be more likely to result in careless, slipshod work than in thoroughness?

The scientist in charge of the above-mentioned investigation was, no doubt, a modest man. Yet he saw fit to question the old assumption that yellow fever was spread by invisible particles called ing of the " "fomites." Indeed, he had the boldness to statements, disprove it. Then he disproved, also, the 8 a fourth assumption that the fever was contagious by stady. contact. After that he set out to test a hypothesis of his own. His attitude toward the results of former investigations was thus skeptically critical. Every proposition was to be questioned, and the evidence of facts, rather than personal authority or the authority of time, was the sole final test of validity.

What should be the attitude of the young student toward the authorities that he studies? Certainly authors are, as a rule, more mature and far better informed upon the subjects that they discuss than he, otherwise he would not be pursuing them. Are they still so prone to error that he should be critical toward them? At any rate, should he set himself up as their judge; at times condemning some of their statements outright, or accepting them only in part, - and thus maintain independent views? Or would that be the height of presumption on his part? While it is true that all authors are liable to error, are they much less liable to it in their chosen fields than he, and can he more safely trust them than himself? And should he, therefore, being a learner, adopt a docile, passive attitude, and accept whatever statements are presented? Or, finally, is neither of these attitudes correct? In- 
stead of either condemning or accepting authors, is it his duty merely to understand and remember what they say?

The scientist is greatly dependent upon his memory. So is every one else, including the young student. 6. Memori- What suggestions, if any, can be made about sing, $a_{B} a$
fift faotor the retaining of facts?

In strdy. In particular, how prominent in study should be the effort to memorize? Should memorizing constitute the main part of study - as it so often does - or only a minor part? It is often contrasted with thinking. Is such a contrast justified? If so, should the effort to memorize usually precede the thinking as is often the order in learning poetry and Bible verses - or should it follow the thinking? And why? Can one greatly strengthen the memory by special exercises for that purpose? Finally, since there are some astonishingly poor ways of memorizing - as was shown in chapter one - there must be some better ways. What, then, are the best, and why?

Does all knowledge, like this of the scientist, require contact with the world as its endpoint or goal? And 6. The using is it the duty of the student to pursue any of ideas, as a topic, whether it be a principle of physics, in stady. or a moral idea, or a simple story, until it proves of benefit to some one? In that case, enough repetition might be necessary to approximate habits habits of mind and habits of action - for the skill necessury for the successful use of some knowledge cannot otherwise be attained. How, then, can habits become best established? Or is knowledge something spart from the active world, ending rather in self? 
Would it be narrowly utilitarian and ever foolish to expect that one's learning shall necessarily function in practical life? And should the student rather rest content to acquire knowledge for its own sake, not bothering - for the present, at any rate - about actually bringing it to account in any way?

The use to which his ideas had to be put gave Dr. Reed an excellent test of their reliability. No doubt he passed through many stages of doubt as he investigated one theory after another. And he could not feel reasonably sure that he was right and had mastered his problem until his final hypothesis had been shown to hold good under varying actual conditions.

What test has the ordinary student for knowing when he knows a thing well enough to leave it? He may set up specific purposes to be accomplished, as has been suggested. Yet even these may be only ideas; what means has he for knowing when they have been attained? It is a long distance from the first approach to an important thought, to its final assimilation, and nothing is easier than to stop too soon. If there are any waymarks along the road, indicating the different stages reached; particularly, if there is a recognizable endpoint assuring mastery, one might avoid many dangerous headers by knowing the fact. Or is that particularly what recitations and marks are for? And instead of expecting an independent way of determining when he has mastered a subject, should the student simply rely upon his teacher to acquaint him with that fact?

Investigators of the source of yellow fever previous to Dr. Reed reached conclusions as well as he. But, 
in the light of later discovery, they appear hasty and roolish, to the extent that they were insisted upon as 7. The ten- correct. A large percentage of the so-called tative atti- discoveries that are made, even by laboratory seventh fao- experiment, are later disproved. Even in tor in strdy. regard to this very valuable work of Dr. Reed and his associates, one may feel too sure. It is quite possible that future study will materially supplement and modify our present knowledge of the subject. The scientist, therefore, may well assume an attitude of doubt toward all the results that he achieves.

Does the same hold for the young student? Is all our knowledge more or less doubtful, so that we should hold ourselves ready to modify our ideas at any time? And, remembering the common tendency to become dogmatic and unprogressive on that account, should the young student, in particular, regard some degree of uncertainty about his facts as the ideal state of mind for him to reach? Or would such uncertainty too easily undermine his self-confidence and render him vacillating in action? And should firmly fixed ideas, rather than those that are somewhat uncertain, be regarded as his goal, so that the extent to which he feels sure of his knowledge may be taken as one measure of his progress? Or can it be that there are two kinds of knowledge? That some facts are true for all time, and can be learned as absolutely true; and that others are only probabilities and must be treated as such? In that case, which is of the former kind, and which is of the latter?

The scientific investigator must determine upon his 
own hypotheses; he must collect and organize his data, must judge their soundness and trace their consequences; and he must finally decide for himself when he has finished a task. All for individathis requires a high degree of intellectual ality, as an independence, which is possible only through tor in study. a healthy development of individuality, or of the native self.

A normal self giving a certain degree of independence and even a touch of originality to all of his thoughts and actions is essential to the student's proper advance, as to the work of the scientist. Should the student, therefore, be taught to believe in and trust himself, holding his own powers and tendencies in high esteem? Should he learn even to ascribe whatever merit he may possess to the qualities that are peculiar to him?. And should he, accordingly, look upon the ideas and influences of other persons merely as a means - though most valuable - for the development of this self that he holds so sacred? Or should he learn to depreciate himself, to deplore those qualities that distinguish him from others? And should he, in consequence, regard the ideas and influences of others as a valuable means of suppressing, or escaping from, his native self and of making him like other persons?

Here are two very different directions in which on may develop. In which direction does human nature most tend : In which direction do educational institutions, in particular, exert their influence? Does the average student, for example, subordinate his teachers and the ideas he acquires to himself? Or does he be 
come subordinated to these, even submerged by them? This is the most important of all the problems concerning study; indeed, it is the one in which all the others culminate.

The above constitute the principal factors in study. But two other problems are of vital importance for the The ability elementary school. of ohildren to Studying is evidently a complex and taxstady.

ing kind of work. Even though the above discussions reveal the main factors in the study of adults, what light does it throw upon the work of children? Is their study to contain these factors also? The first of these two questions, therefore, is, Can children from six to fourteen years of age really be expected to study?

It is not the custom in German elementary schools to include independent study periods in the daily program. More than that, the German language does not even permit children to be spoken of as studying. Children are recognized as being able to learn (lernen); but the foreigner, who, in learning German, happens to use the word studiren (study) in reference to them, is corrected with a smile and informed that "children can learn but they cannot study." Studiren is a term applicable only to a more mature kind of mental work.

This may be only a peculiarity of language. But such suggestions should at least lead us to consider this question seriously. If children really cannot study, what an excuse their teachers have for innumerable failures in this direction! And what sins they have committed in demanding study! But, then, when is 
the proper age for study reached? Certainly college students sometimes seem to have failed to attain it. If, however, children can study, to what extent can they do it, and at how early an age should they begin to try?

The second of these two questions relates to the method of teaching children how to study. Granted that there are numerous very important factors in study, what should be done about The method them? Particularly, assuming that children children bow have some power to study, what definite instruction can teachers give to them in regard to any one or all of these factors?

Can it be that, on account of their youth, no direct instruction about method of study would be advisable, that teachers should set a good example of study by their treatment of lessons in class, and rely only upon the imitative tendency of children for some effect on their habits of work? Or should extensive instruction be imparted to them, as well as to adults, on this subject?

The leading problems in study that have been mentioned will be successively discussed in the chapters following. These two questions, however, Can children study? and If so, how can they be taught to do it? will not be treated in chapters separate from the others. Each will be dealt with in connection with the above factors, their consideration immediately following the discussion of each of those factors. While the proper method of study for adults will lead, much emphasis will fall, throughout, upon suggestions for teaching children how to study. 
The nature of study cannot be known in full until the character of its component parts has been clearly some limita shown. Yet a working definition of the term tions of the and some further limitations of it may be in torm stzdy. place here.

Study, in general, is the work that is necessary in the assimilation of ideas. Much of this work consists in thinking. But study is not synonymous with thinking, for it also includes other activities, as mechanical drill, for example. Such drill is often necessary in the mastery of thought.

Not just any thinking and any drill, however, may be counted as study. At least only such thinking and such drill are here included within the term as are integral parts of the mental work that is necessary in the accomplishment of valuable purposes. Thinking that is done at random, and drills that have no object beyond acquaintance with dead facts, as those upon dates, lists of words, and location of places, for instance, are unworthy of being considered a part of study.

Day-dreaming, giving way to reverie and to casual fancy, too, is not to be regarded as study. Not because it is not well to indulge in such activity at times, but because it is not serious enough to be called work. Study is systematic work, and not play. Reading for recreation, further, is not study. It is certainly very desirable and even necessary, just as play is. It even partakes of many of the characteristics of true study, and reaps many of its benefits. No doubt, too, the extensive reading that children and youth now do might well partake more fully of the nature of study. It would result in more good and less harm; for, beyona 
a doubt, much careless reading is injurious to habits of serious study. Yet it would be intolerable to attempt to convert pleasure-reading fully into real study. That would mean that we had become too serious.

On the whole, then, the term study as here used has largely the meaning that is given to it in ordinary speech. Yet it is not entirely the same; the term signifies a purposive and systematic, and therefore a more limited, kind of work than much that goes under that name. 



\section{PART II}

\section{THE NATURE OF THE PRINCIPAL FACTORS IN STUDY, AND THEIR RELATION TO CHILDREN}





\section{CHAPTER III}

PROVISION FOR SPECIFIC PURPOSES, AS ONE FACTOR OF STUDY

The scientific investigator habitually sets up hypoth. eses of some sort as guides in his investigations. Many distinguished men who are not scientists Tho habit follow and recommend a somewhat similar among emimethod of study.

nent men of setting ap

For example, John Morley, M.P., in his poses of purAspects of Modern Study, ${ }^{1}$ says, "Some great stady. men, - Gibbon was one and Daniel Webster was another and the great Lord Strafford was a third, always, before reading a book, made a short, rough analysis of the questions which they expected to be answered in it, the additions to be made to their knowledge, and whither it would take them. I have sometimes tried that way of studying, and guiding attention; I have never done so without advantage, and I commend it to you." Says Gibbon," "After glancing my eye over the design and order of a new book, I suspended the perusal until I had finished the task of self-examination; till I had resolved, in a solitary walk, all that I knew or believed or had thought on thesubject of the whole work or of some particular chapter; I was then qualified to discern how much the author added to my original stock; and, if I was sometimes satisfied with the agreement, I was sometimes armed by the opposition of our ideas."

$$
\text { 'Puge ii. "Dr. Smith's Gibbon, p. } 64 .
$$


President James Angell emphasizes a similar thought in the following words:-

I would like to recommend to my young friends who desire to profit by the use of this library, the habit of reading with some system, and of making brief notes upon the centents of the books they read. If, for instance, you are studying the history of some period, ascertain what works you need to study, and find such parts of them as concern your theme. Do not feel obliged to read the whole of a large treatise, but select such chapters as touch on the subject in hand and omit the rest for the time.

Young students often get swamped and lose their way in the Serbonian bogs of learning, when they need to explore only a simple and plain pathway to a specific destination. Have a purpose and a plan, and adhere to it in spite of alluring temptations to turn aside into attractive fields that are remote from your subject. ${ }^{1}$

Noah Porter expresses himself even more pointedly in these words: -

In reading we do well to propose to ourselves definite ends and purposes. The distinct consciousness of some object at present before us, imparts a manifold greater interest to the contents of any volume. It imparts to the reader an appropriative power, a force of affinity, by which he insensibly and unconsciously attracts to himself all that has a near or even a remote relation to the end for which he reads. Anyone is conscious of this who reads a story with the purpose of repeating it to an absent friend; or an essay or a report, with the design of using thefacts or arguments in adebate; or a poem, with the design of reviving its imagery and reciting its finest passages Indeed, one never learns to read effectively until he learns to

1 Address at Dedication of Ryerson Public Library Building Grund Rapids, Mich., Oct. 5, 1904. 
read in such a spirit - not always, indeed, for a definite end, yet always with a mind attent to appropriate and retain and turn to the uses of culture, if not to a more direct application. The private history of erery self-made man, from Franklin onwards, attests that they all were uniformly, not only earnest but select, in their reading, and that they selected their books with distinct reference to the purposes for which they used them. Indeed, the reason why self-trained men so often surpass men who are trained by others in the effectiveness and success of their reading, is that they know for what they read and study, and have definite aims and wishes in all their dealings with books. ${ }^{1}$

It is evident from the above that the practice of setting up specific aims for study is not uncommon. Some actual examples of such purposes, Examples of however, may help to make their character specifio purplainer. Following are a number of examples ${ }^{\text {poses. }}$ of a very simple kind: (1) To examine the catalogues of several colleges to determine what college one will attend; (2) to read a newspaper with the purpose of telling the news of the day to some friend; (3) to study Norse myths in order to relate them to children; (4) to investigate the English sparrow to find out whether it is a nuisance, or a valuable friend, to man; (5) to acquaint one's self with the art and geography of Italy, so as to select the most desirable parts for a visit; (6) to learn about Paris in order to find whether it is fitly called the most beautiful of cities; (7) to study psychology with the object of discovering how to improve one's memory, or how to overcome certain bad habits; (8) to read Pestalozzi's biography for the sake of finding what were the main factors that led to his greatness;

1 Noah Porter, Books and Reading, pp. 41-12. 
(9) to examine Lincoln's Gettysburg speech with the purpose of convincing others of its excellence.

Well-selected ends of this sort have two characteris. tics that are worthy of special note. The first pertains The oharao- to their source. Their possible variety is

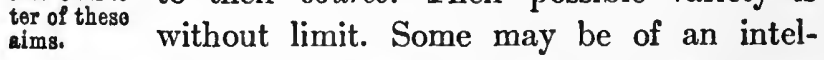
lectual nature, as numbers 6,8 , and 9 among those listed above; some may aim at utility for the individual, as numbers 1 and 7; and some may involve service to others, as numbers 2 and 3 . But however much they vary, they find their source within the person concerned. They spring out of his own experience and appeal to him for that reason. One very important measure of their worth is the extent to which they represent an individual desire.

The second characteristic pertains to their narrowness and consequent definiteness. They call in each case for an investigation of a relatively small and definite topic. This can be further seen from the following topics in Biology: What household plants are most desirable? How can these plants be raised? What are their principal enemies, and how can these best be overcome? Whether we be working on one or more of such problems at a time, they are so specific that we need never be confused as to what we are attempting.

The nature of these aims in study can be made still clearer by contrasting them with others that are very common. The "harmonious development of all the faculties," or mental discipline, for instance, has long been lauded by educators as one chief purpose in study. Agassiz was one such educator, and in his de- 
sire to cultivate the power of observation, he is said to have set students at work upon the study of fishes without directions, to struggle as they might. Many teachers of science before and since his time have followed a similar method. Truth for truth's sake, or the idea that one should study merely for the sake of knowing, has often been associated with mental discipline as a worthy end. Culture is a third common purpose.

Each of these aims, instead of originating in the particular interests of the individual, is reached by consideration of life as a whole, and of the final purposes of education. They are too general in nature to recognize individual preferences, and they are also too general to cause much discrimination in the selection of topics and of particular facts within topics. Strange to say, however, they have discriminated against the one kind of knowledge that the aforementioned specific aims emphasize as especially desirable. Under their exclusive influence, for example, students of biology have generally made an extensive study of wild plants and have paid little attention to house plants. Such subjects as physics, fine art, and biology cannot help but impart much information that relates to man; but that relationship has generally been the last part reached in the treatment of each topic, and the part most neglected. Under the influence of these general aims any useful purpose, whether involving service to the individual or to society at large, has somehow been eschewed or thought too sordid to be worthy of the scholar.

Nevertheless, these two kinds of aims are not 
necessarily opposed to each other. If a person can The relation increase his mental power, or his love of of specifio knowledge, or his culture, at the same time purposes to that he is accomplishing specific purposes, more general. why should he not do so? The gain is so much the greater.

Not only are the two kinds not mutually opposed, but they are really necessary to each other. General purposes when rightly conceived are of the greatest importance as the final goals to be reached by study. But they are too remote of attainment to act as immediate guides. Others more detailed must perform that office and mark off the minor steps to be taken in the accomplishment of the larger purposes. Thus the narrower purposes are related to the larger ones as means to ends.

Specific purposes are necessary in the first place, because they help to supply motive power both for Ways in study and for life in general. Proper study whioh spo- requires abundant energy, for it is hard cifio purposes are valuable. 1. As a work; and young people cannot be expected to engage in it heartily without good reason. source of mo- In particular, it requires very close and sus-
tive power.

tained attention, which it is most difficult to give. Threats and punishments can, at the best, secure it only in part; for young people who thus suffer habitually reserve a portion of their energy to imagine the full meanness of their persecutors and, not seldom, to devise ways of getting even. Neither can direct exercise of will insure undivided attention. How often have all of us, conscious that we ought fully to concentrate attention upon some task, determined to do so in vain 
The best single guarantee of close and continuous attention is a deep, direct interest in the work in hand, an interest similar in kind to that which children have in play. Such interest serves the same purpose with man as steam does in manufacturing, - it is motive power, and it is as necessary to provide for it in the one case as in the other.

Broad, general aims cannot generate this interest, for abstractions do not arouse enthusiasm. It is the concrete, the detailed, that arouses interest, particularly that detail that is closely related to life. We all remember how, in the midst of listless reading, we have sometimes awakened with a start, when we realized that what we were reading bore directly upon some vital interest. Specific purposes of the kind described insure the interest, and therefore the energy, necessary for full and sustained attention. "For remember," says Lowell, "that there is nothing less profitable than scholarship for the mere sake of scholarship, nor anything more wearisome in the attainment. But the moment you have a definite aim, attention is quickened, the mother of memory, and all that you acquire groups and arranges itself in an order that is lucid, because everywhere and always it is in intelligent relation to a central object of constant and growing interest." 1 If eminent scholars thus value and actually make use of concrete purposes, certainly immature students, whose attention is much less "trained," can follow their ex. ample with profit.

Life in general, as well as study, requires motive power. Energy to do many kinds of things is so im. 
portant that one's worth depends as much upon it as upon knowledge. Indeed, if there must be some lack in one of these two, it were probably better that it be in knowledge.

A deep many-sided interest is a key also to this broader kind of energy. Yet how often is such interest lacking! This lack of interest is seen among highschool students in the selection of subjects for commencement essays; good subjects are difficult to find because interests are so rare. It is seen among college students in their choice of elective courses; for they often seem to have no strong interest beyond that of avoiding hard work. It is seen in many college graduates who are roundly developed only in the sense that they are about equally indifferent toward all things. And, finally, it is seen in the great number of men and women who, without ambition, drift aimlessly through life. Well-chosen specific purposes will help materially to remedy these evils, for there is no dividing line between good study-purposes and good life-purposes. The first must continually merge into the second; and the interest aroused by the former, with its consequent energy, gives assurance of interested and energetic pursuance of the latter.

The importance of being rich in unsolved problems is not likely to be overestimated. Most well-informed adults who have little "push" are not lazy by nature; they have merely failed to fall in love with worthy aims. That is often partly because education has been allowed to mean to them little more than the collecting of facts. If it had included the collection of interesting and valuable purposes as well, their devotion to 
proper aims in life might have grown as have their facts; then their energy might have kept pace with their knowledge.

If students, therefore, regularly occupy a portion of their study time in thinking out live questions that they hope to have answered by their further study, and interesting uses that they intend to make of their knowledge, they are equipping themselves with motive power both for study and for the broader work of life.

One of the constant dangers in study is that facts will be collected without reference either to their values as previously stated, or to their arrangement. Nature study frequently illustrates this dan- for the as ger. For instance, $I$ once witnessed a reci- organization tation in which each member of a class of eleven-year-old children was supplied with a dead oak leaf and asked to write a description of it in detail. The entire period was occupied with the task, and following is a copy of one of the papers, without its figures.

\section{The Oak Leaf.}

Greatest length........ Length of the stem.... Greatest breadth........ Color of the stem...... Number of lobes......... Color of the leaf......

Number of indentations... General shape.......

The other papers closely resembled this one. Consider the worth of such knowledge! This is one way in which time is wasted in school and college. Probably the main reason for the choice of this topic was the fact that the leaves could be easily obtained. But if the teacher had been in the habit of setting up specific aims, and therefore of asking how such matter would 
prove valuable in life, she would have never given this lesson - unless higher authorities had required it.

One of my classes of about seventy primary teachers in the study of education once undertook to plan subject-matter in nature study for six-year-old childiren in Brooklyn. They agreed that the common house car would be a fitting topic. And on being asked to state what facts they might teach, they gave the following sub-topics in almost exactly this order and wording: the ears; food and how obtained; the tongue; paws, including cushions; whiskers; teeth; action of tail; sounds; sharp hearing; sense of smell; cleanliness; eyes; looseness of the skin; quick waking; size of mouth; manner of catching prey; claws; care of young; locomotion; kinds of prey; enemies; protection by society for the prevention of cruelty to animals,twenty-two topics in all. When I inquired if they would teach the length of the tail, or the shape of the head and ears, or the length and shape of the legs, or the number of claws or of teeth, most of them said "no" with some hesitation, and some made no reply. When asked what more needed to be done with this list before presenting the subject to the children, some suggested that those facts pertaining to the head should be grouped together, likewise those pertaining to the body and those in regard to the extremities. Some rejected this suggestion, but offered no substitute. No general agreement to omit some of the topics in the list was reached, and most of the class saw no better plan than to present the subject, cat, under the twenty-two headings given.

Although there were college graduates present, and 
many capable women, it was evident that they carried no standard for judging the value of facts or for organizing them. The setting up of specific purposes seemed to offer them the aid that they needed. Since this was in Brooklyn, where the main relation of cats to children is that of pets, we took up the study of the animal with the purpose of finding to what extent cats as pets can provide for themselves, and to what extent, therefore, they need to be taken care of, and how.

Under these headings the sub-topics given, with a few omissions and additions, might be arranged as follows:

Under first aim: -

I. Food (chief thing necessary).

1. Kinds of prey... $\left\{\begin{array}{l}\text { Birds } \\ \text { Mice } \\ \text { Moles, etc. }\end{array}\right.$

2. How found..... $\begin{aligned} & \text { Eyes, that see in dark; } \\ & \text { structure. } \\ & \text { Sense of smell; keenness. } \\ & \text { Ears; keenness. }\end{aligned}$ Approach; use of whiskers. Quietness of movements; how so quiet (padded feet, loose joints, manner of walking).

3. How caught.... Action of tail.

Catching and holding; ability to spring; strength of hind legs.

Fore paws; used like hands. Claws; shape, sharpness,

and sheaths.

II. Shelter. Use of covering.

Finding of warm place in coldest weather. 
Under second aim: -

I. Food (when prey is wariting).

Kinds and where obtained: milk; scrap from table; biscuit; catnip.

Observe method of drinking.

II. Shelter. How provide shelter.

III. Cleanliness. Why washing unnecessary (cat's face washing; aversion to getting wet).

Danger from dampness.

Need of combing and brushing; method.

IV. Enomies. Kinds of insects; remedies.

Dogs; boys and men.

Proper treatment. Value of Society for

Prevention of Cruelty to Animals; how to secure its aid.

Thus a definite purpose, that is simple, concrete, and close to the learner's experience, can be valuable as a basis for selecting and arranging subject-matter. Facts that bear no important relation to this aim, such as the length of the cat's tail and the shape of its ears, fall out; and those that are left, drop into a series in place of a mere list.

A manufacturer must do more than supply himself with motive power and manufacture a proper quality 3. As a of goods; he must also provide for a market. promise of Again, if he makes money, he is under oblioal outcome gations not to let it lie idle; if he hoards it,
of stady in oonduot. he is condemned as a miser. He is responsible for turning whatever goods or money he collects to some account. 
The student, likewise, should not be merely a collector of knowledge. The object of study is not merely insight. As Frederick Harrison has said, "Man's business here is to know for the sake of living, not to live for the sake of knowing." "Religion that does not express itself in conduct socially useful is not true religion"; and, we may add, education that does not do the same is not true education.

It is part of one's work as a student, therefore, to plan to turn one's knowledge to some account; to plan not alone to sell it for money, but to use it in various ways in daily life. If, instead of this, one aims to do nothing but collect facts, no matter how ardently, he has the spirit of a bookworm at best and stands on the same plane as the miser. Or if, notwithstanding good intentions, he leaves the effect of his knowledge on life mainly to accident, he is grossly careless in regard to the chief object of study. Yet the average student regards himself as mainly a collector of facts, a storehouse of knowledge; and his teachers also regard him in that light. Planning to turn knowledge to some account is not thought to be essential to scholarship.

There are, no doubt, various reasons for this, but it is not because an effect on life is not finally desired. The explanation seems to be largely found in a very peculiar theory, namely, that the fewer bearings on life a student now concerns himself with, the more he will somehow ultimately realize; and if he aims at none in particular, he will very likely hit most of them. Thus aimleseness, so far as relations of study to life are coneerned, is put at a premium, and students are directly 
encouraged to be omnivorous absorbers without further responsibility.

Meanwhile, sensible people are convinced of the unsoundness of this theory. How often, after having read a book from no particular point of view, one feels it necessary to reëxamine it in order to know kow it treats some particular topic! The former reading was too defective to meet a special need, because the very general aim caused the attitude to be general or nonselective. How often do young people who have been taught to have no particular aim in their reading, have no aim at all, beyond intellectual dissipation, the momentary tickle of the thought. Thus all particular needs are in danger of being left unsatisfied when no particular need is fixed upon as the object. It is the growing consciousness of the great waste in such study that has changed botany in many places into horticulture and agriculture, chemistry into the chemistry of the kitchen, and that has caused portions of many other studies to be approached from the human viewpoint.

This indicates the positive acceptance of specific purposes as guides in study. They are not by any means full guarantees of an outcome of knowledge in conduct, for they are only the plans by which the student hopes that his knowledge will function. Since plans often fail of accomplishment, these purposes may never be realized. But they give promise of some outcome and form one important step in a series of steps necessary for the fruition of knowledge.

The aims set up by advanced scholars are necessarly an outgrowth of their individual experience and 
interests. Such aims must, therefore, vary greatly. For this reason such men must conceive their purposes for themselves; there is no one who can do it for them.

Younger students are in much the same poches pronsituation, for their aims should also be indi- be conceived. vidual to a large extent. Text-books might be of much help if their authors attempted this task with skill. But authors seldom attempt it at all; and, even if they do, they are under the disadvantage of writing for great numbers of persons living in widely different environments. Any aims that they propose must necessarily be of a very general character. Teachers might again be of much help; but many of them do not know how, and many more will not try. The task, therefore, falls mainly to the student himself.

As to the time of forming in mind these aims, the experimental scientist necessarily posits some sort of hypothesis in advance of his experiments; the eminent men before mentioned conceive the questions that they hope to have answered, in advance of their reading. It is natural that one should fix an aim before doing the work that is necessary for its accomplishment. If these aims are to furnish the motive for close attention and the basis for the selection and organization of facts, they certainly ought to be determined upon early. The earlier they come, too, the greater the likelihood of some practical outcome in conduct; for the want of such an outcome is very often due to their postponement.

On the other hand, the setting up of desirable ends requires mental vigor, as well as a wide and well-con- 
trolled experience. Gibbon's "solitary walk" (p. 31) would hardly be a pleasure walk for most young people, even if they had his rich fund of knowledge to draw upon. While it is desirable, therefore, to determine early upon one's purposes, young students will often find it impossible to do this. In such cases they will have to begin studying without such aids. They can at least keep a sharp lookout for suitable purposes, and can gradually fix upon them as they proceed. In general it should be remembered that the sooner good aims are selected, the sooner their benefits will be enjoyed.

THE FITNESS OF CHILDREN IN THE ELEMENTART SCHOOL TO SELECT SPECIFIC PURPOSES OF STUDY

According to custom, young people are expected to acquire knowledge now and find its uses later. The preceding argument would reverse that order by having them discover their wants first and then study to satisfy them. This is the way in which man has progressed from the beginning - outside of educational institutions - and it seems the normal order.

To what extent shall this apply to children? If the fixing of aims is difficult for adult students, it can be expected to be even more difficult for children of the elementary school age. For their experience, from which the suggestions for specific purposes must be obtained, is narrow and their command of it slight. On the other hand, they are expected to have done a large amount of studying before entering the high school, much of it alone, too. And, after leaving the elementary school, pcople will take it for granted that 
they have already learned how to study. If, therefore, the finding of specific purposes is an important factor in proper study, responsibility for acquiring that ability wiil fall upon the elementary school.

The first question to consider is, Do children seriously need the help of such aims? They certainly do in one respect, for they resemble their elders Do obildren in being afflicted with inattention and unwill- need the help ingness to exert themselves in study. These aims? are the offenses for which they are most often scolded at school, and these are their chief faults when they attempt to study alone. There is no doubt also but that the main reason why children improve very little in oral reading during the last three years in the elementary school is their lack of incentive to improve. They feel no great need of enunciating distinctly and of reading with pleasant tones loud enough to be heard by all, when all present have the same text before them. Why should they?

Good aims make children alert, just as they do older persons. I remember hearing a New York teacher in a private school say to her thirteen-year-old children in composition, one spring day: "I expect to spend my vacation at some summer resort; but I have not yet decided what one it shall be. If you have a good place in mind, I should be glad to have you tell me why you like it. It may influence my choice." She was a very popular teacher, and each pupil longed to have her for a companion during the summer. I never saw a class undertake a composition with more eagerness. In a certain fifth-year class in geography a contest between the boys and girls for the best collection of 
articles manufactured out of flax resulted in the greatest enthusiasm. The reading or committing to memory of stories with the object of dramatizing them - such as The Children's Hour, in the second or third grade seldom fails to arouse lively interest.

For several years the members of the highest two classes in a certain school have collected many of the best cartoons and witticisms. They have also been in the habit of reading the magazines with the object of selecting such articles as might be of special interest to their own families at home, or to other classes in the school, or to their classmates, often defending their selections before the class. Their most valuable articles have been classified and catalogued for use in the school; and their joke-books, formed out of humorous collections, have circulated through the school. The effect of the plan in interesting pupils in current literature has been excellent.

A certain settlement worker in New York City in charge of a club of fourteen- to eighteen-year-old boys tried to arouse an interest in literature, using one plan after another without success. Finally the class undertook to read Julius Casar with the object of selecting the best parts and acting them out in public. This plan succeeded; and while the acting was grotesque, this purpose led to what was probably the most earnest studying that those boys had ever done.

The value of definite aims for the conduct of the recitation is now often discussed and much appreciated by teachers. If such aims are so important in class, with the teacher present, they are surely not less needed when the child is studying alone. 
The worth of specific aims for children as a source of energy in general is likewise great. It is a question whether children under three years of age are ever lazy. But certainly within a few years after that age - owing to the bad effect of civilization, Rousseau might say many of them make great progress toward laziness of both body and mind.

The possibilities in this direction were once strikingly illustrated in an orphan asylum in New York City. The two hundred children in this asylum had been in the habit of marching to their meals in silence, eating in silence, and marching out in silence. They had been trained to the "lock step" discipline, until they were quiet and good to a high degree. The old superintendent having resigned on account of age, an experienced teacher, who was an enthusiast in education, succeeded him in that office. Feeling depressed by the lack of life among the children, the latter concluded, after a few weeks, to break the routine by taking thirty of the older boys and girls to a circus. But shortly before the appointed day one of these girls proved so refractory that she was told that she could not be allowed to go. To the new superintendent's astonishment, however, she did not seem disappointed or angered; she merely remarked that she had never seen a circus and did not care much to go anyway. Shortly afterward he fined several of the children for misconduct. Many of them had a few dollars of their own, received from relatives and other friends. But the fines did not worry them. They were not in the habit of spending money, having no occasion for it; all that they needed was food, clothing, and shelter. 
and these the institution was bound to give. Then ho deprived certain unruly children of a share in the games. That again failed to cause acute sorrow. In the great city they had little room for play, and many had not become fond of games. It finally proved difficult to discover anything that they cared for greatly. Their discipline had accomplished its object, until they were usually "good" simply because they were too dull, too wantirg in ideas and interests to be mischievous. Their energy in general was low. Here was a demand for specific purposes without limit.

One of the first aims that the new superintendent set up, after making this discovery, was to inculcate live interests in these children, a capacity to enjoy the circus, a love ezen of money, a love of games, of flowers, of reading, and of companionship. His means nas the fixing of definite and interesting objects to be accomplished from day to day, and these gradually restored the children to their normal condition. Thus all children need the help of specific aims, and some need it sadly.

There remains the very important question, Are children themselves capable of learning to set up such Is it normal purposes? Or at least would such attempts to expect
ohildren to learn to set ᄀp speoific aims for cannot receive a final answer at present, because children have not been sufficiently themselves? tested in this respect. It has so long been the habit in school to collect facts and leave their bearings on life to future accident, that the force of habit makes it difficult to measure the probabilities in regard to a very different procedure. 
Yet there are some facts that are very encouraging. A large number of the tasks that children undertake outside of school are self imposed, many of these including much intellectual work. Largely as a result of such tasks, too, they probably learn at least as much outside of school as they learn in school, and they learn it better.

Further, when called upon in school to do this kind of thinking, they readily respond. A teacher one day remarked to her class, "I have a little girl friend living on the Hudson River, near Albany, who has been ill for many weeks. It occurred to me that you might like to write her some letters that would help her to pass the time more pleasantly. Could you do it?" "Yes, by all means," was the response. "Then what will you choose to write about?" said the teacher. One girl soon inquired, "Do you think that she would like to know how I am training my bird to sing?" Several other interesting topics were suggested. The finding of desirable purposes is not beyond children's abilities.

Individual examples, however, can hardly furnish the best answer to the question at present; the general nature of children must determine it. If children are leading lives that are rich enough intellectually and morally to furnish numerous occasions to turn their acquisitions to account, then it would certainly be reasonable to expect them to discover some of these occasions. If, on the other hand, their lives are comparatively barren, it might be unnatural to make such a demand upon them.

The feeling is rather common that human experience 
becomes rich only as the adult period is reached; that childhood is comparatively barren of needs, and valuable mainly as a period of storage of knowledge to meet wants that will arise later. Yet is this true? By the time the adult state is reached, one has passed through the principal kinds of experience; the period of struggle is largely over, and the results have registered themselves in habits. The adult is to a great extent a bundle of habits.

The child, and the youth in the adolescent age, on the other hand, are just going the round of experience for the first few times. They are just forming their judgments as to the values of things about them. Their intellectual life is abundant, as is shown by their innumerable questions. Their temptations - such as to become angry, to fight, to lie, to cheat, and to steal are more numerous and probably more severe than they will usually be later; their opportunities to please and help others, or to offend and hinder, are without limit; and their joys and sorrows, though of briefer duration than later, are more numerous and often fully as acute. In other words, they are in the midst of growth, of habit formation, both intellectually and morally. Theirs is the time of life when, to a peculiar degree, they are experimentally related to their environment. Why, then, should they be taught to look past this period, to their distant future as the harvest time for their knowledge and powers? The occasions are abundant now for turning facts and abilities to account, and it is normal to expect them to see many of these opportunities. Proper development requires that they be rained to look for them, instead of looking past them. 
Here is seen the need of one more reform in education. Children used to be regarded as lacking value in themselves; their worth lay in their promise of being men and women; and if, owing to ill health, this promise was very doubtful, they were put aside. For education they were given that mental pabulum that was considered valuable to the adult; and their tastes, habits, and manners were judged from the same viewpoint.

Very recently one radical improvement has been effected in this program. As illustrated in the doctrine of apperception, we have grown to respect the natures of children, even to accept their instincts, their native tendencies, and their experiences as the proper basis for their education. That is a wonderful advance. But we do not yet regard their present experience as furnishing the motive for their education. We need to take one more step and recognize their present lives as the field wherein the knowledge that they acquire shall function. We do this to some extent; but we lack faith in the abundance of their present experience, and are always impatiently looking forward to a time when their lives will be rich.

In feeding children we have our eyes primarily on the present; food is given them in order to be assimilated and used now to satisfy present needs; that is the best way of guaranteeing health for the future. Likewise in giving them mental and spirituai food, our attention should be directed primarily to its present value. It should be given with the purpose of present nourishment, of satisfying present needs; other more fistant needs will thereby be best served. 
A few years ago, when I was discussing this topis with a class at Teachers College, I happened to observe a recitation in the Horace Mann school in which a class of children was reading Silas Marner. They were frequently reproved for their unnaturally harsh voices, for . their monotones, indistinct enunciation, and poorgrouping of words. In the Speyer school, nine blocks north of this school, I had often observed the same defects.

At about that time one of my students, interested in the early history of New York, happened to call upon an old woman living in a shanty midway between these two schools. She was an old inhabitant, and one of the early roadways that the student was hunting had passed near her house. In conversation with the woman he learned that she had had five children, all of whom had been taken from her some years before, within a fortnight, by scarlet fever; and that since then she had been living alone. When he remarked that she must feel lonesome at times, tears came to her eyes, and she replied, "Sometimes." As he was leaving she thanked him for his call and remarked that she seldom had any visitors; she added that, if some one would drop in now and then, either to talk or to read to her, she would greatly appreciate it; her eyes had so failed that she could no longer read for herself.

Here was an excellent chance to improve the chil. dren's reading by enabling them to see that the better their reading the more pleasure could they give to those about them. This seems typical of the present relation between the school and its environing world. While the two need each other sadly, the school is isolated somewhat like the old-time monastery. The fixing 
of specific aims for study can aid materially in establishing the normal relation, and children can certainly contribute to this end by discovering some of these purposes themselves. That is one of the things that they should learn to do.

PRACTICAL SUGGESTIONS FOR TEACHING CHILDREN TO FIND SPECIFIC AIMS FOR THEIR STUDY

The elimination from the curriculum of such subjectmatter as has no probable bearing on ordinary mortals is one important step to take in giving chil- 1. Elimingdren definite aims in their study. There is tion of submuch of this matter having little excuse for that has existence beyond the fact that it "exercises on lifer the mind"; for example: in arithmetic, the finding of the Greatest Common Divisor as a separate topic, the tables for Apothecaries' weight and Troy measure, Complex and Compound Fractions ; ${ }^{1}$ in geography, the location of many unimportant capes, bays, capitals and other towns, rivers and boundaries; in nature study, many classifications, the detailed study of leaves, and the study of many uncommon wild plants. The teaching of facts that cannot function in the lives of pupils directly encourages the mere collecting habit, and thus tends to defeat the purpose here proposed. Not that we do not wish children to collect facts; but while acquiring them we want children to carry the responsibility of discovering ways of turning them to account, and mere collecting tends to dull this sense of responsibility.

${ }^{1}$ For a more complete list of such topics, see Teachers College Record, Mathematics in the Elementary School, March, 1903, by David Eugene Smith and F. M. McMurry. 
By her own method of instruction the teacher can set an example of what she desires from her pupils 2. The exam-in the way of concrete aims. For instance: ple to be set (a) during recitation she can occasionally teacher. suggest opportunities for the application of knowledge and ability. "This is a story that you might tell to other children," she might say; or, "Here is something that you might dramatize." "You might talk with your father or mother about this." "Could you read this aloud to your family?" Again, (b) in the assignment of lessons she might set a definite problem that would bring the school work into direct touch with the outside world. In fine art, instead of having children make designs for borders, without any particular use for the design, she might suggest, "Find some object or wall surface that needs a border, and see if you can design one that will be suitable." As a task in arithmetic for a fifth-year class in a small town, she might assign the problem, "To find out as accurately as possible whether or not it pays to keep a cow." Finally, (c) as part of an examination, she can ask the class to recall purposes that they have kept in mind in the study of certain topics. By such means the teacher can make clear to a class what is meant by interesting or useful aims of study, and also impress them with the fact that she feels the need of studying under the guidance of such aims.

The tcacher need not do a great amount of such work for her class. The children should learn to do it themselves, and they will not acquire the ability mainly by having some one else do it for them.

Therefore, after the children have come to under- 
stand the requirement fairly well, the teacher might occasionally assign a lesson by specifying only the quantity, as such and such pages, or such 3 . The reand such topics, in the geography or history, ${ }_{\text {sponsibility }}^{\text {the children }}$ with the understanding that the class shall sbould bear. state in the next recitation one or more aims for the lesson; for example, if it is the geography of Russia, How it happens that we hear so often of famines in Russia, while we do not hear of them in other parts of Europe; or, if it is the history of Columbus, For what characteristic is Columbus to be most admired? Again, In what ways has his discovery of America proved of benefit to the world? The finding of such problems will then be a part of the study necessary in mastering the lesson.

Likewise, during the recitation and without any hint from the teacher, the children should show that they are carrying the responsibility of establishing relations of the subject-matter with life, by mentioning further bearings, or possible uses, that they discover.

Review lessons furnish excellent occasions for study of this kind. It is narrow to review lessons only from the point of view of the author. His view-point should be reviewed often enough to become well fixed, but there should be other view-points taken also.

John Fiske has admirably presented the history of the period immediately following the Revolution. The title of his book, The Critical Period of American History, makes us curious from the beginning to know how the period was so critical. This is a fine example of a specific aim governing a whole book. But other aims in review might be, Do we owe as much to Washington 
during this period as during the war just preceding? Or were other men equally or more prominent? How was the establishment of a firm Union made especially difficult by the want of certain modern inventions? The pupils themselves should develop the power to suggest such questions.

The teacher can teach the children where to look for suggestions in their search for specific purposes. Dur4. The ing meals, three times a day, interesting sources to
whioh ohil- topics of conversation are welcome; indeed, dren should the dearth of conversation at such times,
look for suggestions. owing to lack of "something to say," is often depressing. There is often need of something to unite the family of evenings, such as a magazine article read aloud, or a good narrative, or a discussion of some timely topic. There are social gatherings where the people "don't know what to do"; there are recesses at school where there is the same difficulty; there are neighbors, brothers and sisters, and other friends who are more than ready to be entertained, or instructed, or helped. Yet children often dramatize stories at school, without ever thinking of doing the same for the entertainment of their family at home. They read good stories without expecting to tell them to any one. They collect good ideas about judging pictures, without planning to beautify their homes through them. Thus the children can be made conscious that there are wants on all sides of them, and by some study of their environment they can find many aims that will give purpose to their school work. Again, by a review of their past studies, their reading, and their experience of various kinds, they can be reminded of objects that 
they are desirous of accomplishing. It is, perhaps, needless to say that the teacher herself must likewise make a careful study of the home, street, and school life of her pupils, of their study and reading, if she is to guide them most effectually in their own search for desirable aims.

Finally, the teacher can lead her pupils to stock up with specific aims even in advance of their immediate needs. A teacher who visits another school 5. Stooking with the desire of getting helpful suggestions ${ }_{\text {specific aims }}^{\text {up with }}$ would better write down beforehand the in advance. various things that she wishes to see. She can afford to spend considerable time and energy upon such a list of points. Otherwise, she is likely to overlook half of the things she was anxious to inquire about.

Likewise, children can be taught to jot down in a notebook various problems that they hope to solve, various wants observed in their environment that they may help to satisfy. Children who are much interested in reading, sometimes without outside suggestion make lists of good books that they have heard of and hope to read. And as they read some, they add others to their list. Keeping this list in mind, they are on the lookout for any of these books, and improve the opportunity to read one of them whenever it offers. A similar habit in regard to things one would like to know and do can be cultivated, so that one will have a rich stock of aims on hand in advance, and these will help greatly to give purpose to the work later required in the school.

In conclusion, it may be of importance to add that this kind of instruction can be easily overdone. and it is better to proceed too slowly than too rapidly. 
It is a healthy and permanent development that is wanted, and the teacher should rest satisfied if it is 6. The Im- slow. It is by no means feasible to attempt portance of moderation in demands made upon children. to subordinate all study to specific aims; we cannot see our way to accomplish that now. But we can do something in that direction. Only occasional attempts with the younger children will be in place; more conscious efforts will be fitting among older pupils. By the time the elementary school is finished, a fair degree of success in discovering specific aims can be expected.

Yet, even if little more than a willingness to take time to try is established, the gain will be appreciable. When children become interested in a topic, they are impatient to "go on" and "to keep going on." This continual hurrying forward crowds out reflection. If they learn no more than to pause now and then in order to find some bearings on life, and thus do some independent thinking, they are paving the way for the invaluable habit of reflection. 


\section{CHAPTER IV}

THE SUPPLEMENTING OF THOUGHT, AS A SECOND FACTOR OF STUDY

Is the preceding chapter the importance of study. ing under the influence of specific purposes was urged. These are such purposes as the student really desires to accomplish by the study of the questext or of other matter placed before him. Since they are not usually included in such matter, but must be conceived by the student himself, they constitute a very important kind of supplement to whatever statements may be offered for study. The questions now arise, Are other kinds of supplementing also generally necessary? If so, what is their nature? Should they be prominent, or only a minor part of study? And is there any explanation of the fact that authors are not able to express themselves more fully and plainly?

For answers to these questions, turn first to Bible study. Take for instance a minister's treatment of a Bible text. Selecting a verse or two as his Answers to theme for a sermon, he recalls the conditions these questhat called forth the words; builds the con- 1 . As sug crete picture by the addition of reasonable Bible stady. detail; makes comparisons with corresponding views or customs of the present time; states and answers queries that may arise; calls attention to the peculiar beauty or force of certain expressions; draws inferences 
or corollaries suggested in the text; and, finally, interprets the thought or draws the practical lessons. The words in his text may number less than a dozen, while those that he utters reach thousands; and the thoughts that he expresses may be a hundred times the number directly visible in the text.

Leaving the minister, take the layman's study of the parable of the Prodigal Son. This is the story as related in Luke 15: 11-32:

11. And he said, A certain man had two sons:

12. And the younger of them said to his father, Father, give me the portion of goods that falleth to me. And he divided unto them his living.

13. And not many days after the younger son gathered all together, and took his journey into a far country, and there wasted his substance with riotous living.

14. And when he had spent all, there arose a mighty famine in that land; and he began to be in want.

15. And he went and joined himself to a citizen of that country; and he sent him into his fields to feed swine.

16. And he would fain have filled his belly with the husks that the swine did eat; and no man gave unto him

17. And when he came to himself, he said, How many hired servants of my father's have bread enough and to spare, and I perish with hunger!

18. I will arise and go to my father, and will say unto him, Father, I have sinned against heaven, and before thee,

19. And am no more worthy to be called thy son; make me as one of thy hired servants.

20. And he arose, and came to his father. But when he was yet a great way off, his father saw him, and had compassion, and ran, and fell on his neck, and kissed him.

21. And the son said unto him, Father, I have sinned 
rgainst heaven, and in thy sight, and am no more worthy to be called thy son.

22. But the father said to his servants, Bring forth the best robe, and put it on him; and put a ring on his hand, and shoes on his feet.

23. And bring hither the fatted calf, and kill it; and let us eat and be merry.

24. For this my son was dead, and is alive again; he was lost, and is found. And they began to be merry.

25. Now his elder son was in the field; and as he came and drew nigh to the house, he heard music and dancing.

26. And he called one of the servants and asked what these things meant.

27. And he said unto him, Thy brother is come; and thy father hath killed the fatted calf, because he hath received him safe and sound.

28. And he was angry, and would not go in; therefore came his father out, and intreated him.

29. And he answering said to his father, Lo, these many years do I serve thee, neither transgressed I at any time thy commandment; and yet thou never gavest me a kid, that I might make merry with my friends;

30. But as soon as this thy son was come, which hath devoured thy living with harlots, thou hast killed for him the fatted calf.

31. And he said unto him, Son, thou art ever with me, and all that I have is thine.

32. It was meet that we should make merry and be glad; for this thy brother was dead, and is alive again : and was lost, and is found.

How simple the story! Even a child can tell it after very few readings, and one could soon learn the words by heart. Is one then through with it? Or has the study then hardly begun? 
Note some of the questions that need to be con. sidered: -

1. What various thoughts probably induced the young man to leave home?

2. What pictures of his former life does he call to mind when starving? Why did he hesitate about returning?

3. What were his thoughts and actions as he approached his father; those also of his father?

4. What indication of the father's character is given in the fact that he saw his son while yet "a great way off"?

5. Which is perhaps the most interesting scene? Which is least pleasing?

6. How would the older son have had the father act?

7. Did the father argue at length with the older son? Was it in place to argue much about such a matter?

8. Describe the character of the elder son. Which of the two is the better?

9. Is the father shown to be at fault in any respect in the training of his sons? If so, how?

10. How do people about us often resemble the elder son?

11. Is this story told as a warning or as a comfort? How ?

These are only a few of the many questions that might well be considered. Indeed, whole books could be, and probably have been, written upon this one parable. Yet neither such questions nor their answers are included in the text. It seems strange that almost none of the great thoughts that should be gathered 
from the story are themselves included with the narrative. But the same is true in regard to other parts of the Bible. The conversation between Jesus and the Samaritan woman at the well (John 4) is, perhaps, the greatest conversation that was ever held. Yet one must discover this fact "between the lines"; there is no such statement included in the account.

Evidently both to the minister and to the layman the Bible contains only the raw materials for thought. It must be supplemented without limit, if one is to comprehend it and to be nourished by it properly.

Does this same hold with regard to other literature? For answer, recall to what extent Shake-2. As sag. speare's dramas are "talked over" in class, gested by the both in high schools and colleges. But as a literatore. type - somewhat extreme, perhaps - take Browning's

\section{MY LAST DUCHESS}

That's my last Duchess painted on the wall, Looking as if she were alive. I call

That piece a wonder, now: Frà Pandolf's hands

Worked busily a day, and there she stands.

Will 't please you sit and look at her? I said "Frà Pandolf" by design, for never read Stranger like you that pictured countenance, The depth and passion of its earnest glance, But to myself they turned (since none puts by The curtain I have drawn for you, but I) And seemed as they would ask me, if they durst, How such a glance came there; so, not the first Are you to turn and ask thus. Sir, 't was not Her husband's presence only, called that spot 
Of joy into the Duchess' cheek; perhaps Frà Pandolf chanced to say, "Her mantle laps Over my lady's wrist too much," or "Paint Must never hope to reproduce the faint Half-flush that dies along her throat": such stuff Was courtesy, she thought, and cause enough For calling up that spot of joy. She had A heart - how shall I say - too soon made glad, Too easily impressed; she liked whate'er She looked on, and her looks went everywhere. Sir, 't was all ons! My favor at her breast, The dropping of the daylight in the West, The bough of cherries some officious fool Broke in the orchard for her, the white mule She rode with round the terrace - all and each Would draw from her alike the approving speech. Or blush, at least. She thanked men, - good! but thanked

Somehow - I know not how - as if she ranked My gift of a nine-hundred-years-old name With anybody's gift. Who'd stoop to blame This sort of trifling? Even had you skill In speech - (which I have not) - to make your will Quite clear to such an one, and say, "Just this Or that in you disgusts me; here you miss, Or there exceed the mark" - and if she let Herself be lessoned so, nor plainly set Her wits to yours, forsooth, and made excuse, - E'en then would be some stooping; and I choose Never to stoop. Oh sir, she smiled, no doubt, Whene'er I passed her; but who passed without Much the same smile? This grew; I gave commands; Then all smiles stopped together. There she stands As if alive. Will 't please you rise? We 'll meet The company below, then. I repeat, 
The Count your master's known munificence

Is ample warrant that no just pretense

Of mine for dowry will be disallowed;

Though his fair daughter's self, as I arowed

At starting, is my object. Nay, we'll go

Together down, sir. Notice Neptune, though,

Taming a sea-horse, thought a rarity,

Which Claus of Innsbruck cast in bronze for me!

How much the word last in the title of this poem suggests! Note how many, and how different, are the topics in the last dozen lines. Yet there is no paragraphing throughout. The page should show things as they exist in the Duke's mind, and he runs from one thought to another as if they were all on the same plane, and closely related.

Was there ever a more vain, heartless, haughty. selfish, bartering gentleman-wretch? Note how single short sentences even surprise one by the extent to which they reveal character. Whole volumes are included between sentences. One can scarcely read the poem through rapidly; for it seems necessary to pause here and there to reflect upon and interject statements.

There is no doubt about the need of extensive supplementing in the case of adult literature. Is that true, however, of literature for children? Is not this, on account of the immaturity of children, necessarily so written as to make such supplementing unnecessary? For a test let us examine Longfellow's The Children's Hour, which is so popular with seven- and eight-yearold boys and girls. 


\section{THE CHILDREN'S HOUR}

Between the dark and the daylight, When the night is beginning to lower, Comes a pause in the day's occupations, That is known as the Children's Hour.

I hear in the chamber above me The patter of little feet,

The sound of a door that is opened, And voices soft and sweet.

From my study I see in the lamplight, Descending the broad hall stair, Grave Alice, and laughing Allegra, And Edith with golden hair.

A whisper, and then a silence: Yet I know by their merry eyes, They are plotting and planning together To take me by surprise.

A sudden rush from the stairway, A sudden raid from the hall!

By three doors left unguarded They enter my castle wall!

They climb up into my turret $\mathrm{O}$ 'er the arms and back of my chair; If $I$ try to escape, they surround me; They seem to be everywhere.

They almost devour me with kisses Their arms about me entwine, Till I think of the Bishop of Bingen In his Mouse-Tower on the Rhinel 
Do you think, O blue-eyed banditti,

Because you have scaled the wall, Such an old moustache as I am

Is not a match for you all!

I have you fast in my fortress, And will not let you depart, But put you down into the dungeon, In the round tower of my heart.

And there will I keep you forever,

Yes, for ever and a day,

Till the walls shall crumble to ruin,

And molder in dust away!

1. How would we plan to dramatize this poem? In answering this question, we must consider how many persons are needed, what arrangement of rooms and doors, etc., will be fitting; are the last three stanzas to be spoken? etc.

2. It seems that here is a family in which an hour is set aside for play. What kind of home must that be?

3. Was this the custom each day? Or did it happen only once?

4. Does the father seem to enjoy it? Or was it rather an unpleasant time for him?

5. Is there any proof that these were especially attractive children? ("Voices soft and sweet.")

6. Which is the best part of the last three stanzas, in which he tells how much he loves them? (Meaning of "for ever and a day.")

7. Do you know any other families that have a time set apart each day for playing together? Why aro there not more? 
8. Does such an arrangement depend on the parents wholly? Or could the children help much to bring it about? How?

9. Have you heard the story about the Bishop of Bingen in his Mouse-Tower on the Rhine River?

10. Meaning of strange words may be explained in various ways, perhaps some of them scarcely explained at all.

These are some of the questions that could well be considered in this poem. It is true that this selection, like most adult literature, is capable of being enjoyed without much addition. But it is not mere enjoyment that is wanted. We are discussing what study is necessary in order to get the full profit. In the case of Hawthorne's Wonder-Book and Tanglewood Tales, numerous questions and suggestions need likewise to be interjected. One of the best books for five-to eightyear-old children on the life of Christ bears the title Jesus the Carpenter of Nazareth. It is an illustrated volume of five hundred pages, which makes it clear that the original Bible text has been greatly supplemented. Yet it is a pity to read even this book without frequent pausing for additional detail.

Thus literature, including even that for young children, fails to show on the surface all that the reader is expected to see. Much of it states only a very small part of this. A piece of literature resembles a painting in this respect. Corot's well-known painting, "Dance of the Wood Nymphs," presents only a few objects, including a landscape with some trees and some dancing women. Yet people love to sit and look at it, perhaps to examine its detail and enjoy its author's skill, but 
also to recall countless memories of the past, of beautiful woods and pastures, of happy parties, of joys, hopes, and resolves, and possibly, too, to renew resolves for the future. The very simple scene is thus a source of inspiration, a stimulus to think or study. A poem accomplishes the same thing.

A warning of the amount of hard work that the student of literature must expect is given by Ruskin in the following forcible words: "And be 3. As stated sure, also, if the author is worth anything, by Ruskin. that you will not get at his meaning all at once, - nay, that at his whole meaning you will not for a long time arrive in any wise. Not that he does not say what he means, and in strong words, too; but he cannot say it all, and what is more strange, will not, but in a hidden way, and in parables, in order that he may be sure you want it. I cannot quite see the reason of this, nor analyze the cruel reticence in the breasts of wise men which makes them always hide their deeper thought. "They do not give it you by way of help, but of reward, and will make themselves sure that you deserve it, before they allow you to reach it.

"But it is the same with the physical type of wisdom, gold. There seems, to you and me, no reason why the electric forces of the earth should not carry whatever there is of gold within it at once to the mountain tops, so that kings and people might know that all the gold they could get was there, and without any trouble of digging, or anxiety, or chance, or waste of time, cut it away, and coin as much as they needed. But Nature does not manage it so. She puts it in little fissures in the earth, nobody knows where. You may dig 
long and find none; you must dig painfully to find any.

"And it is just the same with men's best wisdom. When you come to a good book, you must ask yourself, 'Am I inclined to work as an Australian miner would? Are my pickaxes and shovels in good order, and am I in good trim myself, my sleeves well up to the elbow, and my breath good, and my temper?' And keeping the figure a little longer . . . the metal you are in search of being the author's mind or meaning, his words are as the rock which you have to crush and smelt in order to get at it. And your pickaxes are your own care, wit, and learning; your smelting furnace is your own thoughtful soul. Do not hope to get at any good author's meaning without those tools, and that fire; often you will need sharpest, finest chiseling and patientest fussing before you can gather one grain of the metal." 1

When we turn from literature to the text-books used in schools and colleges, we find the need of supple4. As sug- menting greatly increased. Writers of litergasted by an ature are at liberty to choose any topic they of tert-books. please, and to treat it as fully as they will. But writers of text-books are free in neither of these respects. Their subjects are determined for them; it is the history, for example, of a given period, the grammar of the English language, the geography of the earth. And these must be presented briefly enough to be covered by classes within a prescribed time. For these reasons text-books contain far less detail than literature, and in that sense are much more condensed. 
They are only the outlines of subjects, as their titles often directly acknowledge. Green's History of England, for instance, which has been extensively used as a college text, barely touches many topics that are treated at great length elsewhere. It is natural, therefore, that in our more advanced schools the word text in connection with such books is used in much the same sense as in connection with the Bible; a text is that which merely introduces topics by giving the bare outline of facts, or very condensed statements; it must be supplemented extensively, if the facts or thoughts are to be appreciated.

How about the texts used in the elementary school? Those used in the highest two grades need, perhaps, somewhat more supplementing than those in the high school. But in the middle grades this need is still greater. In the more prominent studies calling for textbooks, such as history, geography, and English language or grammar, nearly the same topics are treated as in the higher grades, and in substantially the same manner. But since the younger children are not expected to take as long lessons, - and perhaps, too, because they cannot carry as large books, - their texts are made briefer. This is mainly accomplished by leaving out much of the detail that is necessary to make the facts clear and interesting. Consequently, supplementing is an especially important factor of study in these grades. In general, the briefer the text, the more "filling in" is needed.

As an illustration, take the following extract from the first page of McMaster's Child's History of tho United States, often used with ten-year-old pupils. 
Four hundred and fifty years ago the people of western Europe were getting silks, perfumes, shawls, ivory, spices, and jewels from southeastern Asia, then called the Indies. But the Turks were conquering the countries across which these goods were carried, and it seemed so likely that the trade would be stopped, that the merchants began to ask if somebody could not find a new way to the Indies.

The king of Portugal thought he could, and began sending his sailors in search of a way around Africa, which extended southward, nobody knew how far. Year after year his ships sailed down the west coast, the last captain going further south than the one before him, till one of them at last reached the southern end of the continent and entered the Indian Ocean.

Observe a few of the thoughts "between the lines" that need to be considered:-

1. Six things are here mentioned as brought from the East Indies. It seems odd that some of these should receive mention as among the most important imports. Which are they? Could any of them have been more important then than now? Why?

2. What were the routes of travel, by land, to the Indies? (Map.)

3. Where did the Turks live; and what reasons had they for preventing this trade?

4. Why could not the first Portuguese captain sail directly to the southern end of Africa?

Again, take the topic desert in geography. The texts usually define a desert as a sandy waste, often a plain, that receives too little rain to support much vegetable or animal life. Pictures are given showing the character of the plants, and perhaps the appearance of such a region. Beyond that little is usually attempted. 
In the larger books the danger from sand storms and some other things are included. Such treatment needs to be supplemented by numerous questions, such as the following:-

1. What animals that are common here are seldom found there, or not at all? (Horses, cows, etc., also birds, flies, bugs, et 2 .)

2. What plants that are common here are not found there? (Trees, flowers, weeds, etc.)

3. Is the weather particularly enjoyable there, o: not? Is it desirable to have sunshine all the time?

4. What about noises of various kinds? (Silence so oppressive to some people that it becomes intolerable.)

5. What would be some of the pleasures of a walk in the desert? (Coloring, change of seasons, trees along streams, appearance of any grass.)

6. What about the effect of strong winds on the sand?

7. Imagining that some one has just crossed a desert, what dangers do you think he has encountered, and how may he have escaped from them?

From the preceding discussion it is clear not only that no important topic is ever completely presented, but also that there is scarcely any limit to the extent to which it may be supplemented. To which the Men get new thoughts from the same Bible supplementtexts year after year, and even century after bo carried. century. How far, then, should the supplementing be carried?

The maximum limit cannot be fixed, and there is no need of attempting it. But there is great need of knowing and keeping in mind the minimum limit; for 
in the pressure to hurry forward there is grave danger that even this limit will not be reached.

What is this minimum limit? Briefly stated, it is this: There should be enough supplementing to render the thought really nourishing, quickening, to the learner. In the case of literature that will involve some supplementing; and in the case of ordinary textbooks it will require a good deal more.

Is this standard met when the child understands and can reproduce in substance the definition of desert? Far from it! That definition is as dry and barren as the desert itself; it tends to deaden rather than quicken. The pupil must go far beyond the mere cold understanding and reproduction of a topic. He must seo the thing talked about, as though in its presence; he must not only see this vividly, but he must enter into its spirit, or feel it; he must experience or live it. Otherwise the desired effect is wanting. This standard furnishes the reason for such detailed questions as are suggested above. The frequency with which stirring events, grand scenery, and great thoughts are talked about in class with fair understanding, but without the least excitement, is a measure of the failure of the so-called better instruction to come up to this standard. No really good instruction, any more than good story books, will leave one cold toward the theme in hand.

It must be confessed that this standard calls for a Reasons why large amount of supplementing. There are

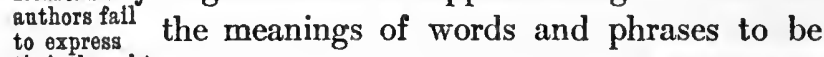
their thought
more completely. to be filled in for the sake of vivid pictures, illustrations to be furnished out of one's own 
experience, inferences or corollaries to be drawn, questions to be raised and answered, and finally the bearings on life to be traced. It might seem that authors could do their work better, and thereby relieve their readers of work.

Yet these omissions are not to be ascribed to the evil natures of authors, nor to the superabundance of their thought, alone. Readers would be dissatisfied if all this work were done for them. Any one has observed that small children are disappointed if they are not allowed to perform necessary little tasks that lie within their power. Also, they enjoy those toys most that are not too complete, and that, therefore, leave some work for their own imaginations. This quality of childhood is characteristic of youth and of adults. An author would not be forgiven if he stopped in the midst of his discourse to explain a reference. Eminent writers, like Longfellow, for example, are even blamed for attaching the morals to their productions; and terseness is one of the qualities of literature that is most praised. In other words, older people, like children, love activity. Although they at times hate to work, they do not want authors to presuppose that they are lazy or helpless; and they resent too much assistance. Since, therefore, the many omissions in the presentation of thought are in accordance with our own desires, we would do well to undertake the necessary supplementing without complaint. 
THE ABILITY OF CHILDREN TO SUPPLEMENT THOUGHT

There are several facts indicating that children have the ability to undertake this kind of studying.

One of the chicf powers necessary is a vivid imagination by which concrete situations can be clearly Reasons for pictured, and children possess such power assuming
that children have that they become frightened by the products this kind of of their own imaginations. Their dolls are 1, Their
vivid imagi- so truly personified that mishaps to them nations. easily cause tears, and their mistreatment by strangers is resented as though personal. Adults hardly equal them in this imaginative quality.

When children are left alone together they do not lack things to do and say. Their minds are active 2. Their enough to entertain one another as well as ability to imitate and adults do, and not seldom better. In fact, $\underset{\substack{\text { think, as } \\ \text { shown in }}}{\text { if }}$ if they remain natural, they are often more conversation. interesting to adults than other adults are. They reach even profound thoughts with peculiar directness. When I was attempting, one day, to throw a toy boomerang for some children, one of the little girls, observing my want of success, remarked, "I saw a picture of a man throwing one of these things. $\mathrm{He}$ stood at the door of his house, and the boomerang went clear around the house. But I suppose that people sometimes make pictures of things that they can't do; don't they?"

The method of teaching called development instruction is based on the desire and ability of children to contribute ideas. That instruction could not succeed 
as it has succeeded, if children did not readily conceive thoughts of their own. Not only do they answer questions that teachers put in such teaching, 3. The sucbut they also propose many of the questions oess of derel. that should be considered. That method instruotion. flourishes even in the kindergarten. In the kindergarten circle children often interrupt the leader with germane remarks; and sometimes it is difficult even to suppress such self-expression. One reason the kindergartner tells her stories, rather than reads them, is that she may have her eyes on the children and thus take advantage of their desire to make contributions of thought. The same tendency is shown in the home, when children want to "talk over" what their parents or other persons read to them. They fail to respond in this way only when they are afraid, or when they have attended school long enough to have this tendency partly suppressed.

Finally, the fact that children's literature, like that for adults, presupposes much supplementing, is strong reason for presupposing that ability on their 4 . Tho charpart. Any moral lessons that belong to fairy acter of tales must be reached by the children's own literatare. thought; the same usually applies to fables also. Hawthorne understood the child mind as few persons have. Yet it is astonishing how much ability to supplement seems to have been expected by him. It would be surprising if such experts were mistaken in their estimate of children. 
PRACTICAL SUgGESTIONS FOR TEACHING CHILDREN TO SUPPLEMENT THOUGHT

Teachers can make use of text-books at least enough to give much practice in supplementing text. Text1. Import books are so uncommon in some schools that ance of nsing one might conclude that they had gone out text-books.

of fashion among good teachers. Yet there is certainly nothing in modern educational theory that advises the neglect of books. Some teachers may have imagined that development instruction, to which reference has just been made, leans that way. But development instruction is of importance rather in the first presentation of some topics. After a topic has been thus developed, it can well be reviewed and further studied in connection with books. Many teachers are neglecting to use texts both to their own detriment and to the serious disadvantage of their pupils.

Teachers who have liberty in choosing their textbooks should select those that contain abundant detail.

2. Find of tert to be preferred.

That means a thick book, to be sure; and many teachers are afraid of such books on the ground that they mean long lessons. A thick book nay be a poor text; but a thin one is almost bound to be. The reason is that books are usually made thin at the expense of detail; and detail is necessary in order to establish the relations between facts, by which the story form can be secured and a subject be made interesting. Without plenty of detail the facts have to be run together, or listed, merely as so many things that are truc; they then form only a skeleton, with all the repulsiveness of a skeleton. Such a barren 
text is barren of suggestions to children for supplementing, because the ideas are too far apart to indicate what ought to fit in between.

The understanding ought to be more common that long lessons are by no means synonymous with hard lessons. The hardest lessons to master are those brief, colorless presentations that fail to stimulate one to see vividly and to think. Many a child who carries a geography text about with him learns most of his geography from his geographical readers, simply because the writer does not squeeze all the juice out of what he has to say in order to save space. A child can often master five pages in such a book more easily than he can one from the ordinary geography, and he will remember it longer.

Whaterer the text chosen, the recitation should be so conducted that the emphasis will fall on reflection rather than on mere reproduction. To this 3 . Character end one should avoid putting mainly mem- of the quesory questions, such as, Who was it - ? prto When was it - ? Why was it - ? What is said about - ? Even the usual request, "Close the books," at the beginning of the recitation can often be omitted to advantage. Why should not the text-book in history and geography lic open in class, just as that in literature, if thinking is the principal object?

Questions that require supplementing can be proposed by both teacher and pupils. Now and then some topic can be assigned for review, with the understanding that the class, instead of reproducing the facts, shall occupy the time in "talking them over." The teacher can then listen. or act as critic. It is a harsh 
commentary on the quality of instruction if a lesson on Italy, or on a presidential administration, or on a story, suggests no interesting conversation to a class.

Occasionally, as one feature of a lesson, a class might propose new points of view for the review of some subject. For example, if the Western states have been studied in geography, some of the various ways in which they are of interest to man might be indicated by questions, thus: What about the Indians in that region? What pleasure might a sportsman expect there? What scctions would be of most interest to the sight-seer? How is the United States Government reclaiming the arid lands, and in what sections? What classes of invalids resort to the West, and to what parts? How do the fruits raised there compare with those further east in quality and appearance? How is farming differently conducted there? In what respects, if any, is the West more promising than the East to a young man starting in life?

These are such questions about the West as large classes of individuals must put to themselves in practical life; they are, then, fair questions for the pupil in school to put to himself and to answer. By thus considering the various phases of human interest in a subject, children can get many suggestions for supplcmenting the text.

The habit of reproducing thought in different ways will also throw different lights on the subject-matter, 4. Different and thus offer many supplementary ideas. types of reprodac-

For example, dramatizing is valuable in this tion,

way. The description, in the first person, of one's experiences in crossing the desert is an illustra. 
tion. I once visited a Sunday-school class that was studying the life of John Paton, the noted missionary to the New Hebrides Islands. The text stated that one of the cannibal chiefs had been converted, and had asked permission to preach on Sunday to the other savages. This permission was granted; but the text did not reproduce the sermon. Thereupon several members of the class undertook, as a part of the next Sunday's lesson, to deliver such a sermon as they thought the savage might have given. Two of the boys brought hatchets on that Sunday to represent tomahawks, which they used as aids in making gestures, and their fire-minute speeches showed a careful study of the whole situation. Likewise the experiences of Columbus might be dramatized, as, when asking for help from the king, or when reasoning with the wise men of Spain, or when conversing with his sailors on his first voyage to America. ${ }^{1}$

Additional suggestions will often be obtained by inquiring, "What part of this lesson, if any, would you like to represent by drawings? Or by paintings? Or by constructive work? Also, How would you do it?"

Much of what has been said about supplementing ideas finds only slight application to beginning reading, writing, spelling, and number work. The 6. The danreason is that these subjects, aiming so largely three $^{\text {ger }} \mathrm{B}_{\mathrm{s} \text { and }}$ at mastery of symbols, call for memory and spelling to skill rather than reflection. For this very flection. reason these subjects are in many ways dangerous to proper habits of study, and the teacher needs to be on

${ }^{1}$ See the story of Columbus in Stevenson's Children's Classics in Dramatic Form, A Reader for the Fourth Grade. 
her guard against their bad influence. They are so prominent during the first few years of school that children may form their idea of study from them alone, which they may retain and carry over to other branches. To avoid this danger, other subjects, such as literature and nature study, deserve prominent places in the curriculum from the beginning, and special care should be exercised to treat them in such a way that this easy kind of reflection is strongly encouraged. 


\section{CHAPTER V}

IHE ORgANIZATION OF IDEAS, AS A THIRD FACTOR IN STUDY

\section{A. The different values of facts, and their grouping into "points"}

IN several branches of knowledge in the primary school it is customary for teachers to attach practically the same importance to different facts. This Extent to is the case, for instance, in spelling, where whioh teacha mistake counts the same, no matter what facts as equal word be misspelled. It is largely the case in tn value. writing. In beginning reading one word is treated is equal in value to any other, since in any review list every one is required. In beginning arithmetic this equality of values is emphasized by insistence upon the complete mastery of every one of the combinations in the four fundamental operations. Throughout arithmetic, moreover, failure to solve any problem is the same as the failure to solve any other, judged in the light of the marking systems in use.

The same tendency is less marked, but still evident, in many other subjects, some of them more advanced. In geography, teachers seldom recognize any inequality of value in the map questions, even though a question on the general directions of the principal mountain systems in North America be followed by a request to locate Iceland. The facts, too, are very often strung along in the text in such a manner that it is next to 
impossible to distinguish values. Here is an example from a well-known text: "Worcester is a great railroad center, and is noted for the manufacture of engines and machinery. At Cambridge is located Harvard University, the oldest and one of the largest in the country. Fall River, Lowell, and New Bedford are the great centers of cotton manufacture; Lawrence, of both cotton and wool; Lynn, Brockton, and Haverhill make millions of boots and shoes; and at Springfield is a United States arsenal, where firearms are made. Holyoke has large paper mills. Gloucester is a great fishing port. Salem has large tanneries." How does this differ from a spelling list, so far as equality of values is concerned?

In nature study all have witnessed the typical lesson where some object, such as a flowering twig, for example, is placed in the hands of every pupil and each one is requested to tell something that he sees. Anything that is offered is gratefully accepted. While this particular kind of study is fortunately disappearing, the common tendency to regard all facts alike is still clearly shown in the case of the topic, cat, discussed on page 40.

In literature, failures are very often condemned alike, whether they pertain to the meanings of words, of sentences, of references, or of whole chapters.

Until very recently at least, even in universities, it has been common to assign lessons in history textbooks by pages, and to require that they be recited in the order of the text. The teacher, or professor even, in such cases has shown admirable ability to place the burden of the work upon the students by assigning to himself the single onerous task of announcing who 
shall "begin" and who shall "go on."- What recognition is there of varying values of facts in such teaching?

Not all of such instruction is avoidable or even undesirable; but it is so common that it has a very important effect on method of study.

The effect of

So long as facts are treated as approx- ing teachimately equal in worth, the learner is bound of stady.

to picture the field of knowledge as a comparatively level plain composed of a vast aggregation of independent bits. In spelling, writing, and beginning reading it is so many hundreds or thousands of words; in beginning arithmetic it is the various combinations in the four fundamental operations; in geography it is a long list of statements; in history it is an endless lot of facts as they happen to come on the page; in literature it is sentence after sentence.

One can get possession of this field, not by taking the strategic positions, - for under the assumption of equality there are none, - but rather by advancing over it slowly, mastering one bit at a time. Thus the words in beginning reading, writing, and spelling are learned and reproduced in all orders, proving them to be independent little entities. In geography and history, when the facts are not wormed out of the pupil by questions, he sees the page before him by his mind's eye, - a fact frequently revealed by the movement of his eyes while reciting, - and attempts to recall each paragraph or statement in its order. In literature he masters his difficulties sentence by sentence, a method most clearly shown in the case of our greatest classic, the Bible, which is almost universally studied and quoted by verses. 
Thus the unit of progress in study is made the single fact; the whole of any subject becomes the sum of its details; and a subject has been supposedly mastered when all these bits have been learned. This might well be called the method of study by driblets. It is probably safe to say that a majority of the young people in the United States, including college students, study largely in this way.

While this method of study is bad in numerous ways, there are three of its faults in particular which need to be considered here.

In the first place, facts vary indefinitely in value. In parts of a few subjects they do have practically

Respocts in which this method of otndy is wrong. the same worth, which is, no doubt, a source of much misconception about proper methods of study. In spelling, for instance, which is probably as important a word as when, and sea as important as flood. In a list of three hundred carefully selected words for spelling for third1. Facte, as year pupils, any one word might properly a rule, vary be regarded as equal to any other in worth. This may be said also in regard to a list for writing. Much the same is true in regard to a possible list of four hundred words for reading in the first year of school. In arithmetic one would scarcely assert that $4 \times 7$ was more or less important than $9 \times 8$, or $8 \div 2$, or $6-3$, or $4+2$. In other words, the various combinations in the four fundamental operations are. again, all of them essential to every person's knowledge, and therefore stand on the same plane of worth.

To some extent, therefore, the three R's and spelling are exceptions to an important general rule. Yet 
even in spelling and beginning reading not all words by any means have the same value. Children in the third year of school who are reading Whittier's Barefoot Boy ought to be able to recognize and spell the word robin; perhaps, also, woodchuck and tortoise; but eschewing is not a part of their vocabulary and will not soon be, and probably the less said about that word by the teacher the better.

The moment we turn to other subjects, facts are found to vary almost infinitely in value, just as metals do. Judged by the space they occupy, they may appear to be equally important; but they are not to be judged in this way, any more than men are. According to their nature, thoughts or statements are large and small, or broad and narrow, or far-reaching and insignificant. A general of an army may be of more consequence to the welfare of a nation than a thousand common soldiers; so one idea like that of evolution may be worth a full ten thousand like the fact that "our neighbor's cat kittened yesterday."

In the second place, facts can by no means be regarded as independent. As before, to be sure, the three R's and spelling afford some exception to this rule. In spelling, writing, and be- dependent ginning reading it is important that any one anober for of a large number of words be recognized their worth. or reproduced at any time, without reference to any others. All of these, together with the combinations in the fundamental operations in arithmetic, are often called for singly, and they must, therefore, be isolated from any possible series into which they might falls and mastered separately. 
Aside from these subjects, facts are generally depen. dent upon their relations to one another for their value. Taken alone, they are ineffective fragments of knowledge, just as a common soldier or an officer in an army is ineffective in battle without definite relations to a multitude of other men.

If the first sentences on twenty successive pages in a book were brought together, they would tell no story. They would be mere scattered fractions of thoughts lacking that relation to one another that would give them significance and make them a unit. Twenty closely related sentences might, however, express a very valuable thought.

James Anthony Froude, impressed with this truth and at the same time recalling the prevalent tendency to ignore it, declares: "Detached facts on miscellaneous subjects, as they are taught at a modern school, are like separate letters of endless alphabets. You may load the mechanical memory with them, till it becomes a marvel of retentiveness. Your young prodigy may amaze examiners and delight inspectors. His achievements may be emblazoned in blue books, and furnish matter for flattering reports on the excellence of our educational system. And all this while you have been feeding him with chips of granite. But arrange your letters into words, and each word becomes a thought, a symbol waking in the mind an image of a real thing. Group your words into sentences, and thought is married to thought, and the chips of granite become soft bread, wholesome, nutritious, and invigorating." 1

A very simple illustration is found in the study of the

2 James Anthony Froude, Handwork before Headwork. 
dates for the entrance. of our states into the Union. Taken one at a time, the list is dead. But interest is awakened the moment one discovers that for a long period each Northern state was matched by one in the South, so that they entered in pairs.

Finally, the whole of a subject is not merely the sum of its little facts. You may study each day's history lesson faithfully, and may retain everything 3 The sum in memory till the book is "finished," and of the details still not know the main things in the book. equal the You may understand and memorize each verse whole. of a chapter in the Bible until you can almost repreduce the chapter in your sleep, and still fail to know what the chapter is about. Probably some readers of this text who have repeated the Lord's Prayer from infancy, would still need to do some studying before they could teli the two or three leading thoughts in that prayer.

An especially good illustration of this fact in my own experience as a teacher has been furnished in connection with the following paragraph, taken from Dr. John Dewey's Ethical Principles underlying Education. "Information is genuine or educative only in so far as it effects definite images and conceptions of material placed in social life. Discipline is genuine and educative only as it represents a reaction of the information into the individual's own powers, so that he can bring them under control for social ends. Culture, if it is to be genuine and educative, and not an external polish or factitious varnish, represents the vital union of information and discipline. It designates the socialization of the individual in his whole outlook upon life and mode of dealing with it." I have had a iarge num. 
ber of graduate students who found it very difficult to state the point of this paragraph, although every sentence is reasonably clear and they are in close sequence.

Thus the larger thoughts, instead of being the sum of the details, are an outgrowth from them, an interpretation of them; they are separate and new ideas conceived through insight into the relations that the individual statements bear to one another.

From the foregoing we see that some facts are very large, while others are of little importance, and that The proper any one statement, taken separately, lacks unit of prog- significance.
ress in

stady.

The field of thought, therefore, instead of being pictured as a plain, is to be conceived as a very irregular surface, with elevations of various heights scattered over it. And just as hills and mountains rest upon and are approached by the lower land about them, so the larger thoughts are supported and approached by the details that relate to them.

A general of an army, desiring to get possession of a disputed region, does not plan to take and hold the lower land without the higher points, nor the higher points without the lower land. On the contrary, each vantage point with its approaches constitutes, in his mind, one division of the field, one strategic section, which is to be seized and held. And these divisions or units all taken together constitute the region.

So any portion of knowledge that is to be acquired should be divided into suitable units of attack; one arge thought together with its supporting details should constitute one section, another large thought together with its associated details a second, etc.; all 
of these together composing the whole field. In other words, the student, instead of making progress in knowledge fact by fact, should advance by groups of facts. His smallest unit of progress should be a considerable number of ideas so related to one another that they make a whole; those that are alike in their support of some valuable thought making up a bundle, and the farther-reaching, controlling idea itself constituting the band that ties these bits together and preserves their unity. Such a unit or, "point," as it is most often called, is the basal element in thinking, just as the family is the basal element in society.

Such units of advance may vary indefinitely in size; but the danger is that they will be too small. A minister who reaches his thirteenthly is not likely to be a means of converting many sinners. suech anits of A debater who makes fifteen points will adrance. hardly find his judges enthusiastic in his favor, no matter how weak his opponents may be. A chapter that contains twenty or thirty paragraphs should not be remembered as having an equal number of points. What is wanted is that the student shall feel the force of the ideas presented, and a great lot of little points strung together cannot produce a forceful impression.

Any thought that is worth much must be supported by numerous facts and will require considerable time or space for presentation. A minister can hardly establish a half dozen valuable ideas in one sermon; he does well if he presents two or three with force; and he is most likely"to make a lasting impression if he confines himself to one. Drummond's The Greatest Thing in 
the World is an example of the possibilities in this direction.

Accordingly the student, in reading a chapter or listening to a lecture, should find the relationships among the smaller portions of the thought that will unify the subject-matter under a very few heads. If several pages or a whole lecture can be reduced to a single point, it should be done. He should always remember that to the extent that the supporting details are numerous they will have a cumulative effect, thereby rendering the central thought strong enough to have a permanent influence.

Such grouping of ideas as has thus far been considered, although of the greatest importance, is only The meaning the beginning of the organization of knowlof organisa- edge. For thus far only the minimum unit
tion of knowledge, of advance has been under discussion. As and its value. one proceeds in the study of a subject these smaller units collect in large numbers, and they must themselves be subordinated to still broader central thoughts, according to their nature. This grouping of details, according to their relationships, into points, and of such points under still higher heads, and so on until a whole subject and even the whole field of knowledge is carefully ordered according to the relationships of its parts, is what is meant by organization of knowledge.

Sometimes an entire book is thus organized under a single idea, Fiske's Critical Period of American History being an excellent example. In this volume the conditions at the close of the Revolutionary War are vividly described. It is shown that great debts re- 
mained unpaid, that different systems of money caused confusion, and that civil war was seriously threatened in various quarters. These and other dangers convinced sober men that a firm central government was indispensable. But then, it was no easy matter to bring such a government into existence; and it is shown how numerous heroic attempts in this direction barely escaped failure before the constitution was finally adopted. On the whole, it is safe to say that each paragraph or small number of paragraphs, while constituting a unit, is at the same time a necessary part of the chapter to which it belongs; likewise, each chapter, while constituting a unit, is an integral part of the book as a whole; and all these parts are so interrelated and complete that the whole book constitutes a unit.

Observe the advantage of such organization. The period of our history immediately following the Revolution used to be one of the least interesting of topics. Under the title "The Period following the Treaty of Paris," or "The Period from the Close of the Revolutionary War to the Adoption of the Constitution," the textbooks attempted nothing more than an enumeration or history of the chief difficulties and struggles of our youthful nation. In some cases, if I remember correctly, this was designated "The Period of Confusion," and its description left the reader in a thoroughly confused state of mind.

Fiske's book was a revelation. What had seemed very complex and confused became here extremely simple; what had been especially dull became here perhaps the most exciting topic in all our history. And the secret of the advance is found to a large extent 
in the organization. Thus organization is a means of effectiveness in the presentation of knowledge, as in the use of a library or the conduct of a business.

All the facts in Mr. Fiske's book are organized about the stirring question expressed in his title, i.e., how our The basis for ship of state barely escaped being wrecked. the organi- Because this idea is of intense interest to us, knowledge in and the entire book bears upon it continually, general.

the story is read with bated breath. Drummond's Greatest Thing in the World is another excellent example on a smaller scale of ideas centered about a vital human question. Thus specific problems 'of various degrees of breadth, that are intimately related to man, can well be taken as the basis for the organization of knowledge in general. Classical literature is organized on this basis, which is called the pedagogical or psychological basis, and it seems desirable that other fields should also be.

Yet there are other kinds of organization in which the relation to man is not so plainly, or not at all, taken as the controlling idea. For example, biology is often organized on the basis of the growing complexity of the organism, the student beginning with the simple, microscopic cell, and advancing to the more and more complex forms. Formerly, after the Linnæan system, plants were classified according to their similarity of structure. Now both plants and animals are often classified on the basis of their manner of adaptation to thair environment. Thus within the ficld of science there is what is called the scientific basis of organization.

There is also the logical basis of organization of 


\section{THE ORGANIZATION OF IDEAS}

thought, according to which some most fundamental idea is taken as the beginning of a system, or the premise, and other ideas are evolved from this first principle. Rousseau attempted to develop his educational doctrine in this way, starting with the assertion that everything was good as it came from the Creator, but that everything degenerated in the hands of man. John Calvin did the same in his system of theology; and he reasoned so succinctly from his few premises that any one granting these was almost compelled to accept his entire doctrine.

Attention is called to these facts here in order to suggest that, while the scientific and the logical bases of organization are in common use, neither of them is adequate as the main basis of organization for $\mathbf{a}$ young student who is studying a subject for the first time. The reason is that each of them secures a careful ordering of facts only with reference to the relations that those facts bear to one another, and not with reference to the relation that they bear to man; and in thus ignoring man they show grave faults. They are indifferent to interest on the part of the learner; they offer no standard for judging the relative worths of facts to man; and instead of exerting an influence in the direction of applying knowledge, they exert some influence in the opposite direction by their indifference to man's view-point. It must be admitted that they are of great assistance in securing thorough ness of comprehension by their revelation of the rela. tions existing among facts, and also that they classify facts in a convenient way for finding them later; but they are of greatest use to the advanced student, who 
is already supplied with motive and with standards for judging worth, and who has proper habits of study already formed; they can well follow but they should not supplant the psychological basis.

An author's organization of subject-matter is frequently poor. But whether it be poor or good, some The sta- hard work on the part of the student is dent's dooble necessary before the proper grouping of
task in the organization ideas can take place in his own mind. The of ideas.

danger is that there will be practically no arrangement of his thoughts, as is well illustrated in the following letter from an eight-year-old boy.

\section{Dear Uncle Charlie:}

Will you please buy some of my 24 package of my Bluine, if you will please buy one package it will help me a lot. One Saturday we played ball against the east side and beat twelve to 1 . I will get a baseball suit if $I$ can sell 24 packages of Bluine. We had quite a blizzard here to-day. For one package it costs ten cents. When we played ball against the east side we only had 6 boys and they had twelve. We have a base ball team, and I am Captain, so you see I need a suit. Gretchen and Mother are playing backgammon with one dice. I catch sometimes when our real catcher is not there. When he is there I play first Base.

$$
\text { Your loving nephew, }
$$

JAMES.

There is one prominent idea in this letter, touching the sale of Bluine, with reasons; and parts of two others, concerning the weather and the occupation of mother and sister. The first is the most fully treated; but, as might be expected from an eight-year-old child, no one idea is supported by sufficient detail to round it out and make it strong. 
In avoiding such defects two things are necessary: First, the student must decide what points he desires to make. They should be so definitely conceived that they can be easily distinguished from one another and can even be counted. Then, in the second place, all the details that bear upon a central idea should be collected and presented together in sequence under the point concerned. By this massing of all supporting statements under their proper heads, overlapping or duplicating is avoided, and clearness is gained. Also, force is secured by the cumulative effect of intimately related facts, just as it is secured by the concerted attack by the divisions of an army.

Even the better students often stop with finding the main thoughts alone. And the temptation to do no more is strong, since teachers seldom require a forceful presentation of ideas in recitation; they are thankful to get a halting statement of the principal facts. But the student should remember that he is studying for his own good, not merely to keep teachers contented; and he should not deceive himself by his own fluency of speech. He should form the habit of often asking himself, "What is my point?" also, "What facts have I offered for its support, and have I massed them all as I should?" He must thus form the habit of arranging his ideas into points if he wishes to be pointed.

The dangers of inaccuracy in this kind of study are numerous. First the individual statements must be carefully interpreted. A certain very intelligent ten-year-old girl studying arithmetic read the problem, "What is the interest on $\$ 500$ at six per cent for one 
year?" Then, probably under the influence of some preceding problem, she found four per cent of the principal, and added the amount to the principal for her Precantions answer, thus showing two mistakes in readaccaracy in ing. Perhaps half of the mistakes that chilthe grouping dren make in the solution of problems is due points. to such careless reading. A certain fifth-year class in history read a very short paragraph about the three ships that were secured for Columbus's first voyage, the paragraph ending with the statement, "On board the three [ships] were exactly ninety men." When they were asked later how many men accompanied Columbus the common answer was, "Two hundred and seventy, since there were ninety men on each ship."

These mistakes are typical of those that are common, even among adults, as in the reading of examination questions, for instance. I have more than once asked graduate students in a university to state the one principal thought obtained from the extended study of an article on education, and have received a paper with a threefold answer, $(a),(b),(c)$. Such responses are due to extreme carelessness in reading the questions asked, as well as to a desire to be obliging and allow an instructor some freedom of choice. Thus the meaning of the individual statements that constitute the material out of which larger truths are derived, must be carefully watched if the final interpretation of an author's thought is to be accurate.

The tendency toward error is greater still when it comes to finding the central thought for a portion of text. This was once amusingly illustrated by a class 
composed only of the principals and high-school teachers in a county institute, some seventy-five persons in all. The text under discussion was the first chapter of Professor James's well-known book, Talks to Teachers. The title of the chapter is "Psychology and the Teaching Art"; and Professor James, fearing that teachers might be expecting too much from his field, sets to work to discourage the idea that psychology can be a panacea for all of a teacher's ills. The larger portion of the twelve pages is devoted to this object, although the explicit statement is made, on the third page, that "psychology ought certainly to give the teacher radical help." But so little space is given to this declaration that, in spite of its definiteness and positive character, the class as a whole reached the conclusion that he was advising teachers not to study psychology at all. In other words, they had failed to balance up one part of the chapter against the other; and their failure left them in the ridiculous position of assuming that an author of a book for teachers was dissuading teachers from reading his book.

A third and perhaps the most common source of error is found in the particular wording given to the central thought. In order to be perfectly definite and accurate any thought should be expressed in the form of 2 full statement. It ordinarily takes at least a whole sentence to express a whole thought. But it is very common for students even, who have formed the habit of thinking by points, to allow brief headings, consisting of single words or short phrases, to represent entire thoughts. Although such headings, on account 
of their brevity, may be useful, they are merely names for the thought, not statements of the thought itself; and it means the loosest kind of thinking to stop with them. A mere title, as a lecture "About Russia," for instance, designates only the outside limits to which a person confines himself - provided he sticks to his theme. It often tells no more about the substance of the thought within those limits than a man's name tells about his character. It is usually easy to tell "what a page is about"; but it usually requires keen thinking to word its principal idea sharply in a full sentence. Many students are inaccurate in the interpretation of authors and in their own thinking, not so much because they lack mental ability as because they lack the energy to continue their thinking to this point of wording the central idea accurately in a full sentence.

\section{THE ABILITY OF CHILDREN TO GROUP FACTS INTO POINTS.}

The grouping of facts into points requires ability to perceive that some statements are more valuable than others, without reference to the space that they happen to occupy on the printed page; it presupposes, also, the power to rearrange a stranger's ideas. It is, therefore, an aggressive kind of work, in which even adults Proofs of often :ail to distinguish themselves. Can such ability. children be expected to assume such respon-
1. As shown by children sibility?

and younger. Proof that any ten-year-old child has already assumed it in a simple way for some years is contained in the following facts:-

1. Long before the school age is reached a child has 
had much practice in picking out the logical subjects of sentences, inasmuch as he has learned to comprehend statements made to him. Distinguishing the subject of a sentence is the same kind of work as distinguishing the subject of a paragraph or chapter, only it is simpler.

2. Any six-year-old child has, likewise, had much practice in detecting the subject of short conversations, especially of those of interest to him. If he happens to overhear a conversation between his parent and teacher touching a possible punishment for himself, he can be trusted to sum it up and get the gist of it all, even though some of the words do not reach him. That is exactly the kind of thinking required in getting the point of a lecture.

3. In relating fairy tales and other stories, during the first years at school, children easily fall into the habit of relating a part, or a point, at a time. And, if the memory or the courage fails, the teacher gives help by asking, "What will you tell about first? And then? And then ?" thus setting them right, and keeping them so, by having them divide the story into its principal sections.

4. In composition, in the lower and middle grades, the paragraphing of thought, first as presented on the printed page, then as called for in oral recitation and in conversation, and finally in the child's written form, is a prominent subject of instruction. No one maintains that such work is unnatural, or too difficult, for such young children.

5. Development instruction, which has already been mentioned as peculiarly successful with young children, would be impossible if children were unable to appre. 
ciate the character of a principal thought, as the topic or point for discussion, and of other thoughts as subordinate to it.

The use of several texts in one subject, as history, by one child, and the use of rcference books, - both of 2. As shown which are common above the fifth year of in the use of school, - presuppose the ability to study texts and of by topics, and to bring together from varibooks. ous sources the facts that support a principal truth.

Finally, the progress that children can make, when direct instruction in this matter is given to them, is 3. As shown good proof of their ability in this direction. improvement For cxample, in a geography class composed they oan
make in suoh stady. a lesson the following section from the text-book:-

Political Divisions. - You will remember that Spain was the nation that helped Columbus make his discovery of America. The Spaniards afterward settled in the southern part of the continent, and introduced the Spanish language there. That is still the chief language spoken in Mexico, in the southern part of North America. Mexico became independent of Spain many years ago.

Other nations also sent explorers and made settlements. Among these were the English, who settled chiefly along the Atlantic coast, and finally came to own the greater part of the continent north of Mexico.

In time the English, who lived in the central portion of eastern North America, waged war against England, and chose George Washington as their leader. On the 4th of July, 1776, they declared their independence of England, and finally won it completely. This part became known as 
the United States; but the region to the north, which England was able to keep, and which she still possesses, is called Canada. Find each of these countries on the map (Fig. 123). Point toward Canada and Mexico.

Besides these three large nations, sereral smaller ones occupy Central America, which lies south of Mexico.

After the children had had time to study it somewhat carefully, I requested them to tell briefly what the section was about. The first three replies were as follows, in the following order, and these were not improved on later, without suggestion: "It tells about discovery." "It tells about the language in Mexico." "It tells about what are nations." This was their first attempt at such work, and it met with meager success. The heading in the text seemed to give them no aid whatever, which was sufficient proof of its unfitness for children.

Yet within one month, with some attention given to this matter every day, I found half of the class of twenty to be reasonably safe in picking out the central thought in a page of their text.

From all these facts it seems that children are reasonably capable of receiving instruction in regard to the grouping of facts into points. It is evident, also, that they need such instruction badly, if they are to study properly the lessons that are assigned to them.

PRACTICAL SUGGESTIONS FOR TEACHING CHILDREN TO GROUP RELATED FACTS INTO POINTS

In the first place, the example of the teacher can be of great influence. Any good teacher should do more than ask questions and explain difficult topics. She 
should now and then talk to her children. Particularly

1. The teacher's example. in general exercises she should give expression to other ideas than those immediately involved in instruction. If at such times her ideas are carefully grouped about one or more central thoughts, her pupils are likely to feel the roundness and the consequent clearness and force of her points, and to be ambitious to imitate her style. Many an adult, no doubt, can recall both the pleasure he experienced in early youth when listening to some speaker who possessed this merit, and early attempts that he made to imitate such a style.

In development instruction, in the lower and middle grades in particular, brief headings representing the 2. Use of main facts reached might be placed on the written ont- blackboard, or written down by each pupil lines in development as the facts are established. Such writing is instruotion. of great assistance in keeping the outline in mind. Frequently, even in the lower grades, review outlines might be required without such visual help. 3. In conneo- A terse statement of the principal thought tion with the in each paragraph of some story or other ase of text. the principal determining the relation that the different sen-
thought in paragraphs. tences in a paragraph bear to one another, and the gist of the whole.

Pupils might point to the place on the page where (b) Finding the treatment of a certain point begins; also where a
point begins and ends. exercise in distinguishing not only the principal thought, but also the turns in the thought, and thereiore the most suitable stopping places for reflection. 
The most valuable statements might well be marked in the text, some system of marks - as, for instance, one, two, or three short vertical lines in the (c) The makmargin - being agreed upon to indicate ing of marks different degrees of worth. It is very common $\begin{gathered}\text { to indice } \\ \text { relative }\end{gathered}$ for adults, particularly very careful students, values. thus to mark books that they read. Unless one does so, it is difficult to find again, or review quickly, the main ideas. Yet one of the especially important things to teach young people in the handling of a book is some way of reviewing quickly the most valuable parts. Many persons who would gladly review the few most interesting portions of a book have no way of doing so except by reading the volume through again. That takes so much time that they omit the review altogether.

In case the books belong to the school or library, all such marks may be objectionable. Certainly the aimless marking of any book is to be condemned. But thoughtful marking, with the view of showing relative values, is likely to increase the amount of reflection on the part of the one who makes the marks. It is likely, also, to increase the amount of reflection on the part of the later reader, for he, seeing the marks, is inclined to weigh the thought long enough to decide whether he agrees or disagrees with the previous reader.

If, however, the objections to such markings are insuperable, children can at least be encouraged to own some of the books that they use. They ought to be developing a pride in a library of their own, anyway. "If a book is worth reading, it is worth buying," says Ruskin. "No book is worth anything which is not worth much; nor is it serviceable until it has been 
read and reread, and loved and loved again, and marked, so that you can refer to the passages you want in it, as a soldier can seize the weapon he needs in an armory, or a housewife bring the spice she needs from her store." 1

It might be added, also, that all the writing thus suggested could be kept on note paper or in note books, if forbidden to appear in printed books.

It should be borne in mind, however, that one important object in using books in school is to teach their proper use outside of school. To this end, books should be used in school in substantially the same way in which they are expected to be used outside. There is often a lack of correspondence between these two methods in various ways.

Wherever the markings indicating relative values happen to be placed, they can well be compared in class and the disagreements discussed. This would throw a class into the heart of the subject-matter of a text on their own initiative. If it resulted in spending a whole recitation in a discussion of relative values, as it frequently would, it should be remembered that that is the most valuable kind of study.

If the books used contain no marginal headings, the pupils might propose some. And if marginal headings (d) The seleo- are found in some, proposals for their imtion of mar- provement would be in place, since such lngs. headings are rarely good. For example, the heading "Political Divisions," quoted above, would be much more definite and significant if changed to "The Countries in North America," and children

2 Ruskin's Sesame and Lilies. 
could soon learn to make such improvements. Headings of chapters, likewise, often need rewording in a simpler, more definite and restrictive way.

Choosing some one of the principal thoughts, the children should have practice in finding the data that support it, and in presenting such lecting of data in good sequence and in an otherwise leapporting forceful manner.

thoughts.

As one way of summarizing review lessons the children might enumerate the leading thoughts in close sequence, giving a careful wording the leading for each in a full statement. close se-

Pupils in the higher grades having to con- quence. sult reference books frequently, and to take notes also from discussions and lectures, should receive careful instruction in note-taking. As preparation for sucb work, the teacher might read to the class, 4. As a prepwhile the latter listen with the object of telling aration for how many and what are the main points. notes. Sometimes they might call "halt" as they realize that a turn is being made and another point is beginning. They should be reminded that the relationships of ideas, which are indicated by punctuation and paragraphing on the printed page, are revealed by a reader's or speaker's manner, as when he makes short pauses between sentences, or emphasizes an idea by voice or gesture, or allows his voice to fall at the end of some minor thought, or turns around, stops to get a drink, walks across the floor, or waits for applause at the close of one of his principal flights. Teacher and pupils might all take notes together, sometimes on principal points, sometimes only on the supporting data for one 
such point. Then the results might be compared, and the small amount of writing necessary might be discussed.

\section{B. The neglect of relatively unimportant facts or statements}

We have seen that the organization of ideas requires the recognition of some thoughts as central, and the grouping of various details about them. While it places peculiar emphasis on these controlling facts, it also recognizes details as an essential part of knowledge.

A question now arises about the relative values among these details. While they are an essential part Neglect as of knowledge, do they themselves vary inomphasis in- definitely in worth? And while many deserve volved in rel- much attention, are there many others that
ative values. may be slighted and even ignored?

The first part of this chapter has really dealt with the emphasis that is necessary for some ideas. But emphasis at one point suggests neglect at another point, for the two terms are correlative. Some persons would even assert that neglect is as important an element in proper study as emphasis, and that the two terms should be in equally good repute. This part of the chapter deals with the neglect that is due in proper study. It is, perhaps, a more difficult topic to treat than the preceding. Certainly many teachers are afraid to advise young people to neglect parts of thcir lessons, lest such suggestion might seem a direct recommendation to be careless.

We have seen that, to a certain extent, the facts in 
the three R's and spelling have practically the same worth. All of the combinations of simple why reglect numbers must be mastered; likewise all the is scarcely words in a well-selected list in spelling, etc. some sabjects. Since differences in value are wanting here, there is no occasion for slighting any part. Any neglect in such cases signifies an oversight or a mistake.

But, as before, these subjects to some extent form an exception to the general rule. In most studies neglect of some parts is positively necessary. Why neglect It has been already shown that no exact in necessary number of facts needs to be brought together jects. in order to make up any particular topic or study. Besides those directly expressed in print, there are others immediately suggested; and the number of possible ideas bearing on a given matter is legion. Neglect, therefore, becomes not only necessary, but even prominent, as a factor in study. One might ask, "Are not all the statements in a valuable book that one happens to be reading worthy of careful consideration?" Not necessarily, by any means. The production of thought parallels the production of grain. An acre of ground, that yields thirty bushels or eighteen hundred pounds of wheat, may easily grow two whole tons of straw and chaff. These latter are absolutely necessary to the formation of the wheat kernel; yet the consumer usually has little use for them; he gets past them to the grain with the least possible delay, often throwing these other materials away.

Likewise, many things that are necessary in the production of thought are of little use to the consumer. For example, there are often introductory remarks 
that have lost their original significance; there are asides and pleasantries; there are careful transitions from one thought to another, to avoid abruptness; there are usually more or less irrelevant remarks due to the fact that even authors' minds wander now and then; and there are often some things that seemed important to the author which in no possible way can be of value to the reader.

For these reasons, some things are to be omitted, if possible, without being read, because they are worthless. Many details are unworthy of a second thought. Many other statements should be cast aside after having been carefully enough examined to make sure that they will not be further needed. Not only should some statements and paragraphs be slighted, but whole chapters as well. Similar practice is familiar to all in connection with conversations and discussions; and books are of the same nature as these, having the same faults, though perhaps to a less degree. What the student wants to carry away is valuable thought, with the details that vitally concern it; and the space occupied by such thought and its supporting details, as in the case of the wheat, is small as compared with the space occupied by the chaff that accompanies them. "Some books are to be tasted," says Bacon, "others to be swallowed, and some few to be chewed and digested; that is, some books are to be read only in part; others to be read, but not curiously [attentively]; and some few to be read wholly and with diligence and attention." If he had added that very many books should not bo read at all, he would have covered the field.

1 Bacon's Lssays, Of Studies. 
As a rule, therefore, it is a serious error for a student to distribute his time and energy somewhat equally over a lesson or a chapter or a book. There are times when he should advance rapidly and even skip, as well as other times when he should ponder carefully and review much.

How can one become safe and skillful in this phase of study? The student must, of course, read or listen to statements largely in the order of the ${ }_{\text {How safety }}$ author's presentation; but two opposite ${ }_{\text {neglect may }}^{\text {nat }}$ courses of procedure are possible, and much be developed. depends upon the aro depends upon the choice that is made ceeding from between them. princlpal thooghts to

On the one hand, one can proceed sentence detalls. by sentence, examining each statement carefully, looking up new words and references, supplementing, tracing the bearings on one's own life, and doing whatever else is necessary to assimilate each thought. The single sentences can be put together so as to reveal the thoughts of paragraphs; and the central ideas of paragraphs and chapters can likewise be brought together, so as to reveal the main thoughts of the work as a whole. Thus the general movement may be from the details to the larger features, and the controlling ideas may be the last to be reached.

The Bible is very commonly studied in this manner, the verses of a chapter and the chapters of a book being taken one by one in the order given and thoroughly mastered, and the outline of the whole being the last thing considered. Geography and history are also frequently studied in the same way.

On the other hand, while the reader is still obliged to 
follow the author's order, he may at the start be mainly on the outlook for the general trend of the thought, for the principal issues that are raised, with the principal answers that are offered; and, if the work is at all difficult, he may for the time pass over many obscure little matters, such as new words, strange references, and meaningless statements, in the sole quest for these larger elements. Then, having determined these tentatively, he can set to work to examine the details on which they depend, making the investigation as thorough as he wishes. Thus the general movement may be from the principal to the minor thoughts, and the details may be carefully considered last of all. In accordance with this plan we hear it recommended that the book of Job be read "at a sitting," or, in case one's spirit of devotion lacks that degree of endurance, at two or three sittings. Likewise, Gray's Elegy might be read through without pause, even several times, before any part is studied in detail; so, also, the drama of William Tell; one act, and perhaps the whole of the drama, of Julius Casar; any one of Browning's shorter poems; and ordinary lessons or chapters in history and geography.

While these two courses may finally bring about the same result, the latter is much the more economical plan, for the following reason: The individual statements vary greatly in value, as we have seen, some requiring only slight attention, while others must be closely scrutinized. What determines their value is their relation to the leading ideas. The latter are the sole standards of worth, the sole guides, in discriminating among them. If, then, the student has not found 
out what the leading ideas are, what basis of selection has he? How, then, is he to know what are the important details and what are the unimportant? What can he do, then, more than merely to distribute his energies somewhat equally and blindly over the various statements offered, until the principal thoughts come to light? Only after that will he be in a position to measure relative values and thus to deal with the details intelligently. The first plan, therefore, involves a great waste of time. For the same reason that it is economical to go sight-seeing with a guide, or at least to examine a guidebook before setting out, it is economical to determine the gist of the thought, the spirit and substance of the whole, before giving careful attention to the minor parts.

The student must not only find the central idea as early as possible, but he must hold it with a firm grip. Both of these things require much tenacity of purpose. In following the order of an ing the standauthor's presentation, considerable detail ard of valnes may have to be traversed before the main mind. thought begins to damn in the student's mind, and temptations to forget about the main issue and to become absorbed in these details are ever present. It is on this account that teachers attending teachers' gatherings frequently fail to reach those topics for discussion that have been advertised; they even fail when printed reports are the avowed subject for conference. After having arrived at their destination with much sacrifice, they seem often to forget exactly what they came for, or to be diverted from it with surprising ease. However, they are not inferior to other adults in this respect. 
Again, after having settled upon the main idea tentatively, one must hold it with determination and use it. Children often fail to hold a question in mind long enough to give a relevant answer. I once asked a fifthyear class in history, "Who discovered America?" when almost immediately came the response, "Vespucci sailed along the coast of South America and named the whole country!" Or they hold it in mind a moment, and then confuse it with other things, or let it go entirely. I asked the class, "What is the color of the Indians?" and received an answer telling about their color and their clothing. At another time $I$ inquired, "How long has it been since America was discovered?" One boy replied, "Two hundred and fifty years," remembering, I suppose, that that number had recently been used in class. But the example in subtraction was solved on the blackboard before the class, and the correct answer, 413, was obtained. Once more I said, "Four hundred and thirtcen years since what?" All were silent for a moment, having quite forgotten the original question. Then came the reply, "Since - since - Columbus sailed the deep."

Such carelessness among children sometimes arouses the ire of teachers; but adults are little better. When a body of them meets for the discussion of a certain question, the probability is that, if the first speaker speaks directly to the point, the second will digress somewhat, the third will touch the subject only slightly, and the fourth will talk about a different matter. Many a discussion that has started off well leads to much excitement without any one's knowing definitely what the subject of dispute is. It is rarely the case that 
every page of a paper that is read before teachers bears plainly upon the subject announced.

Only in parliamentary discussions, where there is always a definite "question before the house," is it customary for participants to remember the topic and stick to it. This happens then only because it is under"tood that any one may be "called to order" at any time, and for the sake of self-protection each person makes a special effort not to forget.

This exceptional caution must become habitual with the student if he is to study effectively. He must look for the principal thought until he finds it; and, having found it, he must nurse it by recalling it every few minutes, while using it as a basis for determination of values.

That various rates of reading are desirable, even to the point of skipping over much matter, is indicated by the way in which some eminent men have Rapid readstudied. For instance, Joseph Cook in his ing snd its Hints for Home Reading remarks, "It is among said that Carlyle reads on an average a ${ }^{\text {scholars. }}$ dozen books a day. Of course he examines them chiefly with his fingers, and after long practice is able to find at once the jugular vein and carotid artery of any author." Likewise, "John Quincy Adams was said to have 'a carnivorous instinct for the jugular vein' of an argument."' "Rapid reading," says Koopman," "is the ... difficult art of skipping needless words and sentences. To recognize them as needless without reading them, is a feat that would be thought impossible, if scholars everywhere did not daily per

' Page 80. 'Koopman, The Mastery of Books: p. 47. 
form it. With the turning of a few leaves to pluck out the heart of a book's mystery - this is the high art of reading, the crowning proof that the reader has attained the mastery of books." The fact that the first and last parts of both paragraphs and chapters very often reveal their leading thought, is of course a great aid in such rapid reading.

It is pertinent to ask whether this method of study does not oppose the spirit of induction. Men like

Is the spirit of induotion turn quickly to the central ideas of a book bere opposed? and, after reading these, cast the work aside. It should be remembered, however, that the minds of such men are so well stocked with information that most, and sometimes all, of the author's details may be unnecessary to them; they are already prepared for the generalization.

The ordinary student, proceeding more slowly, can also be on the watch at the start for the main issues, without offending against induction. In so doing he is not necessarily attempting to master the abstractions first; he may be merely trying to find out what the main questions are, in order to supply himself with a guide.

Many an author states his principal problem near the beginning of his treatment, and then it is easy for the reader or listener to view all the details in its light. But when this is not the case, the student must go in quest of it in order to get the setting for all the statements, rather than in order to assimilate it. He must see the whole in some perspective before he can study the parts intelligently. The worth of specific purposes as discussed in pp. 31-60 is clearly seen in this connection. 
It is of vital importance further to inquire what relation such neglect bears to thoroughness in study.

The answer depends upon the meaning to thoroughattached to the word thorough. We often l. A common hear it said that "Trifles make perfection, of thoroughand perfection is no trifle"; also that infuenco on "thoroughness has to do with details." practioe. Again, as a warning against carelessness in little matters, we are told that -

For the want of a nail the shoe was lost.

For the want of a shoe the horse was lost.

For the want of the horse the rider was lost.

For the want of the rider the battle was lost.

For the loss of the battle the kingdom was lost.

There is certainly a valuable truth in these maxims, and some people, therefore, accept them at their face value. Calling to mind that many of the greatest dis. coveries have hinged on seemingly insignificant facts, and that the world-renowned German scientists are distinguished by infinite pains in regard to details, they conceive that the student is primarily concerned with trifles. Knowing that the dollars will take care of themselves if the dimes are carefully saved, they reason that knowledge is properly mastered if the little things receive close attention. It becomes their ambition, therefore, to let nothing that is little escape them In this spirit the conscientious student, largely identifying conscientiousness with thoroughness, keeps a special watch for little things, feeling that the smaller an item is the more fully it tests his thoroughness, and the more meritorious he is if he attends to it. 
The influence of this notion of thoroughness upon practice has been marked in some schools. And since spelling furnishes excellent material for testing care for details, that subject has often been given high rank partly for that special reason. I have known one large training school for teachers in which for twenty years and more probably more time and energy on the part of both faculty and students were expended on spelling than on any other single subject. It was unpardonable not to cross the $t$ or dot the $i$, not to insert the hyphen or the period. Having written a word in spelling, it was a heinous offense to change it after second thought, and a dozen misspelled words per term seriously endangered one's diploma at the end of the three-year course.

No one can deny great merit to such strenuousness. So definite an aim, applied to all subjects and relentlessly pursued by a whole faculty, - as was the case in this school, - compelled students to work till they overworked, and the school was therefore regarded as excellent. Yet this conception makes thoroughness a purely quantitative matter; it accepts thoroughness as meaning throughness or completeness, signifying the inclusion of everything from "beginning to end," or from "cover to cover."

This notion of thoroughness, however, is certainly wrong in opposing all neglect; and the above-quoted 8. The cor- maxims show themselves, in their disregard rect notion for relative values, to be only half truths.
of thoroughness. In the school just mentioned there was small emphasis of relative worths and of the use of judgment in the choice of objects to receive one's attention. As 
thoroughness consisted in attention to details, little things became per se worthy of study, and comparative worth was on that account overlooked.

But, as we have seen, there is no hope of mastering all the ideas connected with any topic, so that the student must be reconciled to the exercise of judgment in making selection. This choice must be exercised, too, among the details themselves; it is not confined to a selection of the large thoughts in distinction from the details. Details vary infinitely among themselves in value; some, like the horseshoe nail, easily bear a vital relation to large results; others, like the use of a hyphen in a word, in all probability bear no important relation to anything. Those that have this vital relation are essential and need careful attention; the others are non-essential and deserve for that reason to be neglected. In other words, thoroughness is a qualitative rather than a quantitative matter; it is qualitative because it involves careful selection in accordance with the nature and relation of the details. The student, to whom thoroughness is a question of allness needs mental endurance as a chief virtue; the real student, on the other hand, requires constant exercise of judgment. In brief, the proper kind of thoroughness calls for a good degree of good sense.

The thoroughness that is here advocated implies no underestimate of little things; it only condemns want of discrimination among them. Even the painstaking German scientist is no devotee to all things that are little. Carrying on his investigation with reference to some definite problem, he is concerned only with such details as are closely related to it. If he is uncertain 
just what so-called little things do relate to it, - as has been the case, for instance, in the investigation of the cause of yellow fever, - he carefully investigates one thing after another. But in so doing he discriminates very sharply among details, throwing many aside without hesitation, briefly examining some, and finally settling on certain ones for exhaustive study.

It is only those little things that are thus related to something of real value that deserve attention. The mathematician is a stickler for little things. He insists that figures should be plainly made, and that $1+1$ should never be allowed to equal 3. He is wholly in the right, because the slightest error in reading a number, in placing a decimal point, or in finding a sum must vitiate the whole result. Little things of that sort are called little, but they are in reality big.

It is unfortunate that such matters are often called trifles, for a trifle is usually supposed to be something that is of very little account; the name thus misleads. Such details are essential; other details are non-essential. It would be well if people would more generally divide details into these two classes, and apply the term trifles only to the latter sort. By neglecting nonessentials one could find more time for the details that are essential. Neglect of some things, therefore, instead of being opposed to thoroughness, is a direct and necessary means to it.

One cannot deny that this notion of thoroughness has its dangers, for it places the responsibility upon the student of using his own judgment. That is always dangerous. If the student lacks earnestness, or insight, or balance, he is bound to make mistakes. He is likely 
to make them anyway; and he may merely pick and choose according to comfort or whim, and do the most desultory, careless studying. It would be The dangers easier for him to "look out for all the little in these conthings" than to discriminate among them, the conclnfor intelligent selection requires more real 1 . The danthinking. ger in this conception

n the other hand, it should be remem of thoughbered that neglect of details in general has not been advocated; it is only a judicious selection among them. And such selection calls for no more energy or ability than selection among larger facts. If we can trust students at all to distinguish values among the larger thoughts - as every one knows that we must - there is the same reason for trusting them to distinguish the relative worths of details.

The dangers of the alternative plan should also be borne in mind. Suppose that a capable student is taught to let no trifles escape him. The 2. The dandanger then is that, to the extent that he is $\underset{\text { glternative }}{\text { gar in the }}$ earnest, he will fall in love with little things, plan. until his vision for larger things becomes clouded. He may always be intending to pass beyond these to the larger issues; but he is in danger of failing so regularly that he will come in time to value details in themselves, not for what they lead to; the details become the large things, and the really large matters are forgotten.

A former professor in a large normal school illustrated this tendency exactly. At sixty years of age he was an unusually well-informed, cultured man, but he had developed a mania for little things. He had charge 
of the practice department, and each fall term it was customary to receive applications from about twG hundred students for the practice teaching for that term. Each applicant filled out a blank, giving his name, age, preferred study to teach, preferred age of children, and experience in teaching. These papers had to be briefly examined; then at four o'clock in the afternoon of the same first day all these applicants were to be called together in one group for instructions about their teaching. By this arrangement the practice teaching could be started off very promptly.

On one occasion in the writer's knowledge, however, this gentleman could not resist the temptation to blue-pencil every mistake in spelling, punctuation, grammar, etc., that he could find in this entire set of papers, which must have occupied nearly two hours. Meanwhile, this task was so hugely absorbing, he entirely forgot to notify the two hundred applicants that they were wanted at four o'clock, and thus one day out of a year of less than two hundred was largely lost for the practice teaching.

The main fault of half of the good teachers in the elementary schools to-day is over-conscientiousness about little things. Believing that every mistake in written work should be corrected, that the blackboard should be kept thoroughly clean, that each day's lessons should be carefully planned, that, in short, every little duty should be well performed, they putter away at such tasks until there is no time left for much larger duties, such as physical exercise, sociability, and gencral reading. As a result theybecome habitually tired, unsympathetic, and narrow, and therefore schoolish. 
It is a strange commentary on education when conscientiousness means particular care for little things, as it very often does among teachers. It is desirable that a teacher prepare each day's lessons in full, and that she do a hundred other things each day, as well. But when she cannot do all these - and she never can it is highly important that she apportion her time according to relative values; for instance, it is far better that she omit some of her preparation of lessons for the sake of recreation, if recreation would otherwise be omitted. People are unfitted for the work of life until they view it in fair perspective. One of the important objects of abundant and broad educational theory for teachers is to help them preserve the proper balance between large and small things; and, owing to the common tendency to neglect the larger things for the smaller, one of the prominent duties of school principals and supervisors is to remind both teachers and students of the larger values in life in general and in study in particular.

It is evident that grave dangers are at hand, whether one slights some details or attempts to master them all. But no matter what the dangers are, there 3 . The conis one right thing for the student to do, clusion. that is, to develop the habit of weighing worths, of sensing the relative values of the facts that he meets. Good judgment consists largely in the proper appre ciation of relative values; and since that is one of the very prominent factors in successful living, as well as in study, it is one of the most important abilities for the student to cultivate.

Not only the equal valuation of all details, but the 
treatment of various rules and virtues as absolute, is likewise directly hostile to this habit of mind. Young people who are taught to be always economical, or always punctual, or always regular, are thereby tempted to substitute thoughtless obedience for exercise of judgment. It is not always wise to be saving. A certain college boy owned three pairs of gloves; one pair was so old and soiled that it was suitable only for use in the care of the furnace; the other two pairs were quite new. However, having been taught to be always saving, he wore the old pair to college during much of his senior year, and saved the other two. He was true to his early teaching at the expense of good sense.

There are few circumstances in life that can be properly treated by rule of thumb. Good judgment is called for at every turn; and the habit of considering relative values in regard to all affairs is one that the student should constantly cultivate, no matter what dangers have to be encountered.

\section{ABILITY OF CHILDREN TO NEGLECT UNIMPORTANT DETAILS}

This ability is so intimately related to the ability that is necessary in grouping related facts that the one can hardly exist without the other. Yet it is well to observe what a demand there is for neglect in ordinary school work, and how this demand is met by children Mistakes in beginning reading are very common, such as saying $a$ for $a n$, the for thu a comma, leaving out a word, putting in a word, etc. When fairy tales are related, slight omissions, 


\section{THE ORGANIZATION OF IDEAS}

mistakes in grammar, too frequent use of and, etc. are to be expected. In the pupil's board work, penmanship, and written composition minor errors are innumerable. What is to be done with all these? Certainly many of them must be entirely passed over, or more important things will never be reached.

In their literature and in their reference books many little difficulties are met with that must likewise be overlooked. Take for instance the following typical paragraph from Hawthorne's Gorgon's Head:

"Well, then," continued the king, still with a cunning smile on his lips, "I have a little adventure to propose to you; and, as you are a brave and enterprising youth, you will doubtless look upon it as a great piece of good luck to have so rare an opportunity of distinguishing yourself. You must know, my good Perseus, I think of getting married to the beautiful Princess Hippodamia; and it is customary, on these occasions, to make the bride a present of some far-fetched and elegant curiosity. I have been a little perplexed, I must honestly confess, where to obtain anything likely to please a princess of her exquisite taste. But, this morning, I flatter myself, I have thought of precisely the article."

Here is an adult's vocabulary, as well as an adult's ideas, with perhaps a dozen new words, and anything like mathematical thoroughness in the study of this paragraph would destroy its attractiveness. It is well for teachers to consider what would be a thorough treatment of such a section. Encyclopedias and other reference works also present many strange words and difficult paragraphs that children cannot stop to examine with care. In their ordinary school work, therefore, children find many details that must be 
overlooked; the more important things cannot be ac. complished unless these less important ones aro ignored.

It would be strange if children were quite incapable of doing what is so plainly required of them. It is true that they can be taught to reach the extreme of foolishness in the insignificance of the details that they mention. But it is also true that a fair amount of wise guidance will lead them to exercise good judgment in their selection. In other words, thoroughness as a relative and qualitative matter, rather than only quantitative, can be appreciated by them. Any teacher who has tested them carefully in this respect is likely to agree to this assertion. It is as natural for a lot of children to condemn the mention of useless detail, because of its waste of time, as it is for them to condemn selfish or immoral conduct.

PRACTICAL SUGGESTIONS FOR TEACHING CHILDREN TO NEGLECT RELATIVELY UNIMPORTANT DETAILS

The responsibility of deciding what shall be neglected should very often be left with the children, no 1. Plactng matter how many mistakes and how much respousibility
apon chil. opon
dren. chisms and suggestions from the teacher would be in place later. Many parents as well as teachers refuse to place this responsibility upon children for fear of the mistakes that they will make. On account of this fear they make it as nearly as possible unnecessary for children to judge freely, by giving them arbitrary rules to follow, or by directing them 
exactly what they shall do each moment. This cultivates poor judgment by depriving children of the very practice that will make their judgments reliable; it prevents the school requirements from corresponding to those in life outside.

Confidence in the general and growing good sense of children is a presupposition in the sensible parent and teacher. Having such confidence, their mission is to let these young people alone much of the time; to direct, not to control the selections that they make, assuming the rôle of advisers and critics but not dictators.

This training toward independent judgment should begin even in the first year of school. If Johnny raises his hand in beginning reading to state that Mary said $a$ for the, the teacher need not either accept or reject the criticism. She may merely turn to the whole class and ask whether that is a helpful correction to make. A similar course may be pursued with many corrections and suggestions in later years. In this way a class sense of what is fitting or valuable in the way of neglect can be developed.

It should be remembered, however, that children cannot judge the worth of details without a basis of some sort. Unless, therefore, they helplessly rely upon the direction of the teacher in each case, they must be taught what the reading or other subject is for. They must gradually get a fair idea, for instance, of what good reading is, and realize that it includes pleasant tones, a careful grouping of words, much inflection of voice, and clear enunciation of final consonants. As they become acquainted with this standard in reading, 
they will readily learn to overlook such details as have little to do with its attainment.

It is true that it saves much time for the teacher herself to determine what shall or shall not receive attention, or at least for her to accept or reject a child's suggestion dogmatically, rather than to allow him or the whole class to pass upon its worth. Also, the constant demand for "more facts" tempts teachers to save time in this way. But again, it behooves the teacher as well as the pupil to use judgment, and not sacrifice one of the main objects of an education in order to save some time.

Children who use reference works might now and then study an encyclopedic article together merely to 2. Class see what parts should be slighted. When stady of
printed arti. looking for a certain fact they will discover, oles. from the way the paragraphs begin, that one paragraph after another can be discarded without being read in full. In the same spirit newspapers might be studied by the older children, to determine from the headings what articles need not be read at all, what ones in a cursory manner, and what ones carefully, if any. Similar study of some magazines might be in place. It is a duty of the school thus to accustom pupils to proper methods of reading common kinds of printed matter.

Pupils might occasionally be asked to reproduce a story or any other line of thought as fully as they wish. 3. Reduction Suppose that it occupies six pages. Then of repro- they might be requested to reduce it to three duotions. pages, and perhaps, finally, to one page, eliminating eacn time what is of least importance. 
Such an exercise compels a very careful study of relative values.

Having decided upon a definite problem for consideration, all grades of learners might be held responsible for detecting beginning wanderings of thought. They might accustom themselves and carrying to the responsibility of rising to a point of point. order at such times, stating the main question and asking the suspected person to show the relevancy of his remarks. There is no reason why the teacher should carry this responsibility alone; indeed, it is an imposition on the children, checking their growth in judgment and power of initiative.

Again, at times students in all grades might be allowed full freedom, in order to show how quickly they will engage in discussion, and even become excited, with no definite question before them. They may not realize their error, however, until asked to state what they are considering. It should be remembered that the question at issue may be as much neglected in the reading of books as in participation in discussion; on this account the method of reading might be tested in a similar manner.

Finally, varying rates of reading should be encouraged, according to the nature of the subject matter. While some books should be pe- 5 . Encourrused very slowly and thoughtfully, others agement of should be covered as rapidly as possible. different In the case of many novels, for instance, the reading. ideas are so simple that they can be comprehended as rapidly as the words can be scanned.

Many persons, however, can read only as fast as 
they can pronounce the words. They follow an estab. lished series of associations: first, the word is cbserved; this image calls up its sound; the sound then recalls the meaning. Thus the order is sight, sound, meaning. That is a roundabout way of arriving at the meaning of a page and is usually learned in childhood. It explains why many an educated adult can read very little faste:- silently than aloud.

Some adults read fast simply by skimming over the less important parts, which is often justified. Some, however, save time by associating the form of a word directly with its meaning, leaving the sound out of consideration. Then by running the eye along rapidly they double and treble the ordinary rate of advance. It is said that Lord Macaulay read silently about as rapidly as a person ordinarily thumbs the pages; and he must have seen the individual words, because his remarkable memory often enabled him to reproduce the text verbatim.

The slow-reading adult can, by practice, learn to take in a whole line or more almost at a glance, in place of three or four words, and can thus increase his rate of advance. But habit is so powerful that the rapid eye-movement necessary in rapid reading, together with the direct association of the form of a word with its meaning, should be learned in childhood. To this end, children should often be timed in their reading, being allowed only a few seconds or minutes to cover a certain amount. Some exercises might be given them, too, so as to accustom them to taking in a considerable number of words at a glance.

Meanwhile, however, pains should be taken to avoid 


\section{THE ORGANIZATION OF IDEAS}

the impression that rapid reading is always in place. Matter that requires much reflection, like the Bible for example, may well be read slowly. It is not merely rapid reading, but varying rates according to need, that the teacher should encourage.

There is no expectation that children will learn to handle books as Carlyle did. But they should be guided by the same general principles, and should form practical acquaintance with these principles while in school. Ordinarily there is a striking contrast between the use of books in school and outside, and the different rates of reading in the two places afford a striking illustration. Text in school is taken up in a gingerly fashion, scarcely enough of it being assigned for one lesson to get the child interested. Then this is reviewed over and over until any interest that may originally have been excited is long since destrcyed. Thoroughness is aimed at, at the expense of life. In independent reading outside of school the opposite course is pursued. In the reaction from the school influence children revel in their freedom to do the things that their teachers forbid, and they accordingly go racing through their volumes.

Both methods are at fault. The school handling of books is intolerably slow; that outside is likely to be too rapid. In general, the method of using books in school should more closely resemble that desired elsewhere. The school method is the first to be reformed. It is seldom wise to be so thorough in the treatment of a text as to kill it for the learner. As a rule longer textbook lessons should be assigned in the elementary school, and less attention should be given to the minor 
facts. Then, if necessary, the same general field should be covered from another point of view, through another text. This change of method is already largely realized in our beginning reading, and partly realized in several other subjects. 


\section{CHAPTER VI}

JUDGING OF THE SOUNDNESS AND GENERAL WORTH OF STATEMENTS, AS A FOURTH FACTOR

IN STUDY

WE have already seen that proper study places much responsibility upon the student. Instead of allowing him to be an aimless collector of facts, it requires him to discover specific purposes that the facts may serve. With such purposes in mind he must supplement authors' statements in numerous ways, and also pass judgment on their relative values. This all requires much aggressiveness.

A problem now confronts us that suggests even greater aggressiveness. The statements that one hears or finds in print are often somewhat exagger- The problem ated, or distorted, or grossly incorrect, or they here.

may be entirely true. Who is to pass judgment upon their quality? Has the young student any proper basis for carrying that responsibility?

This problem is forced upon one when reading newspapers, particularly during political campaigns. One paper lauds a candidate as a great admin- Pressing istrator, while another condemns him as a rature of this doctrinaire. One advocates protective tariff $1_{\text {. In reading }}^{\text {problem. }}$ and the gold standard, while another urges and magarevenue tariff only and free silver. Among the news columns one article predicts war, while another discerns signs of peace. Russia is at one time 
pictured as moving fast toward complete anarchy, while at another time she is shown to be making important political advances. The Japanese are praised for their high standards of life, and are again condemned for their immorality. Magazine articles show disagreements just as striking. Public men, political policies, corporations, and religious beliefs are approvec ur condemned according to the individual writer. What, then, is the proper attitude for the reader? Is he to regard one authority as about as good as another, or is he himself to distinguish among them and judge each according to the evidence that is offered?

D'Aubigné's History of the Reformation is an extremely interesting work; but it treats the Reformation 2. In the use from the Protestant view-point, and is on of books. that account unacceptable to Catholics. The history of our Civil War presents one series of facts when written by a northerner; a very different series when written by a southerner; and a still different one when written by an Englishman. Shall the student of either of these periods adopt the views of the author that he happens to be reading? Or shall he assume a view-point of his own? Or shall he do neither?

Carlyle and Ruskin indulge in much exaggeration, relying on striking statements for increased effect. Shakespeare possibly intended to present an exaggerated type of the Jew in the character of Shylock. Shall the student recognize exaggeration as such? Or shall he take all statements literally? Or shall he avoid doing either, preserving an inactive mind?

In his work on Education, Herbert Spencer states that "acquirement of every kind has two values - 
value as knowledge and value as discipline. Besides its use for guidance in conduct, the acyuisition of each order of facts has also its use as mental exercise." Many students of education would assert that one very important value of knowledge is here overlooked, i.e., its power to inspire and energize, a value that literature possesses to a high degree. Assuming that they are correct, dare the young student pass such a criticism? Or would such a critical attitude on his part toward a high authority be impertinent?

The first paragraph in Rousseau's Émile runs ps follows: "Coming from the hand of the Author of all things, everything is good; in the hands of man everything degenerates. Man obliges one soil to nourish the productions of another, one tree to bear the fruits of another; he mingles and confounds climates, elements, seasons; he mutilates his dog, his horse, his slave. He overturns everything, disfigures everything; he loves deformity, monsters; he desires that nothing should be as Nature made it, not even man himself. To please him man must be broken in like a horse; man must be adapted to man's own fashion, like a tree in his garden."

At the bottom of the first page of the translation of Émile by Miss Worthington is a note by Jules Steeg, Député, Paris, bearing on the above first paragraph and running as follows: "It is useless to enlarge upon the absurdity of this theory, and upon the flagrant contradiction into which Rousseau allows himself to fall. If he is right, man ought to be left without education, and the earth without cultivation. This would not be even the savage state. But want of space 
forbids us to pause at each like statement of our author, who at once busies himself in nullifying it." Opposing statements like these are certainly enough to place the student in a dilemma.

Here are contradictions in political and religious beliefs and news items; very different interpretations of Proper at- historical events; exaggerations bordering on titude of the misrepresentations; and evident omissions stadent to-
ward anthorities.

philosophers. The weather bureau represents Old Reliability herself, in comparison with authors. What attitude shall the adult student assume toward such contradictory and faulty statements? Shall he regard himself as only a follower, taking each presentation of thought at its face value, sitting humbly at the feet of supposed specialists, and carefully preserving in memory as many of their principal opinions and conclusions as possible? Shall he assume the position of a mere receiver and collector?

That is manifestly impossible, for that would mean an ego divided a thousand times. It would prevent the final using of knowledge by the learner, instead of directing its use wisely; for the many opposing ideas and cross purposes would nullify one another. Besides that, wise application requires far more than a good memory as a guide, since memory takes no account of the adaptations always required by new conditions.

Whether he likes it or not, the student cannot escape the responsibility of determining for himself the fairness and general reliability of the newspapers and magazines that he reads; he must expect bias in historians, and must measure the extent of it as well as 
he can by studying their biographies and by observing their care in regard to data and logic; he must scrutinize very critically the ideas of the world's greatest essayists and dramatists. If a philosopher, like Rousseau, offers brilliant truths on one page, and equally brilliant perversions of truth on the next page, the student must ponder often and long in order to keep his bearings; and if footnotes attempt to point out some of these absurdities, he must decide for himself whether Rousseau or the commentator shows the superior wisdom. "Above all," says Koopman, "he [the student] must make sure how far he can trust the author." 1

" Read not to contradict and confute, nor to believe and take for granted, nor to find talk and discourse, but to weigh and consider," says Bacon."

Every book we read may be made a round in the everlengthening ladder by which we climb to knowledge and to that temperance and serenity of mind which, as it is the ripest fruit of wisdom, is also the sweetest. But this can only be if we read such books as make us think, and read them in such a way as helps them to do so, that is, by endeavoring to judge them, and thus to make them an exercise rather than a relaxation of the mind. Desultory reading except as conscious pastime, hebetates the brain and slackens the bow string of Will. ${ }^{3}$

The student, therefore, must set himself up as judge of whatever ideas appear before him. They are up for trial on their soundness and worth; he must uncover their merits and defects, and pass judgment on their general value. If he is hasty and careless, he suffers the penalty of bad judgment; and if he refrains from

${ }^{1}$ Koopman, Mastery of Books, p. 49.

'Bacon's Essays Of Studies. ${ }^{3}$ Lowell, Books and Libraries. 
judging at all, he becomes one who "does not know his own mind," a weakling.

\section{Who reads}

Incessantly, and to his resding brings not A spirit and judgment equal or superior Uncertain and unsettled still remains, Deep versed in books and shallow in himself. ${ }^{1}$

The need of such an attitude may be granted when the rejection of ideas is necessary. But there are many

The necessity of this attitude in the acceptance as well as in works that have been tried for ages and found the rejection and men, where little if any negative critiof ideas. undoubtedly excellent. There are many men, also, who are acknowledged authorities in their specialties. In the case of such books cism is to be expected, cannot the student set out merely to cnjoy the merits and not bother about the defects? Can he not, therefore, abandon the critical attitude and accept outright what is offered?

That depends on how much is involved in real acceptance. A wise young woman who rejects a suitor does so for reasons of some sort; her reasons should certainly not be less clear if she accepts him; on the contrary, they are more likely to have been investigated with care. The rejection of a lover is, then, no more positive thing, involves no more intelligence and emotion, than his acceptance.

Again, a competent supervisor of instruction who accepts as good some recitation that he has observed, does so on the basis of specific points of merit that he has seen. Otherwise his acceptance is only flattery and is unacceptable to an earnest teacher. So, in general,

1 Milton, Paradise Regained, Book 4, line 322. 
the acceptance of any line of thought or action presupposes a consciousness of certain merits. Intelligent acceptance is thoughtful or critical.

There is a common idea that acceptance is far more easy and far less aggressive than negative criticism. The contrary, however, is probably true. The former idea is due to the fact that much acceptance, as of political and religious doctrine, for example, is only nominal or verbal; it is not intelligent or critical enough to be genuine. Any one can find fault, it is often declared; but the recognition of merit requires special insight. Rejection, therefore, is no more aggressive or positive than acceptance; and if one of these calls for a more critical attitude and more mental energy than the other, it is probably the latter.

What is the relation of this critical attitude to sympathy for an author? One of the essential conditions in the proper study of a book is that it be approached with an open, sympathetic the critical mind. One must look at the world through sympathy the author's eyes in order to understand and and respect. appreciate what he says, and that is possible only when one feels high respect for him and is in close sympathy with him. To this end, it may be well at times for the student to annihilate his own personality, as Ruskin advises, so as to lose himself in another's thought.

If the critical attitude were incompatible with such respect and sympathy, its value might well be questioned. But that is not the case. A sensible parent who is in closest sympathy with a child finds no great diffculty in seeing its defects and even in administering punishment for them. There are parents and teachers 
who cannot thus combine real sympathy with the critical attitude; but they are too weak and foolish to rear children. IIelpful friendships among adults, also, are not based upon blind admiration; they presuppose ability to discern faults and even courage now and then to mention them.

One cannot be a true scholar without making a similar combination. The unquestioning frame of mind that allows a sympathetic approach to an author marks one stage in study; but this must be followed by the critical attitude before the study is complete. That the two attitudes are not incompatible is well stated by Porter in the following words: "We should read with an independent judgment and a critical spirit. It does not follow, because we should treat an author with confidence and respect, that we are to accept all his opinions and may not revise his conclusions and arguments by our own. Indeed, we shall best evince our respect for his thoughts by subjecting them to our own revision." 1

While the demand thus made upon the scholar seems great, there is nothing surprising about it; for How daily the scholar's relation to an author is sublife requiras stantially the same as that of any adult to pendence of other persons with whom he has dealings. jndgment.

If you go to a store to purchase a pair of rubbers, you cannot surrender yourself complacently to any elerk who happens to wait upon you. He is very likely to be satisfied to sell you rubbers that are too long or too short, too wide or too narrow, or at least not of the shape of your shoes. Or he may want

1 Noah Porter, Books and Reading, p. 52. 


\section{JUDGING OF WORTH OF STATEMENTS 143}

to sell you storm rubbers when you prefer low ones. Unless, therefore, you carry a standard in mind and reject whatever fails to meet it, you are very likely to buy rubbers that won't be satisfactory. The same is true if you go to a tailor for clothing; unless you know him to be unusually reliable, it is not enough for him to tell you that a coat fits; you must test the statement by your own observation.

Some years ago a house that I occupied in New York City became infested with rats, and, wanting to reach the kitchen from the cellar, they gnawed an inch hole through a lead drain pipe from the laundry tubs, that lay in their way. The hole was behind a cupboard in the kitchen, very close to the wall, and not easy to reach. If clean clothing was to be had, the pipe had to be fixed; but when a plumber was called in, he stated that a carpenter would be needed to remove the cupboard, and again to replace it after the work was completed. The pipe having the hole, he added, would need to be taken out, and, as it was one arm of a larger pipe that had two other branches, the pipe with the three arms would have to be removed and another put in its place. 'The entire work was estimated to cost about fifteen dollars.

As that seemed a large amount to invest in a rat hole, another plumber was consulted; but he made substantially the same report. Still not being satisfied, I went to a hardware store and asked, "Have you a man who can solder a thin metal plate over a small hole in a lead pipe? The hole is about an inch in diameter and somewhat difficult to reach; but the work can be done by any one who knows his business." 
The merchant said that he had such a man. The man was sent over; he did the work in a few minutes, and the bill was seventy-five cents.

Plumbers are probably as honest and capable in their lines as most classes of workmen; but many persons have learned to their sorrow not to place themselves as clay in their hands.

A man who builds a house should keep more than half an eye on his architect, otherwise the house is likely to cause numerous lifelong regrets. Even one's physician is not to be implicitly obeyed on all occasions. If a patient knows that quinine acts as a poison upon him, as it does upon some persons, he must refuse to take it. Also, if a physician gives too much medicine, as physicians have been known to do, one must discover the fact for himself, or his alimentary canal may suffer. Such men are merely types of the many persons who surround us and help us to live; we must be judges of the conduct of each of them toward us, if we wish to be healthy and happy.

Must we, then, pass upon everything; and is no person to be fully trusted? How can any one find time for the exercise of so much wisdom? And what are specialists for?

Certainly many, many things must be taken for granted. When you board a train, you cannot make sure that the trainmen are all qualified for their positions and that all parts of the train and of the rack are in proper condition. If, however, you choose a poorly managed road, in place of a well-managed one, you are more likely to be killed on the journey. In other words, while many things must be assumed, the 
responsibility of determining what they shall be rests with you, and you suffer the penalty of any bad selection. Your own judgment is still your guide.

Many persons must likewise be trusted. But who shall they be, and to what extent? The objects of choice have now been merely shifted from things to human beings, and independent judgment must still be exercised the same as before. The difficulty is fully as great, too. Says Holmes, "We have all to assume a standard of judgment in our own minds, either of things or persons. A man who is willing to take another's opinion has to exercise his judgment in the choice of whom to follow, which is often as nice a matter as to judge of things for one's self." 1

Reasons for the use of independent judgment may be found in lack of knowledge on the part of others, or of skill, or of judgment, or of energy, or of honesty. But there is a more fundamental reason than either incompetence or dishonesty, and it is found in the peculiar circumstances of each person. The point of view of an architect is not the saine as that of the owner of a house. Every one hundred dollars added to the cost of a building rejoices the architect's heart because it increases his income. On the other hand, every hundred dollars thus added tends to produce depression in the owner's mind. Similarly, the point of view of any specialist or friend is different from yours; it can never be fully your own. Just because no one can look at your affairs from your own point of view, no one is fully qualified to judge them for you, and you must rely upon yourself.

3 Holmes, Autocrat of the Breakfast Tuble. 
The people with whom we trade, therefore, the specialists and friends to whom we go, like the authors that the student consults, are all related to us merely as advisers. No one of them is fitted to tell us exactly what to do, and the proper attitude toward them all is that of friendly suspicion.

This conception of each person's relation to ideas and to the world at large places his judgment on a high Greatness of plane. Whether he will or not, every man is aach person's intellectually a sovereign whose own judgment
responsibility for judging. in the decision of all his affairs is his court of last resort. This is a grave responsibility, indeed; and it is no wonder that many shrink from it.

Yet what better state can be conceived? This responsibility proves the dignity of manhood; it is the price of being a man. Fairly good judgment, exercised independently of everybody, is one essential condition of self-direction and of leadership of others. The importance of good judgment is often emphasized; and the reason for it is here evident, since it must guide us at every turn. The reason for education of judg. ment is also evident. Every person is bound to make many mistakes; but he will make far fewer when his ability to judge has been properly trained. 'The utter inadequacy of instruction that aims mainly at aequisition of facts is likewise evident; for the exercise of judgment involves the use or adaptation of knowledge to particular conditions, and the mere possession of facts bears little relation to this ability.

It may seem presumptuous for a young student of education to pass judgment upon the greatest writers on education that the world has produced, such as 
Spencer and Rousseau. Certainly the opinions of such great men are far more valuable and reliable, on the whole, than those of an immature student. The basis The architect's knowledge of building, like- that every wise, is superior to that of a novice in that sor fnd hing line. Granted, therefore, that no one person is in a position to judge for another, what right, what basis has this other, particularly the inexperienced person, to judge aay and every sort of affairs for himself ?

$\mathrm{He}$ has basis enough. Speaking of the value of expert knowledge, Aristotle says: " Moreorer, there are some artists whose works are judged of solely, or in the best manner, not by themselves but by those who do not possess the art; for example, the knowledge of the house is not limited to the builder; the user, or, in other words, the master of the house will even be a better judge than the builder, just as the pilot will judge better of a rudder than the carpenter, and the guest will judge better of a feast than the cook." ${ }^{1}$ The reason that the non-expert ean thus sometimes even surpass the expert himself in judging of the latter's work is found in the fact that the non-expert as well as the specialist has had much valuable experience bearing on the specialist's line.

A very important truth is here suggested concerning the student. Nothing that one is fitted to study is wholly new or strange to him. Any person must have had experiences that parallel an author's thought in order to understand that author. For, according to the principle of apperception. intimately related past experience is the sole basis for the comprehension of new facts.

1 Aristotle, Politics (Jowett), p. 88. 
Values are no newer or stranger to the student than other phases of experience. The student's related past, therefore, furnishes as good a basis for judging soundness or worth as it does for getting at meanings. When, for instance, he reads Spencer's statement that 'acquisition of every kind has two values, - value as knowledge and value as discipline"use out of his own life. He can determine for himself that the assertion holds. On the other hand, he can quite likely recall how he has sometimes been aroused and stirred to new effort by things that he has read; and he may, in consequence, question whether Spencer has not here overlooked one great value of knowledge. Again, when the student is told by Rousseau that "in the hands of man everything degenerates," he can, no doubt, justify the assertion to some extent by recalling observed instances of such degeneration. But, in addition, when he recalls what he has observed and read about the wonderful advance made by man toward a higher civilization, and realizes that Rousseau is denying that there has been an advance, he is in a position to consider whether Rousseau is mainly in the right or mainly in the wrong.

It is true that the student may be wrong in his conclusions; also that, even though he be often right, he may become a confirmed fault-finder. But that is not discouraging, for he is surrounded with dangers. The essential fact remains that, just as his past related experience furnishes a fair basis for understanding the meaning of what he hears and reads, so, also, it furnishes a fair basis for estimating its value. 


\section{ABILITY OF CHILDREN TO JUDGE VALUES}

Many persons who agree to the necessity of independent judgment on the part of adults may demur at the idea of placing similar responsibility $A$ conception upon children. Are not children normally of child naturo uncritical and imitative or passive? they say. such ability. And if we teach them to judge and criticise freely, are they not very likely to develop priggishness that will result in immodesty and disrespect for others? "Memory," says John Henry Newman, "is one of the first developed of the mental faculties; a boy's business, when he goes to school, is to learn, that is, to store up things in his memory. For some years his intellect is little more than an instrument for taking in facts, or a receptacle for storing them; he welcomes them as fast as they come to him; he lives on what is without; he has his eyes ever about him; he has a lively susceptibility of impressions; he imbibes information of every kind; and little does he make his own in the true sense of the word, living rather upon his neighbors all around him. He has opinions, religious, political, literary, and, for a boy, is very positive in them and sure about them; but he gets them from his schoolfellows, or his masters, or his parents, as the case may be. Such as he is in his other relations, such also is he in his school exercises; his mind is observant, sharp, ready, retentive; he is almost passive in the acquisition of knowledge. I say this is no disparagement of the idea of a clever boy. Geography, chronology, history, language, natural history, he heaps up the matter of these studies as treas. ures for a future day. It is the seven years of plenty 
with him; he gathers in by handfuls, like the Egyptians, without counting; and though, as time goes on, there is exercise for his argumentative powers in the elements of mathematics, and for his taste in the poets and orators, still while at school, or at least till quite the last years of his time, he acquires and little more; and when he is leaving for the university he is mainly the creature of foreign influences and circumstances, and made up of accidents, homogeneous or not as the case may be."1

This view of childhood is somewhat common; and according to it children are almost exclusively receptive, any active exercise of judgment scarcely beginning before college entrance.

Let us see to what extent this view holds when examined in the light of children's actual conduct. Extent of A first-grade pupil who had attended the 1. As evi- kindergarten the previous year remarked individual to his former kindergarten teacher, "I wish

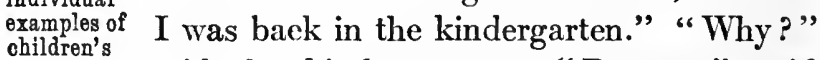
obildren's he, "we did hard things in the kindergarten last year." Then he added confidentially, "You know our teacher was in the fourth grade last year. She used to come in to see us when we were playing, and she thinks we can't do anything else. Why, the things she gives us to do are dead easy." His teacher herself afterward admitted that his criticism was just.

A small boy, being asked if he went to Sunday school, replied "Yes." "Have you a good teacher?" was the next question; to which eame the response,

1 John Henry Newman, Scope and Nature of University Educa. tion, Discourse V. 
"Yes, pretty good; good for a Sunday school. She would not be much good for day school." Was n't he probably right?

A five-year-old boy was taken to Sunday school for the first time by his nurse. There the chief topic of instruction happened to be eternal punishment. On the way home he was not altogether good, and the nurse, in the spirit of the day's lesson, assured him that he would go to the bad place when he died, and would burn there always. When he entered the house he hurried, sobbing, to his mother and declared vehemently: "Nurse says I'll go to the bad place when I die, and that I'll burn there always. I won't burn always; I know I won't! I may burn a little bit. But I'm bad only part of the time; I am good part of the time; and I know I won't burn always." His reasoning on theology was as sound as that of many a preacher.

I was standing near a second-year class in reading one day when I overheard a boy say "Nonsense!" to himself, after reading a section. I agreed with him too fully to offer any reproof.

An eight-year-old girl said to her mother, " May I iron my apron? I ironed a pillowcase." " Did Sarah [the maid] say that you ironed it well?" asked the mother. "No, she didn't say anything," was the response. "But I know that I ironed it well." Is that an entirely passive attitude?

Rebecca had spent six years in the public.schools of two large cities when she entered the seventh grade of the State Normal School. She had been called a " quiet child," "nervous" and " timid," by different 
teachers. After a very few days in the new school, however, she volunteered this expression of her thoughts: "I did n't think the Normal School would be anything like that. It's very different from the public schools. There only the teacher has opinions and she does all the talking; but in the Normal School the children can have opinions, and they can express them, and I like it."

Any one who has had close contact with children knows that they have a remarkably keen sense of the justice or injustice of punishments inflicted upon them. As a rule, I would rather trust their judgment of their teachers than their parents' judgment, although it is true that parents form such judgment largely from hearing remarks from their children. Children are reasonably reliable, also, in judging one another's conduct, which they are prone to do.

Such facts as these indicate that it is quite natural for children - even very young ones - to pass judgment of some kind on things about them, and that their judgments are fairly sound. They are hardly to be called merely passive receivers of ideas, mildly agreeing with the people about them.

The school plainly assumes the presence of this ability by the requirements that it makes of children. 2. As eri- One of the common questions in the comdenced by requirements bination of forms and colors, even in the ef the school. kindergarten, is, "How do you like that?" In instruction in fine art throughout the grades their judgment as to what is most beautiful is continually appealed to.

The judging of one another's compositions and other 
school products is a common task for pupils. In connection with fairy tales six-year-olds are frequently asked what they think of the story. Many say, "It is beautiful"; but now and then a bold spirit declares, "I don't like it."

Children are expected to judge the quality of literature, distinguishing with ease between what is literal and what is imaginative, or figurative, or humorous. When they read that the rope with which the powerful Fenris-Wolf was bound was "made out of such things as the sound of a cat's footsteps, the roots of the mountains, the breath of a fish and the sinews of a bear, and nothing could break it," ${ }^{1}$ they are not deceived; they only smile. Now and then they make mistakes; but in general such stories as Through the Looking-Glass and the "Uncle Remus" stories do not overtax their power to interpret conditions.

What literature or history is there for children that omits the passing of moral judgments? Cinderella is approved of for her goodness, William Tell for his independence, Columbus for his boldness; Cinderella's sisters are condemned for their selfishness, and Gessler for his meanness. Without such exercise of judgment these two studies would miss one of their main benefits. The data that must be collected in nature study and history for the proof of statements give much practice in the weighing of evidence; and the self-government that is now so common, in various degrees, in good schools is supposed to be based upon a reasonable ability to weigh out justice. Thus the method both of instruction and of government in our better schools

3 Hamilton Mabie's Norse Myths, p. 166. 
presupposes the ability on the part of pupils to judge worth; and the better teachers have considered it so important that they have constantly striven to develop it through instruction, just as sensible parents have placed upon their children some of the responsibility of buying their own clothing, doing the marketing, and planning work at home, in order to cultivate the power to make wise choice. If the ability to judge were really wanting in children, our supposedly best methods of teaching and governing them would need to be abandoned.

The best proof that children possess this ability is that they can scarcely get on without it. Several years 3. As eri- ago, when I reached Indianapolis on a jourdenced by ney, I gave my bag to a boy ten or eleven of child life. years of age to carry to my hotel. While we were walking along together another boy stopped him and drew him to one side. I observed that they were having a serious conversation, and when we soon proceeded further I inquired what the trouble was. "That boy," said he, "wants me to divvy up with him." "What do you mean by that?" said I. "He wants me to give him half of the money that I am to get from you for carrying this bag," was the reply. "But," I responded indignantly, "he has not helped you at all. Why, then, should he receive anything?" "He should n't," came the answer; "but he belongs to a crowd of fellows, and he told me that if I did n't divvy up with them they would pornd the life out of me." I pondered for some time, but I gave no advice. What advice should have been given?

This is a striking case; but it only illustrates very 
forcibly that children are not merely slecping, and eating what is given to them, like cattle and sheep. Like adults they are surrounded with human beings and are leading moral lives. At home, in school, on the street, a hundred times a day they must "size up" people and situations and decide what is best to do. If they are weak in such decisions, they are regarded as weak in general; and if very weak, other persons must assume responsibility for them and "tote" thicm through life. On the other hand, if they are strong, they are classed as sensible persons, and they "get on" well. Children distinguish themselves as balanced and sensible, just as adults do, simply because they are wise in measuring values.

Those persons who regard childhood as almost solely a period for receiving knowledge, scem to think that active life really begins only when one becomes of age. The fact is, it begins from eighteen to twentyne years sooner than that; and throughout all those earlier years one has nearly as great a variety of trials, and trials usually of greater intensity for the moment, than adults have. In the midst of so much need, it would be strange, indeed, if one were endowed with no power, called judgment, to cope with difficult situations, if one had only the power to collect facts. That would leave us too helpless; it certainly would not be adaptation to environment, or normal evolution.

In conclusion, therefore, those who deny a fair degree of sound judgment to children deny what seems a marked natural tendency of childhood; they pass a sweeping criticism upon what is now supposed to be the best method of instructing and governing 
children; and, finally, they deny to the child the one power that can make his knowledge usable and insure his adaptation to his environment. Self-reliance, which parents and teachers strive for so much, becomes then impossible among children, for self-reliance is nothing more than independent direction of self, made possible by power to judge conditions. Certainly most persons are unwilling to take this position in regard to the nature of childhood. They will agree that a twelveyear-old boy, sitting for an hour in the presence of the President of the Unitcd States and hearing him converse freely, without forming judgments about him, and many fairly accurate ones too, would be an abnormality.

What about the threatened priggishness and related evils that may result when the responsibility for passDanger of ing judgment frequently is laid upon chilpriggishness. dren? Certainly a modest sense of one's own merit and proper respect for others are highly desirable qualities. These qualities, however, are not greatly endangered by the exercise of intellectual independence, for it is little related to immodesty and impertinence.

A few years ago when many distinguished scientists celebrated in Berlin the discovery of the Roentgen rays, Mr. Roentgen himself was not present. Although he had possessed boldness enough to enlarge the confines of knowledge, he lacked the courage to fact the men who had met to do him honor, and he telegraphed his regrets. St. Paul, Erasmus, and Melanchthon were, intellectually, among the most independent of men; but St. Paul possessed the humility 
of the true Christian, and both Erasmus and Melanchthon were extremely modest. Pestalozzi was once sent by his government is a member of a commission to interview Napoleon. On his return from Paris he was asked whether he saw Napoleon. "No," said he, "I did not see Napoleon, and Napoleon did not see me." Recognizing the greatness of a real educator, he took away the breath of his friends by ranking himself alongside Napoleon as a truly great man. Yet he was one of the most modest, childlike men that the world has ever known. These examples show that the keenest, boldest of analysts and critics may yet be the humblest of men.

Self-reliance is the more common name for similar independence among children; and it is no more nearly related to priggishness in their case than in the case of adults. The five-year-old child will often reject statements from his parents, even though he have the greatest respect and lore for them. It is only natural for him to do so when assertions that he hears do not tally with his own experience; and he will retain such boldness throughout life unless made subservient by bad education.

There is some danger, however, that the cultivation of this independence may make one a chronic faultfinder. It should not be forgotten, therefore, that judging means approving as well as condemning, and in case of children probably much more of the former than of the latter. In addition, care should be taken that children shall pass judgment only on matters lying fairly within their experience, and shall recognize the need, too, of giving good reasons for their conclu. 
sions. If these precautions be taken, the danger of priggishness is reduced to the minimum. What danger remains can afford to be risked; for independent judgment is the very basis of scholarship among adults, and mental submissiveness in childhood is not the best preparation for it.

PRACTICAI, SUGGESTIONS FOR THE DEVELOPMENT OF INDEPENDENT JUDGMENT AMONG CHILDREN

Responsibilities that require exercise of judgment should be placed upon children throughout the school, 1. Plaoing from the kindergarten on. Scarcely a reciresponsibil- tation need pass without opportunities of ity upon obildren at school.

this kind. For example, children can determine the correctness of answers to questions put in class, can weigh the relative merits and the efficiency of tasks performed, can propose suitable ways of illustrating topics, such as lumbering, irrigation, mining, etc. The wisdom of plans for preserving order in the school, for decorating the building, and for improving the school in other respects can also be submitted to their judgment. It is by the exercise of judgment in many ways that young people will become judicious in numerous directions. It is not difficult for any teacher to do some work of this kind, but it is difficult to be consistent in it. Many teachers who are zealous in cultivating independent judgment a part of the time, undermine this influence at other times by arbitrary decisions or by a personality so overpowering that it allows no free scope to the child's personality. Some study of the responsibilities that different chil. dren bear at home may prove very profitable. While 
some carry much responsibility there, others are given no option as to when they shall start to school each day, or how they shall dress, or who shall 2. siady of buy their clothes, or how they shall spend responsimoney. Thus they are allowed no oppor- at home. tunity to decide things for themselves or to develop independent judgment. Interviews with individual parents, and parents' meetings, may prove very fruitful along this line.

In order to teach the nature of self-reliance and the scope of its exercise, the use to be made of the advice of friends should be a topic for occasional discussion. Many a young man and woman eration of the besites to ase to be hesitates to ask the advice of others for made of fear that they may be offended if the advice given is not followed. They are justified, too, for many persons are offended in this way. The propriety of rejecting advice should be far more generally understood than it is. Then children, as well as young men and women, would seek it much oftener, to their lasting benefit.

Since modesty should be cultivated along with independent judgment, examples of distinguished men and women who have combined these two qual- 4. Fxamples ities should now and then be considered. of com-

It is well to mark out for special attention modesty $\begin{aligned} & \text { moth } \\ & \text { with inde- }\end{aligned}$ such pupils as seem to be untrue to their own pendence. experience in judging, or such as seem to lack the energy to use it as a basis of judgment. For example, many eleven- and twelve-year-old children in their study of Excelsior feel that the young man very rashly exposed himself and merited his death. Yet some of 
these will suppress this judgment, and even praise him as a noble youth, in order to please their teacher, 6. Obser- or because they think that that is what they vation of
babits of ought to say. They lack the boldness to be papils in use honest with themselves.

of judgment.

Again, very many young people fail to think far enough to "weigh and consider." They stop short with the concrete narrative, failing to judge whether the story is reasonable, whether the characters are representative, whether the moral is sound, etc. Thus they omit a portion of the thinking that should be expected of them. Whether they are wanting in mental energy or do not realize that this is one of the important parts of study, they should be taken in hand. Right habits of mind are even more important than knowledge.

As one means of overcoming the defect just mentioned, different children, or different committees of a 6. Reports class, might examine the same newspapers, on merits of magazines, articles in reference books, etc., printed
matter, with and then report on their merits independently discussion. of one another, giving their reasons. The diseussions that would be likely to follow as the result of disagreements would be of the highest value. 


\section{CHAPTER VII}

MEMORIZING, AS A FIFTH FACTOR IN STUDY

"All the intellectual value for us of a state of mind depends on our after-memory of it," says Professor James. ${ }^{1}$

In other words, there would be little object Importance in reading, or reflection, or travel, or in ex- of memory. perience in general, if such experience could not later be recalled so as to be further enjoyed and used. Want of reference thus far to memory does not, therefore, signify any lack of appreciation of its worth. No time is likely to come when a low estimate will be placed upon memory.

How prominent memorizing should be, however, is a question of great importance.

The four factors of study that have now Jsual prombeen considered are the finding of specific inence of aims, the supplementing of the thought of as a factor in authors, the organizing of ideas, and the the resalt. judging of their general worth. These four activities together constitute a large part of what is called thinking. Memorizing - meaning thereby, in contrast to thinking, the conscious effort to impress ideas upon the mind so that they can be reproduced - has usually been a more prominent part of study than all these four combined. The Jesuits, for example, who were leaders in education for two hundred years, made repetition "the mother of studies," and it is still so prominent, even

2 William James's Psychology, Vol. I, p. 64t. 
among adults, that the average student regards mem. orizing as the nearest synonym for the term studying. Repetition, or drill, however, is far from an inspiring kind of employment. It involves nothing new or refreshing; it is mere hammering, that makes no claim upon involuntary attention. When it is so prominent, therefore, it stultifies the mind, starving and discouraging the student and defeating the main purpose of study.

If the work of memorizing is so uninteresting and even injurious, why is it made so prominent? There

Reasons for saoh promi- three will here be considered.

nence.

In the first place, memorizing is more superficial than real thinking, and people generally prefer to be somewhat superficial and mechanical. It takes energy to dig into things, and, being rather lazy, we are very often content to remain on the outside of them. Children show in many little ways how natural it is to be mechanical. For instance, rather than think the ideas adverb and present active participle, they will recognize words ending in $l y$ as adverbs, and those ending in ing as present active participles. They will class words as prepositions or conjunctions by memorizing the entire list of each, rather than by thinking the relations that these parts of speech express. Young men and women, likewise, will memorize demonstrations in geometry rather than reason them out, and will memorize other people's opinions rather than attempt to think for themselves. Even though it is often really easier to rely upon one's own power to think than upon memory, it takes some depth of nature to recognize the fact and act accordingly. 
Teachers show this tendency as plainly as students. In preparing lesson plans, for example, very few will get beyond what is mechanical and formal. The reason that recitations are so largely memory tests, too, is that teachers put mere memory questions more easily than they put questions that provoke thought. It is, therefore, a well-established natural trait that is back of so much mechanical memorizing.

A second reasol. for the prominence of memorizing is found in the desire to strengthen the memory through its exercise. We know that the arm may be developed by the lifting of weights, so that it will be stronger for lifting anything that comes in its way. So it has long been a common belief that memory, as a faculty of the mind, could be developed by any kind of exercise so as to be stronger for all kinds of recall. Many words in spelling, many dates in history, many places in geography, many facts in grammar and even in the more advanced studies, have been learned rather because they were supposed to develop memory than for any other reason. Thus the desire of strengthening memory has considerably increased the amount of memorizing.

The belief that memorizing normally precedes thinking rather than follows it, is a third very important reason for the prominence of memorizing. "The most important part of every Mussulman's training," says Ratzel, "is to learn the Koran, by which must be understood learning it by heart, for it would be wrong to wish to understand the Koran till one knew it by heart."' We hold no conscientious scruples against understand-

'Ratzel, The History of Mankind, Vol. III, p. 218. 
ing statements before attempting to memorize them; but one might think that we did, for our practice in memorizing Scripture generally corresponds to that of the Mussulman in learning the Koran. I venture to affirm, also, that the average student habitually begins the study of his lessons by memorizing, with the expectation of doing whatever thinking is necessary later. The average teacher conducts recitations in the same manner. There is the defense for this practice, too, in the fact that it seems logical to get the raw materials for reflection into our possession before trying to reflect upon them. The result, however, is that a surprisingly small amount of thinking is done; for the memorizing requires so much time and energy that, in spite of good intentions, the thinking is postponed for a more convenient season until it constitutes an insignificant part of study, while memorizing, the drudgery of study becomes its main factor.

If it is possible to reduce the prominence of mechanical memorizing, it is highly desirable to do so, for it How this is unreasonable to defeat the ends of eduprominence cation in the attempt to educate. Let us see rodnced. how this may be accomplished.

There is no complete cure for our tendency toward the superficial and mechanical, due to mental laziness;

2. By prothe defect is too deep. Yet to the extent that viding more we increase our motive for effort a cure is motivation.

found. Live purposes give force; they make one earnest enough to fix the whole attention upon a task, and to determine to get at the heart of it; they deepcn one's nature. Full concentration of attention, due to interest and exercise of will power, is one of the 
chief conditions of rapid memorizing. Some of the ways in which such purposes may be supplied have already been discussed in Chapter III.

In the second place, we can afford to abandon all attempts to develop the general power of memory. The power of various crude materials to $2 . \mathrm{By}$ retain impressions that are made upon them absudoning varies greatly according to their nature. strengthen Jelly, for instance, has little such power; the general sand has little more; clay possesses it in a memory. higher degree, and stone in a far higher still. But whatever persistence of impressions a given lot of any one of these materials may possess, it can never be changed, it is a fixed quantity.

The same holds in regard to the brain matter. Some men have brains that retain almost everything. Professor James tells, ${ }^{1}$ for instance, of a Pennsylvania farmer who could remember the day of the week on which any date had fallen for forty-two years past, and also the kind of weather at the time. He tells further of an acquaintance who remembered the old addresses of numerous New York City friends, addresses that the friends had long since moved from and forgotten; nothing that this man had ever heard or read seemed to escape him. Other persons, on the other hand, possess little power to retain names, dates, quotations, and scattered facts; their desultory memory, as it is called, is very poor. But whatever native retentive power any particular brain happens to have, can never be altered. The general persistence of impressions of each person is a physiological or physical porver depending on the

1 Psychology, Vol. I, p. 660. 
nature of his brain matter, and it is invariable. "No amount of culture would seem capable of modifying a man's general retentiveness," ' says James. Again, "There can be no improvement of the general or ele. mentary faculty of memory." ${ }_{2}$ Our desultory memories, in other words, are given to us once for all.

It is commonly supposed, on the contrary, that persons who memorize a great deal, sucl as actors, greatly strengthen their general memory in that way. "I have carefully questioned several mature actors on the point," says James, "and all have denied that the practice of learning parts has made any such difference as is alleged." 3 Actors certainly do increase their abi.. ity to memorize certain kinds of subject-matter. Any one who has much practice in learning lists of names, even, is likely to increase his ability for that and similar tasks, just as one who learns to play tennis well is aided thereby in playing baseball. The reason for such improvement, however, is found largely, if not wholly, in improvement in one's method of work, as will be made clear later, rather than in any increase in general retentive power.

While the question of improving the memory is somewhat in dispute, ${ }^{4}$ and some psychologists assert that any kind of memorizing will have some effect on all other kinds, it is safe to say that mere exercise of memory is, for all practical purposes, useless as a means of strengthening general memory. Only those things, therefore, should be memorized that are intrinsically worthy of being reproduced.

${ }^{1}$ Psychology, Vol. I, p. 663.

2 Talks to Teachers, p. 128.

Psychology, Vol. I, p. 664.

- See Educational Review for June, 1908. 
Even though a person's native retentive power cannot be improved, the skill with which he uses whatever power he has can be increased. Men who lift pianos 3. By im. find the work very difficult at first; but soon $\begin{gathered}\text { proving the } \\ \text { method of }\end{gathered}$ it becomes reasonably easy. The greater memorizing. ease is not due to any marked increase in strength, but rather to increased skill in using strength. It is due to improvement in method; they learn how.

So it may be with memorizing. A large portion of such work is usually awkward, consisting of repetitions that consume much time and energy. But it is possible so to improve the method that memory tasks will occupy comparatively little time.

Before discussing ways in which the method of memorizing can be improved, it is necessary to consider how facts are recalled.

Impressions are not stored away in the are recalled. brain, and afterward recalled, in an isolated state, or independently of one another. On the contrary, they are more or less intimately related as they are learned, and recall always takes place through association of some sort. "Whatever appears in the mind must be introduced; and, when introduced, it is as the associate of something already there." 1

The breakfast $I$ ate this morning recalls the persons who sat around the table; memory of one of those persons reminds me of a task that I was to attend to to-day; that task suggests the fact that I must also go to the bank to get some money, etc. Thus every fact that is recalled is marshaled forth by the aid of some other that is connected with it, and which acts as

1 James's Talks to Teachers, p. 118. 
the cue to it. This is so fully true that there is even the possibility of tracing our sequence of ideas backward step by step as far as we wish. "The laws of association govern, in fact, all the trains of our thinking which are not interrupted by sensations breaking on us from without," says James. ${ }^{1}$

Since any idea is recalled through its connection with other ideas, the greater the number and the closeness How method of such relations, the better chance it stands of memoriz- to be reproduced. Improvement in one's improved. method of memorizing, in other words, must consist mainly in increasing the number and closeness of associations among facts. A list of unrelated words is extremely difficult to remember; every additional relation furnishes a new approach to any fact; and, the closer this relation, the more likely it is to cause the reproduction.

Even the simplest associations, that are largely mechanical, may be important aids to memory. For 1. By more example, it is much easier to learn the teleor less mo- phone number 1236 by remembering that
chaniosl association. the sum of the first three numbers forms the fourth than by memorizing each figure separately. Teacher is a word whose spelling often causes tromble; but when teach is associated with each, which is seldom misspelled, the difficulty is removed. There and their are two words whose spelling is a source of much confusion; but it is overcome when there is associated with where and here, and their with her, your, our, etc. Sight, site, and site are still worse stumbling-blocks in spelling; but the difficulty is largely overcome when 
sight is firmly associated with light and night, site with situation, and cite with recite. The association of the sound of a word with its meaning is an important help in remembering the meanings of some words, as rasping, for example. Professor James, I believe, tells of some one who forgot his umbrella so often that he practiced associating umbrella with doorway until the two ideas were almost inseparable. Then, whenever he passed through a doorway on his way out of doors, he was reminded to take his umbrella along. While there might be some disadvantages in this particular association, it forcibly suggests the value of association in general.

The various mnemonic systems that have been so widely advertised have usually been nothing more than plans for the mechanical association of facts. Sometimes, to be sure, it has been more difficult to remember the system than to memorize the facts themselves; yet they, too, give witness to the value of association.

I once asked a thirteen-year-old girl, in a history class, when Eli Whitney lived. She gave the exact month and day, but failed to recall either the year or the part of the century, or even the century. Her answer showed plainly that her method of study was doubly wrong; for she not only offended against relative values in learning the month and day while forgetting the century, but she rerealed no tendency to associate Whitney's invention with any particular period of history. Even cross-questioning brought no such tendency to light. She was depending on mere retentiveness to hold dates in mind. The habit of memorizing facts in this discomected way is common 
among adults as well as children, and as a remedy against it the student should form the habit of frequently asking himself the question, "With what am I associating this fact or idea?"

In contrast with associations that are more or less mechanical, there are vital associations that are possible in all studies containing rich subjectmatter.

Early association of the principal ideas, or early recognition of the outline of thought, is perhaps the 2. By olose most important of these. One can proceed thought sentence by sentence, or "bit by bit," in association. memorizing as in thinking, adding one such fragment after another until the whole is learned. But the early recognition of the main ideas in their proper sequence is far superior. These essentials (1) Throngh give peculiar control over the details by attention to grouping them in an orderly manner and the ontline. furnishing their cue so that the whole is more easily memorized. This is true even in the case of verbal memorizing, as is evidenced by a certain minister quoted by Professor James. "As for memory, mine has improved year by year, except when in ill-health, like a gymnast's muscle. Before twenty it took three or four days to commit an hour-long sermon; after twenty, two days, one day, one-half day, and now one slow analytic, very attentive or adhesive reading does it. But memory seems to me the most physical of intellectual powers. Bodily ease and freshness have much to do with it. Then there is great difference of facility in method. I used to commit sentence by sentence. Now I take the idea of the whole, then 
its leading divisions, then its subdivisions, then its sentences." 1

Thus early attention to organization is a large factor in memorizing, as in study that aims principally at comprehension of the thought. Where good organization is wanting, - as in tracing lessons in geography, and other mere tests of facts, - this aid to memorizing is lacking, and one must depend more upon brute memory power. On the other hand, where the portions of one's knowledge have become so closely interrelated and so well organized that they form a well-knit system of thought, one's ability to remember may be surprising. Spencer and Darwin were examples of men whose ideas were thus organized. Neither of them possessed phenomenal memories to start with; but their observations so generally found a group of close relations to sustain them, and these groups were associated with one another in such a close and orderly way, that the outline of the whole could be easily surveyed, and any fact could be quickly reproduced, just as any book can be speedily found in a well-organized library. Thus, as we grow older, if the organization of our knowledge is improving, the power of reproducing it will likewise be increasing.

Comparisons are another means of establishing valuable thought connections. Study by topics, also, furnishes special opportunity for compari- (2) Through sons. "It is generally better," says James oomparisons Baldwin, "to learn what different writers have thought and said concerning that matter of which you are making a special study. Not many books are to be 2 James, Psychology, Vol. I, p. 668. 
read hastily through." 1 Koopman likewise declares, "A single trial will prove to any student the superiority, in interest, of the topical and comparative over the chronological and consecutive method of studying history." 2 Again, "The student who has not known the pleasure of reading all the works of an author, as a study in personality, has a great source of enjoyment still before him." 3

Many persons have the feeling that it is a moral duty, after having begun a book, to read it through. Here is the recommendation that our reading for a time "converge to one point"; that we find, for example, what several psychologies have to say on one topic, such as memory, rather than read one psychology from cover to cover. The value of comparison for thoroughness has already been emphasized. Its value from the view-point of memory is great, not only because it insures more lasting impressions due to increased interest, as just suggested, but also because each new comparison, while reviewing, also establishes new and closer associations among old ideas.

Memorizing According to the above, we can best mem"Seal Lulla orize by establishing whatever associations by." seem interesting and reasonable. Take, for instance, Kipling's Seal Lullaby: -

Oh! Hush thee, ny baby, the night is behind us, And black are the waters that sparkled so green.

The moon, o'er the combers, looks downward to find us At rest in the hollows that rustle between.

1 James Baldwin, The Book Lover, p. 43.

2 Koopman, Mastery of Books. p. 43.

Ibid., p. 44. 
Where billow meets billow, there soft he thy pillow;

$\mathrm{Ah}$, weary wee flipperling, curl at thy ease!

The storm shall not wake thee, nor shark overtake thee,

Asleep in the arms of the slow-swinging seas.

The music of the rhythm leads one to read it aloud from time to time. The first two lines are an announcement of bedtime; the next three tell where the resting place is, and the last three give assurance of safety that is the outline. Any one has often observed how black the waters become as night approaches, and the picture is vividly recalled as the first couplet is read. "Combers" is almost a strange word, but its use makes its meaning reasonably clear. Is there a cradle of some sort? And a good pillow, too? Is there any tenderness indicated on the part of the mother? Any pet names applied? What dangers might cause uneasiness? Which is the most beautiful part? What lullabies of our childhood does this recall? How does this one compare in beauty with "Rock-a-bye-baby" ? Let us sing each, in order to judge. What marked contrast is there between the two, in the latter part?

I first ran across this lullaby in company with two friends, to each of whom it was entirely new. It appealed to us so strongly that we read it aloud several times and talked it over. We considered some questions such as the above, and compared it with " Rocka-bye-baby," disagreeing somewhat in our opinions. When we left it, each of us nearly or quite knew it by heart, although we had scarcely thought of trying to memorize it. In this way the association of ideas with one another, particularly with things that have been long cherished, is a very valuable aid to memory. 
To some persons this method of memorizing through association of ideas will seem very slow. It must be Where the acknowledged that there is a more rapid way, fault in cramming called cramming. Every mature student has lies. found that, under great pressure, he can commit to memory the substance of thought, and even the words, for an astonishing amount of matter. The difficulty is, however, that it will hold only up to a certain hour, the hour after examination, for example; then it goes so rapidly that one can fairly feel it slipping away. Such rapid memorizing is a witness to the value of very close attention in study; but the rapid escape is testimony to the necessity of a closer association of facts. Owing to undue haste the ideas are crowded into the memory without becoming intimately related, or tied together, in numerous ways. Then, when some part is forgotten, as is sure to happen, the other parts, being unrelated to it, offer no cue for its reproduction. Thus one part after another is lost; and, even though the ideas are closely related by nature, the lack of appreciation of such relationship on the part of the student allows the whole to escape as rapidly as mere lists of facts. To be firmly remembered, cither a great amount of drill is necessary, or else the ideas must be assimilated, and assimilation cannot be hurried in this manner.

The ordinary plan of study, by which memorizing precedes thinking, results, as we have seen, in crowding out thinking by leaving little time and energy for it. Memorizing thus becomes a substitute for thinking, and makes study an extremely dull task. This is an inversion, however, of the true order. If thinking 
is made to precede conscious attempts to memorize, the nourishing character of study is assured, and direct attempts at memorizing become largely un- The prinoinecessary, because most of the memorizing pal means has already been accomplished unconsciously. mechanical In other words, memorizing then becomes a memorizing by-product of thinking, instead of a substi- nent. tute for it. We often regret the prominence of memorizing in study, and here is probably the principal means of reducing it. There will be less of it, to the extent that we do more thinking; and there will be far more thinking if we put thinking first in time, thereby making it first in importance.

I once saw Kipling's Seal Lullaby presented to seven-year-old children. The teacher read it aloud from the blackboard, then the class read it. Then the class set to work to memorize it, a line or two at a time. This was a good example of bad method, for adults as well as for children. If they had planned first to enjoy the poem by trying to read it several times aloud with expression, by talking it over, illustrating it and singing it, the memoriziug would have taken care of itself. As it was, their teacher's haste to have it learned, amounted to a direct advocacy of the principle of cramming; for they were attempting to memorize through force rather than through association of ideas. One reason older students practice cramming to such an extent is that they have never been fully taught a better method; the schools have never fully stood for a better method of memorizing.

So long as memorizing is put first in time, and therefore in importance, those persons who have quick 
memories will be held up as the ideal students, whether they have higher abilities or not. Quick memories, however, are poor educators indeed unless they are coupled with unusual earnestness and energy. With all classes of students, therefore, the thinking should habitually precede attempts to memorize.

From all that has been said, it is plain that how to memorize is closely bound up with the question when Examples of to memorize. We are now ready to appreimprovement ciate the statement that good memorizing is in memory through closer attention and better mothod. really good thinking, and that improvement in memory is mainly improvement in attention and in method of thinking.

This is in general true, even in spite of some opinions to the contrary. Thurlow Weed, the journalist and politician, for example, greatly increased his ability to remember, and attributed the improvement to an increase in his general power of memory, due to its exercise. He relates his experience in the following words:-

My memory was a sieve. I could remember nothing. Dates, names, appointments, faces - everything escaped me. I said to my wife, "Catherine, I shall never make a successful politician, for I cannot remember, and that is a prime necessity of politicians."

My wife told me I must train my memory. So, when I came home that night, I sat down and spent fifteen minutes trying silently to recall with accuracy the principal events of the day. I could remember but little at first; now I remember that I could not then recall what I had for breakfast. After a few days' practice I found I could recall more. Events came back to me more minutely, more accurately, and more vividly than at first. After a fortnight or so of this, Catherine 
sid, "Why don't you relate to me the events of the dry. instead of recalling them to yourself? It would be interesting, and $m y$ interest in it would be a stimulus to you."

Having great respect for my wife's opinion, I began a habit of oral confession, as it were, which was continued for almost fifty years. Every night, the last thing before retiring, I told her everything I could remember that had happened to me, or about me, during the day. I generally recalled the dishes I had had for breakfast, dinner, and tea; the people I had seen, and what they had said; the editorials I had written for my paper, giving her a brief abstract of them. I mentioned all the letters $I$ had sent and received, and the very language used, as nearly as possible; when I had walked or ridden - I told her everything that had come within my observation.

I found I could say my lessons better and better every year, and instead of the practice growing irksome, it became a pleasure to go over again the events of the day. I am indebted to this discipline for a memory of somewhat unusual tenacity, and I recommend the practice to all who wish to store up facts, or expect to have much to do with influencing men. ${ }^{1}$

Professor James comments on this experience as follows:-

I do not doubt that Mr. Weed's practical command of his past experiences was much greater after fifty years of this heroic drill than it would hare been without it. Expecting to give his account in the evening, he attended better to each incident of the day, named and conceived it differently, set his mind upon it, and in the evening went over it again. He did more thinking about it, and it stayed with him in conse. quence. But I venture to affirm pretty confidently . . . that

1 Quoted by James, Psychology. Vol. I, p. 665. 
the same matter, casually attended to and not thought about, would have stuck in his memory no better at the end than at the beginning of his years of heroic self-discipline. He had acquired a better method of noting and recording his experiences, but his physiological retentiveness was probably not a bit improved. ${ }^{1}$

Again, as to the memorizing of facts by actors, Professor Jamcs says:-

What it has done for them is to improve their power of studying a part systematically. Their mind is now full of precedents in the way of intonation, emphasis, gesticulation; the new words awaken distinct suggestions and decisions; are caught up, in fact, into a preëxisting network, like the merchant's prices or the athlete's store of records, and are recol:ected easier, although the mere native tenacity is not a whit improved, and is usually, in fact, impaired by age.

It is a case of better remembering by better thinking. Similarly when schoolboys improve by practice in ease of learning by heart, the improvement will, I am sure, be always found to reside in the mode of study of the particular piece (due to the greater interest, the greater suggestiveness, the generic similarity with other pieces, the more sustained attention, etc., etc.) and not at all to any enhancement of the brute retentive power. ${ }^{2}$

It still remains to consider the extent to which mere repetition or drill should be prominent. Some help toThe promi- ward an answer may be found in certain renence of cent investigations into the value of drill, and drill. in certain recent improvements in method.

Spelling, arithmetic, and language being the subjects that have required the largest amount of drill, these will be the principal studics here considered.

' James, Psychology, Vol. I, p. 666.

I Ibid., p. 604. 
Dr. O. P. Cornman in his Spelling in the Elementary School recounts some very interesting investigations into the value of drill in that subject. In two schools, each containing the usual eight grades, the use of the spelling book and home lessons in the subject were abandoned for a period of three years. At the same time the period which had been devoted to studying and reciting in spelling in school was omitted from the school program, making the mastery of spelling entirely an incidental matter. The results thus obtained were then compared with the results previously obtained in spelling in those two schools, and also in a number of other schools that devoted from ten to fifty minutes daily to spelling. The conclusion reached was that "the spelling drill as at present administered throughout the country adds little or nothing to the effectiveness of the mere incidental teaching of spelling "; ${ }^{1}$ or, again, that it "is of so little importance as to be practically negligible." 2 This result may have been due to a considerable extent to poor texts in spelling and to the ineffective methods of drilling used.

A large portion of the time spent on arithmetic in the first six grades is usually occupied with drill. Some schools devote a full fifth of their time to this study, thus making the drill in arithmetic very prominent. It is commonly supposed that so much repetition greatly improves the results. Yet, according to investigations undertaken by Dr. C. W. Stone, "a large amount of time spent on arithmetic is no guarantee of a high degree of efliciency. If one were to choose at

'Cornman, Spelling in the Elementary School, p. 66.

- Ibid., p. 65. 
random among the schools with more than the modian time given to arithmetic, the chances are that he would get a school with an inferior product; and, conversely, if one were to choose among the schools with less than the median time cost, the chances are about equal that he would get a school with a superior product in arithmetic." 1

Such conclusions as these give ground for suspicion of any very large amount of drill, even in these drill subjects; it involves too much waste. One important reason for the waste is the fact that drills usually are uninteresting or lack motive, and on that account attention lags, until one learns slowly or not at all. It is true that one can and ought to will to do certain necessary things. But even adults are so made that an act of will insures close attention for only a moment at a time, then attention lags again; sustained attention is assured only when the work undertaken is subordinated to some real interest, so that attention is involuntary.

Recent advances in method of studying language offer further suggestions in regard to the advisable prominence of drill. In the study of modern languages, for example, it used to be the custom to depend largely upon drill for the mastery of a vocabulary, and of the forms of the verbs, nouns, and other parts of speech. Likewise in teaching children to read English it was customary for much drill on new words to precede the actual use of such words in reading. Now much more rapid progress is effccted both in modern languages and in our vernacular by greatly increasing the amount

1 Stone, Arithmetical Abritities : Some Factors Determining Them, p. 62. 
of matter read and decreasing, correspondingly, the quantity of drill. The suggestion, therefore, is here made that not only the extensive drills of former times involve much waste, but also that they are probably unnecessary. Further than that, since a closer and more abundant association of facts has already elimi nated a large amount of drill, it may be expected that the good work of elimination will go on much farther. Very extensive drills in the future, therefore, do not promise to be a recommendation for the teacher who is responsible for employing them; they will be the resort of those persons who lack the energy or ability to do a higher kind of work, that is, to think.

We need not congratulate ourselves, however, that drills will ever disappear entirely; some drill, like some. punishments for children, will probably always be in place, and a considerable amount is still necessary. We must expect a fair amount because we shall probably never be bright enough to make the associations of ideas fully take the place of review by drill. In particular it must be remembered that those portions of our knowledge that we expect to use daily must become second nature to us, or be reduced to habit; that means that many facts must become familiar enough to be reproduced instantly without effort. That is the case, for example, with the multiplication table. Thoughtful association is only a good beginning in the formation of habits; repetition also has a very important place, which must be continued until the knowl. edge stands at our command "without thinking." 
THE ABILITY OF CHILDREN TO MEMORIZE BY THINKING

No one doubts the ability of children to memorize; that is the one thing that they have always been known The crooial to be able to do. One argument for teaching question. them foreign languages as well as many things unintelligible to them now, but possibly useful later, is that they can learn them so easily. That is the ground also, on which much verbatim memorizing of literature and Scripture, that they could not hope soon to appreciate, has been required of them.

The crucial question in this connection, therefore, is not, "Can children memorize?" but rather, "Are they capable of more than mechanical memorizing, or learning by rote? Can they think well enough to memorize largely through association of ideas, like older persons?"

The answer to this question has already been practically given. It has been shown that children can Ohildren's conceive specific purposes; can supplement ability to
memorize by the thought of authors; can measure the thinking. relative importance of facts well enough to establish fair organization among them; and can judge the soundness and general worth of statements. They not only can do these things, but they normally do do them; their present daily lives constantly call for these several kirids of mental activity.

These several factors, however, largely compose the activity of associating ideas with one another, or of thinking. Children can, therefore, memorize through thinking, just as naturally as adults can.

While very extensive drills are perhaps generally recognized as questionable in the case of adult students, 
there is a tendency to regard them as entirely proper in childhood. And the helplessness of children - in spite of frequent little rebellions on their The desirablo part - prevents the establishment of a con- promininenco of trary conviction. We admit that a considera- ing in childble amount of drill is guaranteed to children through the three R's and spelling, whether any one approves of it or not. But what about much beyond this minimum? Shall the teacher willingly increase the amount by neglecting possible associations within those four subjects, and also by requiring much memorizing of literature and facts in other subjects that cannot be appreciated at the time? Or shall she regard the close association of ideas as the normal activity of children and a great quantity of drill and rote learning as at least verging on the abnormal and the unhealthy? These are questions of great importance in the instruction of children.

It seems safe to affirm that, in general, there are the same reasons for regarcing drill and thoughtless memorizing as an evil - though to some extent a necessary one - in childhood as in adult life. Indeed, if there be any difference, the evil is probably greater in child. hood, for drill furnishes no nourishment to childhood, while that is peculiarly the period of growth, when abundance of nourishment is most important.

Granted that the ability of children to memorize things that do not brighten the eye is striking, it must be remembered that their mental and moral growth in numerous directions is also striking. It is far more important that their spiritual welfare as a whole be provided for - as live ideas lying within their sphere 
of experience can be made to provide for it - than that they starve themselves now for the sake of storing up material for the future. The latter plan shows a very low estimate of child-nature, and a misapprehension of the relation of the present to the future.

Aside from this, it is in the elementary school that children must mainly acquire their permanent habits of study; the methods of work there acquired will not be made over on entering the high school or college. If they there become accustomed to beginning their lessons by memorizing, and to memorizing words without appreciating their import, the chances are good that they will have the same habits later. Why not, if there is anything in habit? At least, they will have much to overcome if they reform. On the other hand, if they there begin the mastery of lessons by studying the thought, and memorize largely through the association of ideas, they are likely to continue that plan later. By thus becoming thoughtful in regard to childish matters, they give best promise of being thoughtful on larger subjects later.

In all these remarks there is no intention of making philosophers out of children; but there is a feeling of the necessity of preserving and developing their live-mindedness. Opposition to this feeling indicates that children are not expected to do much thinking even in their own sphere of experience.

PRACTICAL SUGGESTIONS FOR TEACHING CHILDREN TO MEMORIZE PROPERLY

Other things being equal, the depth and hence the permanence of impressions varies as the degree of atten- 
tion varies. For example, if a child's whole attention is given to a name, or a date, or the spelling of a word, he may retain it in memory after having 1 . Need of heard it only once; otherwise it may have $\begin{gathered}\text { concentra- } \\ \text { tion of atten- }\end{gathered}$ to be repeated several times.

tion, and

Children, however, easily fall into the mectring it habit of dividing their attention between work and play, so that half of their time is wasted; yet they labor under the impression that there is much virtue merely in spending time on lessons.

Divided attention is not confined to children, either. It is frequently observed that announcements made before large schools are never understood rightly by all, simply because there are always some who are thinking partly of something else. A certain professor of English in one of our large universities has for years becn in the habit of dictating the following directions, with illustrations, to his students beginning composition: "Fold the paper lengthwise from right to left, leaving the single edge to your right hand. Endorse on the first three lines. Do not use abbreviations in writing the date. Omit all punctuation, or, if you punctuate, use commas at ends of lines and after date of month." In classes ranging from forty to seventy-five persons, as many as 90 per cent have failed to follow these directions. What better proof is needed of common laxness of attention?

To remedy this evil among children teachers would do well to refer much less to the time spent in study and much more to the kind of attention given. More than that can be done. Children are often directed to "pay close attention," or to "concentrate their attention 
fully," sometimes without comprehending the meaning of the command, and more often without knowing what steps to take in order to obey. Both difficulties can be partially overcome by fixing time limits to tasks, even in the lower grades. For example, two minutes can be announced as the limit for reading a half page in the second reader. Under that stimulus the children will do their best; and when they have undergone several such tests successfully, reference to these tests will explain what is meant by close attention; reference to their successes also will instill confidence that they know how to give close attention, for they can do again what they have already frequently done. The dawdling that is so common among children is partly due to lack of an ideal, and such time limits should be resorted to somewhat frequently in order to keep the ideal fresh in mind, as well as to cultivate confidence that the ideal can be realized. Military governments often obtain undivided attention to a remarkable degree, showing that attention is a thing that can be cultivated in some directions. Similar determination tosecure it should be exercised in the school, only the pressure applied should be of a different kind.

College students are not the only ones who gulp down facts, hold them undigested for a few hours, and 2. Danger of then disgorge them. Many children study and its avoidanoe. daily recitations, as is shown by the fact that they retain facts a very short time, even though they seem to know each day's lessons. It is true in spelling, for example, and in geography and history. It is true likewise in verbatim memorizing of poetry and Bible verses on Sinday mornings. 
The general remedy for this evil is found in the requirement that ideas be associated, and as far as possible enjoyed, before any special attempt is made to memorize. This is most difficult in spelling; but some associations are possible there, as suggested (p. 168). It is comparatively easy in geography and history, after children have received some instruction as to method. It is impossible in verbatim memorizing of literature, if selections are made that are far beyond children's appreciation. But there is no need of such selections; there are plenty of poems and Bible verses that can be at least partly understood and really enjoyed by very young people, and it is that kind that should be choser.

Naturally the thinking that is thus required cannot be expected in large amount from the younger children, for they will feel and enjoy much more than they can analyze. Also, it should, perhaps, be expected very little in memorizing that is entirely voluntary, as when a poem is learned by some child simply because he likes it. But memorizing that is a part of school work, and therefore a part of serious study, should be undertaken in this way, because it is the right way. The number of associations, too, is not so important as the method of study that the child gradually leading ohiladopts.

dren to memorize

How children study in preparation for the through recitation will depend upon how the recita- steding in tion itself is conducted, upon what is first called for there and what is most emphasized. The reason that memorizing constitutes the main part of study, not only in the elcmentary school, but in the high school and the college, is that reproduction has 
been the principal thing required in the recitations all along the line. It is the character of the recitation, therefore, that must first be changed.

The questions that are considered in the recitation are the factor of greatest influence. If the children find that the teacher's questions usually begin with what, or where, or when, thereby merely calling for direct reproduction of the substance of text, she may talk ever so much about right methods of study, but they will memorize before thinking and without thinking.

Very many of the questions should test not so much knowledge of the text as the pupil's way of treating the text. The spirit of the teacher's usual general question should be, How have you associated or related these facts? And some of her detailed questions might well be: What object do you see in studying this topic? What statements here need filling out, and how have you done it? What are the most important ideas here? Or the most beautiful? How do these statements remind you of others that you already know? Have you found any of these statements questionable? And, if so, how? Thus the conduct of the recitation will show the kinds of questions that must be expected. Gradually the teacher should refrain from putting the questions herself and leave that to the pupils. That becomes very important as they mature; for how otherwise will they learn to study alone?

The questions should include higher forms of comparison far more than is customary. Much of the study of geography, for example, should consist of the comparison of countries with one another. Poems should be compared and grouped. The Children's Hour, Snow. 
Bound, Evangeline, and the parable of the Prodigal Son taken together reveal a conception of home life that is not obtained by the study of literary selections in an isolated way. So Burke's three addresses, On Taxation, in 1774, On Conciliation, in 1775, and Letters to the Sheriffs of Bristol, in 1777, throw light on one another and form a unit. Such comparisons continually review original facts, and in that way eliminate much customary drill. Preparation for such comparison in the study period properly puts mere memorizing far in the background.

The cross lights that different studies throw upon one another through careful correlation - as when literature and history deal with the same topic - are valuable in a similar manner and should be included in the questions that are considered.

Finally, when the text is so intolerably dull that it discourages reflection, instead of stimulating it, - as is not seldom the case, - it very often lies within the teacher's power to accomplish her objects mainly by the use of other books that are supplementary and for reference. This she should do without hesitation. Much routine drill on geography text, for instance, can be avoided by using geographical readers. Pointed questions, of course, would be in control here as in other cases.

These various thought questions, coming from teacher and pupils, should not be reserved until toward the close of the recitation, to be put then if any time is left. That defeats their object. They should occupy the time from the beginning of the period; it is the memory questions that should follow, if there is time and if they are 
needed. The order in time for the thinking and the special attempt to memorize is one of the most vital matters, and it is highly important that the recitation itself stand for the order that is expected in private study.

While it is the rign of a weak mind to give great prominence to drill, some drill is unavoidable. There 4. Conditions are two conditions that must be fulfilled in for the best
kind of drill. sufficient motive be provided to secure very close attention. The use of motor activity may be an important aid in this direction, as when children are allowed to walk about and point in locating places in geography, to dramatize in reproducing literature, and to use sand and clay in representation of various kinds.

Emulation is a powerful motive, but has so many dangers that it should be used sparingly. 'The coöperative spirit is the kind that the school should cultivate, and heated competition does not readily lead to coöperation. There is, however, much profit and no danger in making comparisons among one's own products.

The teacher herself may be one of the most potent factors securing close attention. If she has force and has cultivated the friendship of her pupils until they are anxious to please her, her appeals to their own wills will not be in vain. If, in addition, her skill in handling a class inspires confidence, she can do much toward conducting her class through drills without waste of time. Very many drills are failures mainly because the teacher is a poor manager, not knowing how to distribute materials quietly and quickly and to assign and supervise work so that all are kept busy. The strong 
personality, however, has its dangers, also, for it may carry children through drills instead of letting them carry themselves. In the main, unless children furnish their own steam when they work with a teacher, they will have little steam to do work when left to themselves.

The healthiest provision for motive in drills is found in the recognition of a given drill as a necessary step toward the accomplishment of some already greatly desired end. A child will willingly practice mixing colors in order to obtain a certain shade, if he is much interested in painting a certain kind of calendar. And he will gladly drill upon the rendering of a poem, if he is anxious to surprise his mother with it on her birthday. Such subordination of uninteresting tasks to larger purposes is highly educative, and no one has found the limit to which it can be carried.

The second condition of successful drills is that they be short. Even under the most favorable circumstances children cannot long remain alert on subject-matter that lacks intrinsic interest. In brief, therefore, drills to be effective must be made sharp by the presence of motive, and must be short. 


\section{CHAPTER VIII}

THE USING OF IDEAS, AS A SIXTH FACTOR IN STUDY

The student has accomplished much when he has discovered some of the closer relations that a topic The indefi- bears to life; when he has supplemented the niteness of thought of the culthor; when he has deterin stady. mined the re'ative importance of different parts and given them a corresponding organization; when he has passed judgment on their soundness and general worth; and when, finally, he has gone through whatever drill is necessary to fix the ideas firmly in his memory. Is he then through with a topic, or is more work to be done? Digestion of food is likewise a long process, the food having to be acted upon in various ways in the mouth, the stomach, and the intestines. But with food there is always a certain end to be reached, called assimilation, which is the actual changing of its nutriment into the solids and liquids of our bodies. Is there a similarly definite end to be reached in the study process?

It must be admitted that while we can define this end somewhat sharply in words, it is very difficult to know when it has been actually reached. Many a business man has felt convinced that he understood a certain business project perfectly, until the outcome has proved the contrary. Business failures are largely due to such deception. Even highly educated men are often surprised at their want of mastery of questions that they had supposed to be fully within their grasp. 
Socrates spent much of his time bringing such surprises to the promising but overconfident young men of Athens. Robert Y. Hayne, the distinguished champion of nullification, no doubt experienced such a surprise when Webster delivered his great speech on that subject. The actual mastery of subjects is perhaps never complete; it is only relative. Even a child may have as good a grasp of one subject as a philosopher has of another, and each may be deceived in regard to the extent of his understanding.

The common ignorance as to how much study is necessary for the mastery of knowledge is suggested by the common ignorance as to how much work is necessary for the assimilation of food. It takes from three to five hours for food that has been eaten to get beyond the stomach, and people ordinarily assume that the assimilative process is pretty well completed by that time. The fact is, however, that it is then only well begun; for it requires from ten to twelve hours to dispose fully of a meal, and most of the work of digestion takes place after the food leaves the stomach. While the assimilation of knowledge is what the student is supposed to aim at, how much that involves is even less understood.

In the digestion of food our organisms provide for themselves, so that we do not need to worry greatly over some ignorance of the process. But our Importance responsibility in the assimilation of knowl- of as great edge is much greater, for that does not go on in the enduninterruptedly even while we sleep; it will possible. he carried only so far as we have the energy and insight to take it. 
That being the case, it is very easy for one to stop too soon in the study of a topic. For instance, when a lesson in history has been only memorized, the digestive process has been carried little further than physical digestion has been taken when food reaches the stomach. That is, it is barely begun. Yet very many young people stop near this point, and they sometimes even take credit to themselves for getting so far.

We might add comprehension of the thought to the work of memorizing and still be far from the end. We can have comprehended and memorized the Beatitudes, for example, and be as free from any effect from them as the proverbial duck's back is from the effect of water. We can pass good examinations in psychology and logic with the same absence of influence. That certainly does not signify assimilation. Assimilation means the spiritual nourishment that is received by making new thought homogeneous with one's own thought, by making it an integral part of one's self.

Remembering how young people generally study, it seems probable that many of them spend a large part of their time providing for nourishment that they never get. 'They do a lot of hard work collecting the raw materials of knowledge without working them over so as to reap either the pleasure or the profit intended. Here is where some of the waste in education lies.

It is highly important, therefore, that the student reach as definite as possible a conception of the endpoint to be attained in study. Although the meaning of assimilation may not be perfectly clear, a few of its characteristics at least may be distinguished, so that we can feel some ccrtainty as to how far we have got 
in the process, and have some notion as to how much more must be done in order to reach the approximate goal.

Study of the useful arts, such as the various trades, consists of two distinct parts. On the one hand, facts must be mastered that pertain to the nature The endpoint of materials, to methods of using implements accepted in or tools, and to plans for construction. In mastery of cabinet-making, for example, the qualities of woods and paints, the rules for using the saw, plane, and chisel, and the various ideas governing designs for household furniture must all receive attention. In other words, a considerable body of theory must be acquired.

On the other hand, this theory must find application under particular conditions; a table must be made out of certain materials, with certain tools, according to a certain design. This also involves much thinking; but, in addition to all that, there is execution of theory, called doing or practice.

There is, further, a definite relation between these two parts, for the theory is merely a means to an end. What is wanted is a good product, and the theory is valuable to the extent that it affects the product. The useful arts, as studies, stand, therefore, both for theory and for the application or use of theory, and the latter is the goal. No one thinks of pursuing any one of the trades without including the use of his knowledge in practice as the culminating part of his work.

To what extent should other branches of knowledge resemble the useful arts in their combination of knowl- 
edge with the use of knowledge? Should the use of ideas be their goal? The answer must depend upon The endpoint one's conception of the purpose of life in in the stady general and, therefore, of education.
of other

subjects. Abilities of various kinds in the animal world find their purpose not in themselves but in adaptation to environment. Fear on the part of the rabbit, for instance, increases its speed in running, and in that way protects its life. The bear's strength aids in repelling its enemies, and the intelligence of both animals finds its purpose both in protection against enemies and in finding food. Living, in the case of animals, thus means getting on, and any ability, whether physical or intellectual, is of importance to the extent that it makes such getting on suecessful. The endpoint among animals, then, is the use of their powers in effecting adaptation to their environment.

Man's environment is far broader than that of animals, being moral and spiritual as well as physical. But his relation to it is substantially the same; for his success is likewise measured by the degree of adaptation accomplished. Human abilities are not mainly valuable in themselves, but rather as means in securing fuller adaptation, "complete living"; that is, they are valuable for their use.

The end to be attained in education is in full harmony with this idea. The object of education most emphasized in recent years is efficiency, which means power to accomplish. It presupposes a good degree of intelligence, the more the better, but it goes beyond that; for an efficient person is one who does things. Knowledge without the ability to apply 
or use it leaves one theoretical, which is a term of reproach.

The various subjects of instruction recognize the necessity of use very plainly. Painting and music, for example, contain, each, a large body of theory. They also include an abundance of practice, a practice, too, that centers in the betterment of man's condition. Literature deals largely with ideals, presenting the theory of living. But this theory is valuable chiefly as a guide to conduct. The student of literature who professes admiration for its ideas without applying them to himself has derived only a small part of the benefit from it that he should. Literature is like religion in this respect. The latter emphasizes the worth of insight into divine truth and of faith in God; but both this insight and faith are to find their fruitage in conduct. " Pure religion and undefiled before God and the Father is this," says the apostle, "to visit the fatherless and widows in their affliction, and to keep himself unspotted from the world." 1 Similarly, a study of philosophy that does not end in affecting our own philosophy of life, and thereby our conduct, has been unsuccessful, even though examinations have been successfully passed.

Pure science is knowledge that has been proved and properly organized; and it is highly desirable that specialists devote their lives to its further development. The main reason, however, is that its applications may finally be more abundant; and science used for the purpose of education must recognize the relation of such knowledge to man as one of its integral and prom.

1 James 1, 27. 
inent parts. So long as efficiency is the recognized purpose of education, there is little excuse for a young person's studying science apart from its applications, or pure science. There is some profit in it, but there is more profit in something better. That kind of study should be left to the specialist.

Much has been said in times past about art for art's sake, science for the sake of science, and knowledge for the sake of knowledge; but these are vague expressions that will excite little interest so long as the worth of a man is determined by what comes out of him, by the service he renders, rather than by what enters in. Other branches of knowledge used for educative purposes, therefore, resemble the useful arts in the recognition of their bearings on man, their actual use as the goal in their study.

It might be unnecessary to emphasize this matter were it not that this conception of study has been Why the reached only after long development and is asing of still actively opposed. The old Greeks stood knowledge for a very different idea. To Plato, the use $\underset{\text { ptady noeds }}{\text { point in }}$ of the intellect for practical purposes was subemphasis.

ordinate and almost disgraceful. The summation of existence was to be found in reflection, and the ambition of the educated man was to escape from the concrete world, in order to live in the world of abstract truth. Many of the monks of the Middle Ages resembled the ancient Greeks in this regard, desiring to separate themselves as completely as possible from society for the sake of the contemplation of spiritual matters. Reflection, contemplation, was thus not a means to an end but an end in itself, and the thinker 
or dreamer, rather than the efficient man, was the ideally educated person.

That goal is now condemned for its extreme selfishness; we want men and women as citizens who are glad to identify themselves with their feilow beings and ambitious for efficient service among them, not those who conscientiously ignore the world. Yet there are still plain tendencies in this direction, as is seen in the fact that an education that is liberal and cultural is often contrasted with one that is useful as being of a higher order. "That alone is liberal education," says Cardinal Newman, "which stands on its own pretensions, which is independent of sequel, expects no complement, refuses to be informed (as it is called) by any end or absorbed into any art, in order duly to present itself to our contemplation." ${ }^{1}$ Liberal education is something which "is desirable, though nothing come of it"; "worth possessing for what it is, and not merely for what it does." Art for art's sake, rather than art for man's sake, would thus represent the true spirit of a liberal college course, in the estimation of this author; the admission of service to mankind as a prominent purpose, particularly as its goal, would deprive it of its liberal character, and in the same degree expose it to condemnation.

That is strange doctrine indeed. Liberal is originally a term opposed to narrow and restricted, and a liberal education might properly be contrasted with the very narrow bread-and-butter kind that aims at the mastery of art without theory. But how the restriction caused by the presence of worthy specific purposes of a thou-

1 Scope and Nature of University Education, p. 135. 
sand kinds is inimical to the broadening effects of study and to its general value is difficult to comprehend. The hypothesis guiding a scientific investigation narrows the work only enough to give it point, and a well-chosen particular aim will have the same effect on any study.

Further than that, the consciousness in advance that any conclusions reached must be tested by actual conditions has only a good influence by nerving us to do our best; and the actual test is of value in informing us as to the degree of soundness of our ideas. All persons must be shocked by the misfit between what they supposed to be true and what they find by trial to be fact, before they will waken up and do their best thinking. The superabundance of advice that bachelor uncles and maiden aunts offer in regard to the rearing of children is due to the fact that their theory has not been refined by practice. It is the direct contact with the world in the use of knowledge that reveals the latter's real significance and that converts it into experience; and it is only the knowledge that becomes experience that really counts in education.

Again, in arguing the question of allowing normal schools to grant degrees, a certain well-known educator declares: "Where ability to exercise a practical art is concerned, degrees are or should be valueless. They should be restricted merely to the position of evidences of culture. For this reason normal schools should not grant degrees." 1 Our better normal schools - which are the only kind that might be expected to grant degrees - give instruction in literature, history, geog-

1 Year Book of National Sosiety for Scientific Study of Education, 1905, p. 93. 
raphy, fine art, etc., the same as the degree-conferring colleges. To these subjects the normai school adds the history of education and the principles of education, which are presumably harmless so long as they are not applied, and they usually are not. There remain then the subjects that involve practice, such as special method courses, applied psychology and practice teaching; these must be the baneful studies. The good fouryear normal school course presumably requires as much thinking and other strenuous work as that of the college. But the presence of the last group of subjects signifies that this study is to culminate in the use of knowledge; and there's the rub. It is this latter fact that vitiates the course and precludes the cultural effect that a college course insures.

If this is a proper interpretation, it is, indeed, strange doctrine. One can understand how carpentry might not have as great a cultural effect as literature; but one would think that, if the untested and therefore halfdigested thoughts of literature have a certain cultural effect, the same thoughts might have a fuller refining influence if their meaning and force were more fully realized in the way their use in life might secure their realization; and one would think that the same might hold in regard to any subject.

The difficulty is that there are two opposing notions of culture. On the one hand there are persons who conceive culture to be a refinement that is directly endangered by contact with the realities of life, for instance by participation in local politics and other social contests, and by such practice of charity as must be accompanied by physical exertion and bad smells. 
Culture is, to them, the name for that serenity and loftiness of mind that can be attained and preserved only by keeping a safe distance from the maddin crowd; and the cultured man is pictured by them as sitting in a comfortable chair, preferably with a book in his hand, and rapt in meditation on lofty themes.

On the other hand there are those who conceive that culture - if more than a veneer - is a refinement that can be attained only by direct participation in social life. Such contact with the world may bring embarrassment, temptation, and failure, as well as their opposites; but all of these, instead of debasing, are the very experiences that purify and make gentle; they are the fire without which the refining process could not take place. Culture means to these people the ennobling effect of such actual struggles upon a person's whole outlook on life and upon his way in general of conducting himself; and the cultured man is pictured by them as in action, even with his sleeves rolled up, engaged in the accomplishment of high purposes.

Culture is so valuable a quality that each person must determine for himself which of these two conceptions of it is sound, before he can decide whether the using of knowledge is worthy of being made the goal in study or not.

In declaring that the using of knowledge is the proper endpoint in study, it is important that the breadth of Breadth of meaning of the term use be held in mind. meaning of
the term "nse."

livelihood covers only a small part of what is included. A man is using his knowledge when he is getting inspiration from poetry that he has memorized, 
or drawing new conclusıons from previously acquired facts. He is using it, further, when he entertains his family with it, or by its means makes himself otherwise agreeable to them. He is using it when it is made to count in the rearing of children, or in the performance of the manifold duties of membership in a community, or in worshiping Grod. In short, it is being used when its content is turned to account in the accomplishment of purposes, whatever they be, or is made to function in one's daily adaptation to physical, moral, and religious environment.

The student should continually carry in mind the fact that facility in the use of knowledge is the end of his study, and the only reliable proof of stages in tho mental assimilation. It is a long road, how- sssimilation ever, to this goal, and any clearly marked edgo. stages that must be passed through in reaching it should be well known, since they will help the student greatly to keep his bearings and preserve his courage. Here are given a few such stages.

First, under the influence of as full a sympathy with the author as possible, one obtains a fair comprehension of the thought. Much supplementing ${ }_{1}$. Collection may be necessary to this end, as well as care- of crude maful consideration of relative values. This terials. may require one or several perusals of the thought, according to the difficulty of the subject and to individual ability. Proof of comprehension may be given by the expression of the thought in one's own words, either from memory or with the book open. Such study is a comparatively passive kind of work, calling for subordination of the student to the author, and 
amounts to litile more than a collection of the crude materials of knowledge. The corresponding stage in the assimilation of food would be, perhaps, its preparation and mastication.

"What am I getting from this author?" or "What profit is this material bringing me?" is the principal 2. Selection consideration in the second stage. With the and reor-
ganization ganization
of the profit- student recalls or further defines any specific able portion of these materials. purposes of the study that may have occurred to him; under their guidance he casts aside as non-essential much of what is presented, and centers his attention on those ideas that seem to have real value for him.

These he further re-words, in order to determine their very essence, and also carefully weighs. In addition he reorganizes them, unless their original organization appears to him peculiarly fitting. The self must enter so fully, in true assimilation, that neither the author's wording nor his organization is likely to prove satisfying. One will seldom quote another's words or follow his order of treatment when presenting a topic that has been really digested. Not seldom the last point made by an author will become the first in the student's mind, showing how radical the reorganization may be.

This step, requiring much discrimination and exercise of judgment from the learner's own view-point thereby entirely subordinating the author to the student - requires a high degree of independence. It might be called the profit-drawing stage, or the stage in which the part that promises profit is extracted. The corresponding step in the assimilation of food is what is 
iechnically called digestion, which is the separation of the nutritious from the waste elements, or the conversion of food into chyme, preparatory to assimilation.

Even after a person has determined what portion of the crude materials can be of value to him and has reorganized it in a satisfactory manner, it may 3. Translastill seem somewhat strange to him,- - another portion into person's thought rather than his own. This experience. is an indication that more work must be done, for assimilation of knowledge, like assimilation of food, requires the full identity of the nourishing matter with the self. "A thought is not a thought," says Dr. Dewey, "unless it is one's own." 1

The student may thus far have reached nothing more than a consciousness of facts by themselves, while consciousness of them as a part of the self is a much more advanced stage. In order to reach this last point the student may find it necessary to review the thought a number of times in various ways, stating the pertinent questions and their answers. He may also practice making the main points with force, using them either under imagined or under actual conditions. In such a manner they are tossed about, overhauled, and restated, until a much closer and more abundant association of the ideas with one another and with the past experience of the learner is secured; he warms up to them until he welds them to himself.

As a result a sense of ownership of the knowledge is finally established, a condition in which one largely loses consciousness of the original wording and, perhaps, even of the original source of the thought. The

1 School and Society, p. 66. 
ideas now seem simple and their control easy, and one enjoys the feeling of increased strength due to real nourishment received. The feeling of ownership is fully justified, too, for, no matter where the thought may have originated, it has been worked over until it has been given a new color and has received one's own stamp, the stamp of self. This is the step in which the profitable matter extracted from the crude materials is translated into the learner's own experience; it corresponds to that part of food assimilation in which the nutritious portion of our food, secured through digestion, is made over into the bone, tissue, and muscle of the body.

While these steps overlap more or less, each represents a distinct advance. Study of many topics may be 4. Forma- allowed to stop at this point, although it tion of babit. should be understood that assimilation is perhaps never complete, and that the appreciation of a great thought, together with the ability to use it, may continue to grow from year to year. On that account one should expect to review from time to time, by use and otherwise, the valuable experiences that have already been "mastered" through study.

Certain portions of knowledge, however, cannot be left as properly under our control when they have been translated into experience as described. Study has thus far brought the student only to the ability to use his knowledge with fair ease consciously, and extensive portions of knowledge have to be used quite unconsciously; they must not only become truly ours but they must become second nature to us. In all the trades, for example, the many facts about the use of materials and 
tools, etc., must be applied "without thinking" before skill is attained. The same holds in the fine arts. In grammar, knowledge of the rules must be carried over into habit before one's speech is safely grammatical. Knowledge of the political and moral truths contained in history and literature must likewise be converted into habit before proper conduct is assured. In learning how to study one must fall into the habit of associating ideas, weighing values, and carrying points, unconsciously, before the subject is properly mastered. "Ninety-nine hundredths, or, possibly, nine hundred and ninety-nine thousandths of our activity is purely automatic and habitual," says Professor James, "from our rising in the morning to our lying down each night. Our dressing and undressing, our eating and drinking, our greetings and partings, our hat-raisings and giving way for ladies to precede, nay, even most of the forms of our common speech, are things of a type so fixed by repetition as almost to be classed as reflex actions." Professor James is here referring mainly to motor activity; but habit is evidently a large factor in all phases of life; and, while many of the valuable thoughts assimilated by study probably do not need to be applied unconsciously, it is safe to say that prominent portions of most branches of knowledge must be converted into habit, or become second nature, before we can be said to have reached the desirable endpoint in their pursuit.

The extent of this last advance, in which experience becomes habit, is indicated by the wide difference that exists between using a correct form of speech consciously and using it unconsciously, for even years of

1 James, Talks to Teachers, p. 65. 
trial may intervene between the two. Repetition by use, under as nearly natural conditions as possible, must be the principal means of getting through this fourth step. But such practice should be influenced by certain very important precautions stated by Professor James. He has in mind primarily the formation of moral habits in his suggestions, but they apply in large measure also to the formation of other habits.

1. "In the acquisition of a new habit, or the leaving off of an old one, we must take care to launch ourselves with as strong and decided an initiative as possible. Accumulate all the possible circumstances which shall reinforce the right motives; put yourself assiduously in conditions that encourage the new way; make engagements incompatible with the old; take a public pledge, if the case allows; in short, envelop your resolution with every aid you know."

2. "Never suffer an exception to occur till the new habit is securely rooted in your life. Each lapse is like the letting fall of a ball of string which one is carefully winding up; a single slip undoes more than a great many turns will wind again."

3. "Seize the very first possible opportunity to act on every resolution you make, and on every emotional prompting you may experience in the direction of the habits you aspire to gain. It is not in the moment of their forming but in the moment of their producing motor effects, that resolves and aspirations communicate the new "set' to the brain." 1

It is evident that real assimilation of knowledge is

1 James, Talks to Teachers, pp. 67-70. See also James, Psy chology, Vol. I, Chapter IV, "Habit." 
a very complex process, requiring a great amount of time and labor. "And be assured, also," says Ruskin, "if the author is worth anything, you The time will not get at his meaning all at once -- and labor nay, that at his whole meaning you will not real assimifor a long time arrive, in any wise." 1 Ruskin knowledge. is here doubtless referring mainly to insight into the thought; but, as has been shown, a point is not assimilated when one merely sees it clearly; insight into an idea usually precedes experience or ownership of it by a long interval; and the latter generally precedes habit by another long period.

We are familiar with these facts as applied to mechanical subject-matter, such as the multiplication tables and forms of discourse. We recognize that we must come back to these over and over again if we are to obtain automatic control over them. Yet we act as though there was ground for assuming that the more fertile ideas, which are to be reduced to habits of thought and conduct, require less energy and patience. There is no justification for any such assumption; it would seem more reasonable to expect to devote more time to the latter, rather than less.

Probably not much knowledge acquired either in school or college is carried through the three or four stages named above; but it is also true that comparatively little of that knowledge becomes a source of power, and it is safe to assume that the one fact is at least part explanation of the other. It is highly important, therefore, that the student become early reconciled to the fact that the real mastery of knowledge is a long and laborious process.

1 Ruskin, Sesame and Lilies. 
CHILDREN'S CAPACITY TO INCLUDE THE USE OF KNOWL. EDGE AS A FACTOR IN THEIR STUDY

One of the most attractive baits that can be offered to a discontented, restless child is to propose that he The natural tendency to carry ideas into execntion.

do something; and having received such a proposal, his impatience over delay in its execution shows how closely his nature links doing with thinking and planning. The games of children call for comparatively little study; yet children's desire to be acting is so dominant that they can scarcely wait to learn the rules before beginning to play. An eight-year-old girl who had been studying at home'with her mother complained to a friend, "Mother does n't have me do anything! She has had me read and spell and learn arithmetic, and that 's all." It is partly because we have come to appreciate, in recent years, this pressing need of doing, that we have been reforming the elementary school by introducing manual training, cooking, and sewing. Onc of the early surprises and disappointments of children produced by adults is the failure of the latter to carry into practice plans that they have heen heard to make, and ideals that they have professed to admire. Having set up specific aims, such as were suggested in Chapter III, children expect to realize them in practice, because instinct tells them that the value of theory is found in its application. That is the reason that they so often inquire, "What is the use of it?" in connection with their study at school, and that they disapprove so heartily of any project that won't work. 
Living means substantially the same thing with children as with adults. They have the same general environment as adults; they study the same large fields of knowledge; and they likewise tendency in find the object of education in efficiency. edncation.

There are the same reasons, therefore, as in the case of more mature students, for making the using of knowledge the aim of their study.

The prospect of applying knowledge is a source of motive for all grades of learners. I have never seen a class more attentive to every detail of its procedure than were a certain group of girls who felt under obligations to eat the stramberry jam that they were making at school. Furthermore, the actual doing of the things imagined is a great clarifier of thought for children, as is shown in the very extensive use that the school makes of motor activity in numerous studies, and particularly of dramatizing in literature and history. It is also the most natural test of the practicability of the plans of children, and on that account a means of developing their soundness of judgment. This is well illustrated by a certain six-year-old girl who was making a doll's dress. After working in a very absorbed way for a time she impatiently exclaimed, "I won't have any lace in my sleeves!" "Why not?" asked one of her playmates. " Cause I can't see any way to put it on," was the reply. One of the chiet reasons why the experience of children outside of school is so educative is the fact that their ideas and plans are thus continually corrected by trial.

Bricfly, therefore, it is normal for children to carry ideas into execution, and there is the same need of it 
as in the case of adults. It might be added that the peculiar ease with which children form habits furnishes a special reason why the conversion of ideas into habits should constitute a very important part of their study.

PRACTICAI SUGGESTIONS FOR TEACHING CHILDREN TO MAKE THE USING OF KNOWLEDGE A PART OF THEIR STUDY

While all of one's knowledge should become familiar enough to form experience, some of it should be worked 1. Special over until it is translated into habit. Facts recognition
of those faots of this latter kind should be clearly distinthat shoold buished from others, in order that they may into habit, reccive the special attention due them. The moral truths of literature and history belong plainly to this group. But there are many others, such, for instance, as the picturing of places upon the earth's surface rather than upon maps; the association of places with their latitudes; in the case of such a live problem as protective tariff, the association of the main facts in its history; the association of our leading transportation routes with the progress of our country; looking to the evidence in considering the value of statements; and the accurate and pointed wording of questions and answers.

The habits that should be insisted upon in arithmetic are pretty well agreed upon, such as neatness of written work, accuracy of oral and written statements, the statement of a problem in one's own words, in case the meaning is at all doubtful, and the use of the approximate answer as a guide in finding the exact answer. But only when the great importance of such 
procedures is definitely recognized are they likely to receive the attention necessary to convert them into habits. If accuracy of statement were recognized as one of the very valuable habits to be acquired in literature and geography, as well as in arithmetic, much more effort would probably be put forth to establish that habit in those studies. Rules for thinking and for the expression of thought that should result in habits, like the rules of grammar, pervade all the studies, but until this fact is better established, and until the principal habits to be expected from each study are more clearly defined, somewhat as in arithmetic, there will be much wasted effort in study because important parts of the work will not be carried to completion.

The average "good" student scarcely gets beyond the first of the four stages of study outlined, i.e., the collection of the crude materials of knowledge. One very important reason for this is for one's own that he fixes his eyes too intently upon his teacher in the preparation of his lessons; he studies to satisfy her rather than himself, as though somehow the school was established for her benefit. This subordination to the teacher is shown in the attitude toward marks; many a college student, even, waits helplessly until he can learn his mark before he knows whether or not he has done well; he seems to lack any conviction of his own about the matter. The student who feels responsibility primarily to himself, and therefore bothers little about marks, is rare.

Yet the selection of that portion of the subjectmatter that promises profit, and its conversion into experience, presuppose the ability to subordinate both 
author and teacher to the self, indeed to forget about both. No teacher can direct a student just what to select, or inform him when it has become experience with him; the real student must have a self big enough to carry that responsibility alone. Weakness in this respect manifests itself very early. Many a child is so absorbed in his teacher as not to know when he knows a thing until the teacher's approval is given. In some schools probably half of the pupils ten to twelve years of age fall into such a halting, apologetic frame of mind, that they would scarcely risk a meal on the accuracy of any statement that they make. In comparison, the boy who won't study, who plays hookey on warm spring days in spite of his teacher's warnings, and who otherwise defies his teacher, is to be admired; he is preserving his individuality, his most important possession.

It is largely the teacher's fault if children show no power to discriminate the values of facts to themselves, and to determine when they know a thing. They will not always show wisdom in their selections, and will not always be right when they feel sure. A good degree of reliability in these respects is something that has to be acquired by long training. But the spirit of selfreliance is a child's birthright, and if it is lacking in his study it is because his nature has been undermined. Teachers, therefore, should take great pains to avoid a dogmatic manner toward children; they should impress upon them the fact that they are primarily responsible to themselves in their study, and that teachers are only advisers or assistants in intellectual matters, and not masters. No doubt many a college student finds it next to impossible to accomplish the second and 
third stages in study here outlined, simply because he finds no individual self within him to satisfy; it has been so long and so fully subordinated to others that it has become dwarfed, or has lost its native power to react; on that account independent selection is difficult and the sense of ownership is weak.

The principal means on which the teacher must rely for influencing children to include the using of knowledge as a part of their study, is the recitation. Since at least most of the recitation period is 3 . Mesns of Since at least most of the recitation period is infuencing necessarily spent in talking, it might at first papils to use seem that it could accomplish little in the way ${ }_{(1)}^{\text {edgi. The rea. }}$ of applying what one learns. But when it itation."

is remembered that perhaps the main use of knowledge is found in conversation and discussion, the situation need not seem so hopeless.

The great thing, then, is to see that the talk of the class room takes place under as natural conditions as serious conversation and discussion elsewhere, thus duplicating real life. We know that children may spell words correctly in lists that they will miss in writing letters, and that they can solve problems in arithmetic correctly in school that seem quite beyond them when accidentally met as actual problems outside. Such facts emphasize the truth that only actual life secures a full and normal test of knowledge, and, therefore, that the recitation secures it only to the extent that it duplicates life.

Here is seen a fundamental weakness of the customary recitation. It tests only the presence of facts in the minds of pupils, while the outside world tests their ability to use these facts, which is another and far more difficult matter, requiring true assimilation. Not 
merely that; but the customary recitation makes a sym. pathetic teacher the center of activity, she putting most of the questions, interpreting the answers, foreknowing what the children are trying to say, and deciding all issues. The children are not expected to offer ideas that are new to any one present, and they even acknowledge responsibility only to the teacher, looking toward her, addressing their statements to her, and usually endeavoring only to make her hear. All this holds largely in college recitations as well as elsewhere, - in case the students have the privilege of doing anything beyond listening to teachers there. This is an extremely unnatural situation and an inadequate test, as is indicated by the fact that the replies to the teacher's questions seldom convey clear meaning to strangers present. Such recitations secure far less individuality of thought and far less directness and force in its expression than is acceptable anywhere outside of the academic atmosphere.

The special importance of having the school periods duplicate life conditions is seen in the fact that the character of the recitation determines the character of the preparation for it. Both the child and the more mature student will ordinarily go only so far in preparation as is necessary in order to meet the demands made upon them in class. If, therefore, the recitation does nothing more than give a weak test of the presence of facts, the preparation will include little selection and reorganization of facts and little effort to translate them into experience.

How, then, should the customary recitation be modified? Let the young people come together much of the 


\section{THE USING OF IDEAS}

time for the same purpose that they have in serious conversation outside; i.e., not to rehearse or recite, but to talk over earnestly points that are worth talking over. With an assigned topic for a lesson, and with a teacher present as adviser and critic, let them compare their conceptions of what seem to them the principal facts, supplementing, rejecting, and selecting what seems to them fit. The relationship that they would bear toward one another might be the same as in any socia! gathering; but since it would be real work and not entertainment that they were attempting, attention would be centered on a definite subject and remarks would be more pointed. While the teacher would preserve order in the usual fashion, and might often come to their aid by correcting and advising, responsibility for taking the initiative and for making fair progress would rest primarily upon the children, so that they would be adopting an attitude and a method that could be directly transferred to the home and elsewhere. This is the ideal that Dr. Dewey urges in his School and Society when he says: "The recitation becomes a social meeting place; it is to the school what the spontaneous conversation is at home, except that it is more organized, following definite lines. The recitation becomes the social clearing house, where experiences and ideas are exchanged and subjected to criticism, where misconceptions are corrected, and new lines of thought and inquiry are set up." ${ }^{1}$ The recitation then becomes a period where children talk before the teacher rather than to her; and in questioning and answering one nother in a natural way they not only learn pointed.

' Dr. John Dewey. School and Society, p. 65. 
ness in thinking, but they increase and test their knowledge by using it. Thus they give witness to the truth of Bacon's words: "Whosoever hath his mind fraught with many thoughts, his wits and understanding do clarify and break up in the communicating and discoursing with another; he tosseth his thoughts more easily; he marshalleth them more orderly; he seeth how they look when they are turned into words; finally, he waxeth wiser than himself; and that more by an hour's discourse than by a day's meditation.... A man were better relate himself to a statue or picture, than to suffer his thoughts to pass in smother." 1

When many of the school periods are occupied in this way, the lessons are not likely to be prepared with the teacher first in mind; what the others will say, what they will accept and reject and enjoy, as well as what one can one's self present and maintain, will chiefly occupy the attention. The child will then be selective in his study, having a view-point of his own; and he may even practice the forcible presentation of his ideas in the privacy of his study - before "a statue or picture" if need be. Moreover, with the use of his knowledge in prospect, he will cease to rely weakly upon his teacher to tell him whether or not he knows, because he will carry his own standard.

There is no reason for assuming that all recitations should be spent in this manner, nor, perhaps, half of them; and they would not prove highly successful without training on the part of both teachers and pupils. But such a method of procedure should be common, and it should be fundamental to other study. In fact, 
it has succeeded admirably where tried by intelligent teachers.

While the recitation can furnish occasion, in the way described, for the first use of knowledge, its use must be carried much further before a fair degree (2). The of assimilation can be assured. For this school and purpose the community life of the school, in- the papil. cluding the conduct of the children toward one another in the schoolroom and on the playground, may be of great value. A teacher of six-year-old children can, by close observation, find many ways in which the morals contained in fairy tales that she tells will apply to their daily lives, and with skill she can draw their attention to the fact in a helpful manner. So, any teacher who is earnest and observant of the thought, speech, and general conduct of her pupils can find numerous needs for the ideas that have been presented in class. The community life of a school is not very much narrower than that of any ordinary social community, such as a village; and certainly in a village the uses of knowledge are without limit, if one will only find them.

If, in addition to a close watch of the school life, the teacher finds energy to study the home life of her pupils, even to visit them in their homes, so as to become acquainted with their parents and their home conditions, she can gather many more suggestions for the application of school knowledge. If she then makes mention of such uses at fitting times, and also as a part of examinations calls upon pupils to report on uses actually made of facts learned, she can both secure much real use of knowledge acquired at school and at the same time cultivate responsibility for its further use. 


\section{CHAPTER IX.}

PROVISION FOR A TENTATIVE RATHER THAN A FIXED ATTITUDE TOWARD KNOWLEDGE, AS A SEVENTH FACTOR IN STUDY.

A FIXED attitude toward facts and conclusions is harmful in several ways. The following incidents suggest how greatly it interferes with the usefulness of knowledge.

A certain man living in one of the suburbs of Greater New York was commissioned by his wife to buy some Reasons why flannel for her at one of the large department a fixed atti- stores in the city. She knew exactly what
tude toward ideas is un- she wanted, for she had already purchased
desirable. desirable,
l. It inter- some of the goods at this store. So she gave feres with the
nsefulness of her husband a sample, with the explicit knowledge. directions, emphasized, that the new piece should be of exactly the same quality, with white edges, and one yard wide.

On arriving at the right counter, the man delivered his sample and gave his order. But, after same searching, the clerk said, "The exact thing that you want has all been sold; but I have here just the right piece," throwing down a bolt, "except that it is slightly coarser. Could you take that?" Recalling his wife's instructions, the man replied, "No," somewhat doubtfully.

After more searching the clerk said, "Well, I have here a piece of just the desired quality, and one 
yard wide, only it has red edges. Could you not use that ?" and he threw another bolt down on the counter. Again, remembering the emphasis on the directions received, the man responded weakly, "No, I think not."

Finally, after further search, the clerk produced a third bolt, with the remark, "This will probably suit you. It is the exact quality that you want, and has white edges. The only objection is that it is not quite a yard wide. Can you not take it?" When for a third time the hesitating response came, "I think not," the clerk turned away with an expression of disgust for his customer, mingled with sorrow and pity.

Although the man had done his best, he did not feel sure of his wife's approval on his return home. When she asked for his purchase he stated that he had failed to make it, and explained the circumstances. "Well," she replied, "but why did n't you use your own judgment and take one of the other pieces?" To which he responded, "I understood that I was not expected to use any judgment. You strongly emphasized the fact that you wanted material exactly like the sample, with white edges and just one yard wide. You told me nothing about what was to be made out of the goods. How, then, was $I$ in a position to do anything more than to follow your exact directions?" That ended the discussion; but the need of less fixedness in instructions given was strongly impressed upon the husband, and a similar need in the following of instructions was equaily impressed upon the wife. They were thus agreed as to the desirableness of some adaptability in one's ideas. 
A certain class of girls was learning to make French cream candy, and the recipe for the same, namely,

$$
\begin{aligned}
& 1 \text { cup of sugar, } \\
& \frac{1}{3} \text { cup of water, } \\
& \frac{1}{2} \text { salt-spoon of cream of tartar. }
\end{aligned}
$$

was placed on the board for them to follow. After reading the recipe and listening to some directions from the teacher, including special emphasis on accuracy of measurements, the class set to work and produced some candy that even the visitors were glad to eat.

The recipe seemed so simple that one of the visitors a few days later proposed to his little daughter that they make some French cream candy at home. They measured out a cup of sugar and one-third of a cup of water; but there was a halt when it was discovered that there was no salt-spoon in the house. The man's wife came to their rescue, however, by giving them some idea of the size of such a spoon. Then it was found that they had no cream of tartar. On further consultation with the wife it was learned for the first time that the object of cream of tartar was to prevent too quick granulation, and that probably some other acid-like substance, such as vinegar or lemon juice, might do just as well. So a small amount of vinegar was used instead, and reasonably good candy was produced.

In a later attempt the exact amount of water necessary to a cup of sugar had been forgotten, and too much water was used; but by boiling the mixture longer, excellent candy was made. As a result of these experiments it was found that only enough water was needed to dissolve the sugar, and that any one of sev- 
eral other things would do as well as cream of tartar to prevent granulation. Without this knowledge there would be many a family which, either on account of bad memory of proportions or of want of certain materials, could make no use of the recipe. Such knowledge secured some adaptability or flexibility in the directions, thereby greatly extending their use.

One of the common objections to preparing lesson plans for teaching is that they can seldom be followed. More than that, it is declared, children have such a disappointing way of doing and saying the unexpected, that a carefully memorized lesson plan is likely to hinder the teacher in adapting hersclf to her pupils, and on that account may do more harm than good.

These objections contain much truth; and if preparing a lesson plan means mapping out only one fixed procedure, they may be entirely valid. That is not, however, what such preparation should signify. One of the principal objects of making one plan is to think out others, that may be followed or not as occasion demands. That kind of preparation, instead of tying a teacher's hinfuds, keeps her superior to any fixed course and gives freedom to deal skillfully with almost any kind of response.

These examples may be sufficient to show that a fixed attitude toward directions and plans, or toward knowledge in general, is a serious barrier to its application. The conditions are always changing, and one's ideas must be capable of corresponding modification if their full use is to be enjoyed.

Our attitude toward knowledge is intimately related also to the progress that re make; a fixed state of 
mind precludes reflection about one's course by precluding a feeling of its nced. Men frequently show

2. It is opposed to blindness to new truth. Boss politicians count progress. upon from eighty to eighty-five per cent of all voters "standing pat" and voting according to party, no matter what facts may be discovered against one candidate and in favor of another. This fact is what gives the bosses their security. It was thought to be a wonderful sign of progress a few years ago when sixty thousand out of six hundred thousand voters in a certain election in Massachusetts ignored party lines and voted according to the merits of the candidate. One reason that we have so many mediæval educational institutions is that persons in control have so many fixed ideas. There are few colleges and universities to-day, for instance, in which courses that prepare young women for home-keeping, such as domestic science and domestic art, receive credit toward a degree. Progressive changes in any line are conditioned upon sensitiveness toward changing circumstances and new ideas, and a fixed attitude is directly opposed to such responsiveness.

History is full of instances of the extent to which intolerance resulting from fixed convictions may carry 3. It is people. Innumerable murders and many peace and wars, entailing untold suffering, have found happiness, their principal cause in religious bigotry. Educational and political bigotry are likewise sources of much bad feeling and unhappiness. Family disputes, as between father and son, are in large measure due to too great fixedness of views and opinions; and much of the discontent of old age is found in the inability of 
old people to abandon their old-fashioned notions, so as to adjust themselves to new conditions and enjoy them. A fixed attitude toward ideas is, therefore, far from an unmixed virtue; it seriously limits the usefulness of knowledge; it greatly checks progress; and it strongly opposes peace and happiness.

Finally, a fixed attitude toward ideas finds little justification in the nature of knowledge. If supposed facts were always true, and if they were always truly understood, a fixed state of mind toward 4 . It ands truly understood, a fixed state of mind toward little jnsthem might still find justification; but that the nature of is far from the case. Probably some things knowledge. are true for all time, such, for example, as the facts of the multiplication table, propositions in geometry, and some of the laws of physics. But perfect reliability is attached to very little of our knowledge. Some of the fundamental propositions in the exact sciences of physics and chemistry are only hypotheses, that have undergone extensive modification in recent years. Political opinions are subject to constant change. Sixty years ago the secret ballot was feared as one of the worst of evils, iest voters might then wreak awful vengeance upon those in authority; now its desirability is unquestioned.

So many new ideas have become established in recent years about the nature of childhood, the aims of the school, and even the use of school buildings, that education is a radically different field from what it was only twenty years ago. In the same way, facts in all lines are ever undergoing modification, and evolution prophesies such modification through all time to come. Even our statements of scientific law, instead of being final, only 
express man's interpretation of unvarying phenomens of nature, and are subject to error, like all other work of man. Huxley declares that "the day-fly has better grounds for calling a thunder storm supernatural than has man, with his cxperience of an infinitesimal fraction of duration, to say that the most astonishing event that can be imagined is beyond the scope of natural causes." 2 Even within the field of science, thercfore, we can never feel sure that the last word has been said, and the best established conclusions may have to submit to correction.

Turning from the better established fields of knowledge to such other facts as influence daily life, we find them to be remarkably uncertain. The facts about the weather, that guide the farmer, for instance, are only beginning to be fully known, and consequent miscalculations in the planning and the care of crops are without limit. In ordering goods only six months in advance, the merchant must be controlled by probabilities, many of which are only narrowly distinguishable from guesses. The facts that establish friendships are frequently still less tangible, blind feelings of affinity and faith alone being not seldom the basis of the attraction. 'Thus our so-called knowledge ranges all the way from ideas that possess a very high degrec of probability to those that are a product of faith and hope, the greater portion of them approaching the latter. More than that, even in cases where the statements of principles, as in physics and ethics, seem thoroughly reliable, the variety of their application is so great and any individual's horizon is so narrow, that crrors in their 1 T. II. Huxley, Life of Hume, p. 132. 


\section{FLEXIBILITY OF KNOTLEDGE}

application to concrete cases must be very common. Correct theory about any matter by no means carries with it the correct application of that theory, as every one finds out sooner or later. It follows, then, that the highest wisdom represents only a rough approximation to the truth, and that ordinary facts are more nearly hypotheses than certainties.

Since, therefore, so few ideas are fully relis ble and unalterably fixed, a settled attitude toward thesu is undesirable, not only because it is opposed to utility, growth, and happiness, but because it finds so warrant in the real nature of knowledge.

What, then, is the proper attitude toward knowledge? While one should not be ultra-conservative, as though everything were finally settled, neither The proper should one be ultra-radical, as though nothing attitade towere established; bigotry and skepticism are edge. alike to be condemned.

The ideal state of mind is illustrated by leaders in industrial pursuits, like manufacturing. They corfidently make the fullest possible use of existing knowledge pertaining to their business, uncluding the latest inventions, while they keep a very careful lookout for further improvements. That is, they preserve an unprejudiced, open mind toward both the old and the new. It is just such a tentative attitude toward knowledge that all people should cultivate. So much of the old is defective, and so much new truth may come to light at any moment, that the fair, judicial mind is always in demand, a mind that is ever ready for new adjustments and that weighs and decides solely according to evidence. Colonel F. W. Parker used to declare 
that the grandest discovery of the nineteenth century was the suspended judgment. Yet this attitude is one that has long been insisted upon as essential to the scientist; indeed, it is most generally called the scientific attitude. It is strange, however, that those fields in which facts are best established should be the ones in which the importance of a tentative attitude is most emphasized. One would think that its worth for the non-scientific man would be far greater, for the facts that he hears about people and things, which guide him daily, are far less reliable, and his consequent necessity of changing his views is much more frequent.

While a tentative attitude toward knowledge may be of great importance for the scientist or theoretical The relation student, may it not be even harmful to the of this atti-
tade to energetic action. the chief requirements in the world of action; and if a person becomes much impressed with the unreliability of his ideas, as seems necessary in the cultivation of a tentative attitude, may he not come finally to lack decision and energy? Certainly we now and then see examples of indecision and half-hearted action, due at least in part to appreciation of opposing points of view and to consequent uncertainty of conclusions.

There may be such a danger; but it is, on the whole, to be courted rather than avoided; for, while examples of indecision are sometimes seen, examples of too decided convictions and of excessive energy in pushing them are far more common. It is not mere action that is wanted, but safe action. Force must be under the guidance of reason if it is to be free from danger, and 
reason is hardly possible without an interested but impartial attitude toward evidence. Possibly the energy of educators would be at least temporarily increased if they formulated and subscribed to definite educational creeds; but the partiality that would thus be encouraged would soon lead to strife and wasted effort.

A tentative attitude undoubtedly does limit activity somewhat, but only as good judgment limits it, for it is one of the leading factors in such judgment. It tends to eliminate misguided effort, and to check other action until its object is found to be worthy. Each of these effects is highly desirable.

On the other hand, there is no reason why it should be expected to diminish energy after favorable judgment on a project has been passed. It does not imply indifference or any lack of devotion; it merely favors the subordination of enthusiasm to insight, and delays expression of the former till the latter has given lief. The result is likely to be greater and better sustained effort than otherwise, because the tested excellence of the cause must be a source of inspiration and will help to carry one through discouraging intervals. Washington and Lincoln were both distinguished for freedom from blind prejudices and corresponding openness to the influence of new ideas; but they were also distinguished for uncommon energy and firmness in the pursuit of their main purposes. A tentative attitude toward ideas is, therefore, a real aid to energetic action in all but unworthy and doubtful causes; in these cases it is a very desirable hindrance. ${ }^{1}$

${ }^{1}$ For a valuable discussion of this general topic, see J. W. Jenks' Citizenship and the Schools, particularly Chapter I. 


\section{HOW THIS MATTER CONCERNS CHILDREN}

A receptive state of mind is supposed to be one of the peculiar merits of children. Indeed, they are so sympathetic with any view that the last presentation that they happen to hear in regard to a disputed matter is likely to be the one that they accept. It might seem, therefore, that there is no need of emphasizing the importance of open-mindedness as a factor in their education. That is far from the case, however. Children are peculiarly open-minded toward many things; but it is mainly those that they have had no previous opportunity to learn about. It is hard to take sides on a matter that you have never heard of. But the test of an impartial mind is found in those matters that are already somewhat familiar, so that one has already had some temptation to choose a side. Note how children act in such cases. How readily they declare allegiance to the political party of their fathers and shout with all the vehemence of stand-patters! How stubbornly they insist upon their teacher's method of solving problems in arithmetic when their parents undertake to assist them by showing a better way! They are nearly as intolerant as their parents on such occasions. How hastily they take sides in disputes among friends! And how very frequently their impatience with the statements and opinions of their companions gets them into quarrels and fights!

When we recall the great variety of decisions that they reach in daily life, and the impulsiveness with which many of them are made and supported, it becomes cvident that precautions against prejudice and 
intolerance are not at all out of place in their education. The need is emphasized, too, when we realize that many persons adopt inflexible views on so great a number of disputed questions, that they show signs of becoming old fogies quite early in life. "Old fogyism begins at an earlier age than we think," says Professor James. "I am almost afraid to say so, but I believe that in the majority of human beings it begins at about twenty-five." I If instances of intolerance become numerous enough to begin to class a majority of us as old fogies at this age, certainly many tendencies toward a fixed state of mind must appear and need treatment at a much earlier age.

The matter is of special importance with young children, owing to the nature of the school curriculum during the early years of school. Beginning reading, writing, and spelling are systems of conventional signs, where authority and not reason decides what is right. Arithmetic, also, consists of absolutely definite, indisputable facts. Thus the facts in the three R's and spelling, which make up most of the curriculum in the majority of schools for the earlier years, show no flexibility whatever. They must be learned as fixed things, and they tend to give the impression that the definiteness and finality belonging to them are to be expected in all subjects. This impression is strengthened, too, rather than destroyed, by the behavior of average parents. The conditions are, therefore, very favorable for the development of snap judgments and fixed attitudes among children, unless such influences are coun. teracted by very careful training.

1 Talks to Teachers, p. 160. 
SPECIFIC SUGGESTIONS FOR CULTIVATING A TENTATIVB ATTITUDE AMONG BOTH CHILDREN AND MORE MATURE STUDENTS

University students preparing for supervision of instruction often observe recitations together, with the 1. Aoquaint- object of discussing their merits and defects. variety of No matter how carefully they may have ana-

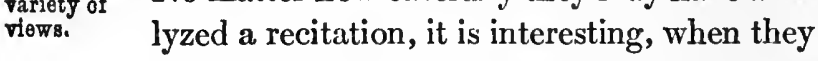
come to compare conclusions, to observe how their view-points vary, how many things each person has overlooked, and how widely their judgments at first differ. Many a student who has pursued such a course of study has reached the conviction that no one person is capable of discovering all the important factors in thirty minutes of instruction, and that his own conclusions are probably faulty in numerous serious respects. This impression in regard to the fallibility of individual judgment has a wholesome effect on any tendency to be too positive and fixed, while it directly engenders respect for other people's opinions.

Frequent discussion of questions in class, even among younger children, can have a similar influence, as can also the use of reference works and different texts on a subject. The young student should come to regard acquaintance with varying views as necessary to the formation of a reliable opinion on any topic and of sound judgment in general. That conviction will compel him to keep on the lookout for new light.

Says John Stuart Mill: "The whole strength and value, then, of human judgment, depending on the one property that it can be set right when it is wrong, reliv 
ance can be placed on it only when the means of setting it right are kept constantly at hand. In the case of any person whose judgment is really deserving of confdence, how has it become so? Because he has kept his mind open to criticism of his opinion and conduct. Because it has been his practice to listen to all that could be said against him; to profit by as much of it as was just, and expound to himself, and on occasion to others, the fallacy of what was fallacious. Because he has felt that the only way in which a human being can make some approach to knowing the whole of a subject, is by hearing what can be said about it by persons of every variety of opinion, and studying all modes in which it can be looked at by every variety of mind. No wise man ever acquired his wisdom in any mode but this; nor is it the nature of human intellect to become wise in any other manner." 1

A second means by which a student may be kept from too positive and fixed an attitude is by by being trained to feel satisfied that many in passing a clearly stated problem that has arisen with jodgment. him cannot be definitely and finally answered at the present time, and perhaps not at all.

Slowness in passing judgment may usually be urged with propriety. Even the mere attempts to reply to a query should occasionally be checked in class when it is evident that they are hasty. Some answers should be delayed even several days, the time mean while being occupied with the collection of data. Too many diffieult questions are answered "at a sitting," with meager reflection and investigation, as though final answers in general could be obtained easily and quickly.

' John Stuart Mill. On Liberty, Chapter II. 
There are some problems also that should not be answered at all; not because they are not valuable, but because their solutions cannot yet be understood by the student, or are as yet impossible. The consciousness that knowledge is too difficult, or is positively wanting here and there, destroys overconfidence in the completeness of one's attainments and awakens the need of further study. One of the principal values of many a recitation, in any grade of work, should consist in the unsolved problems that have been worded.

A good measure of kindly feeling in one's make-up is, perhaps, the greatest single remedy against a too 3. Culti- static condition of ideas. Feeling seems to vation of have a double function in making one open sympathy, and plastic. A kindly attitude toward new ideas is necessary before they can be viewed long enough to have their value tested. We must be positively friendly, or willing to see worth, before we can see it. Sympathy thus secures a hearing for new ideas. It was because the Jews lacked this feeling and consequent willingness, that Jesus condemned them for seeing not, though they had eyes, and for hearing not, though they had ears.

Feeling is also a condition of the appreciation of new thought after it has once secured a hearing. By a sort of intuition the significance of a fact is often felt long before the intellect has furnished proof of its value, the power of feeling supplying motive in this way for the intellect to do its work. And, again, until the conclusions formed by the intellect have reached the feelings, they exert little influence upon one's ways of thinking and acting. Cold sermons have little effect 
on most persons, even though their logic forces assent to them. Appreciation of worth thus greatly depends upon one's capacity of feeling.

Considerable warmth of heart or mellowness of nature due to sympathy is, therefore, an important factor in rendering one willing to listen to new ideas and to be influenced by them. Without much feeling, a man is likely to be narrow and unyielding. Gradgrind, in Dickens's Hard Times, is a shining example of this type. In his excessive devotion to "hard facts" his emotional nature atrophied, until the many valuable sues or suggestions about the conduct of his business and the training of his children that a kindlier nature would have caught from the events occurring about him, failed to affect him, and on that account he went to smash. He admirably illustrates in a negative way Carlyle's striking statement that "never wise head yet was without warm heart," and he throws light on the profoundness of Saint Paul's meaning when he said, "Love is ... never conceited ... but has full sympathy with truth."

Without an abundance of affection a man is selfcentered, a selfish aristocrat. Sympathy or love allows the ideas of others to be lifted to a plane on a level with his own and thus helps greatly toward his tolerance and receptiveness.

It is true that the scientist urges the elimination of all personal feeling in his investigations. He wants to be as purely intellectual as possible, in order to see things as they are, while personal bias tends to color facts and to that extent to vitiate them. It is chiefly, however, prejudice of all sorts in testing and judging 
truth that he is anxious to avoid, rather than any feeiing of unalloyed interest in it. A certain warmth of feeling is necessary for its comprehension as well as its evaluation. The biologist, for instance, must be in close sympathy with birds in order to understand them, just as a mother must be in close sympathy with her child in order to understand him.

It would scarcely be worth while to include these thoughts were we not able to preserve and increase our capacity of feeling, in kind and degree, just as we can preserve and increase our knowledge. It is partly with this object that we have so broad a curriculum, even in the primary school, including music, painting, and literature, as well as other subjects. Literature certainly possesses great value for developing broad sympathy; it is at least a question if literary men do not exhibit less prejudice toward new ideas than scientists, although so much emphasis is placed upon induction, and judgment according to evidence, in the training of the latter that they might be expected to be especially open-minded.

In addition to broad study, we can take pains not to study too much, that is, not so much as to crowd out the emotional life. Insight is only one of several large factors in a good education, and the ambitious student is always in danger of becoming too exclusively intellectual for the highest scholarship. The true relation of insight to feeling is well illustrated in Lincoln's life, when in the midst of the most serious and pressing problems he took time for iesting and humorous tales. In spite of condemnation by his subordinates for levity, be had excellent grounds for such conduct; for not only 
was relaxation secured in this manner - which was important enough - but his own natural warmth of sympathy was also restored, which was of greatest value in weighing the worth of suggestions and events. Humor is an important aid to any serious person in preserving balance; a good laugh restores perspective.

While it is the duty of the more mature student to cultivate for himself a many-sided emotional life, even at the expense of some knowledge, it is the duty of teachers of children in particular to give them material help in this direction. There are few schools that do not emphasize learning to the neglect of feeling. The teacher can help first of all by avoiding setting a coldly intellectual example. In addition she can study the conduct of children with the object of correcting their narrowness. Many \& child who isolates himself from conversation and play at recess is growing one-sided, whether he spends the time in doing nothing or in studying. He should be influenced to enjoy play and social life, just as he should be influenced to study. and it is the teacher's task to single out such cases and restore them to their normal condition.

Young people can learn to distinguish between authority on the one hand and evidence or reason on the other, and to subordinate the former to $4.8 \mathrm{sab}$ the latter, thus allowing conclusions to be ordination of based chiefly on facts rather than on persons. reason.

The assertion of authority over children, requiring blind obedience on their part in matters of discipline, is very common. Similar assertion of authority over both children and adults in intellectual matters is also common. The authority of custom, for instance, as 
represented in the teacher, is dominant in beginning (1) The two reading, writing, spelling, and in language bases of con- in general. In many advanced subjects, also, clnsions.

students are accustomed to accept many statements as true simply because the instructors declare them to be.

Some subjects, however, to a peculiar degree eliminate authority, basing conclusions mainly on reason. Mathematics affords an example. Personal authority sinks so completely out of sight here that even a child can dare sometimes to correct the teacher. While the majority of studies lie between the extremes represented by literature and mathematics, it is safe to say that conclusions generally can be based upon reasons that are fairly within the understanding and the reach of young people, if it seems desirable.

Blind obedience is of doubtful value in the discipline of children, because it is so unintelligent; it is well (2) Inferior- called blind. Blind submission to authority ity of anthor-in intellectual matters, on the part of either ity to reason. children or adults, is no less objectionable. It is not any person's mere assertion that makes a thing true, but evidence of some sort; and evidence is likewise usually necessary to make it interesting and comprehensible. The artificiality of the authority of a teacher as the main support for conclusions is plainly seen in the fact that there is no substitute for it outside of and after school and college. Its evil influence is also evident from the fact that persons accustomed to rely much upon it easily come to overlook evidence to the extent of blindly jumping to conclusions. And, having formed their opinions independently of reason, 
they cannot be easily influenced; for an attitude that has not been reached rationally is not likely to be modified rationally. Submission to authority easily ends in the most extreme dogmatism.

There is a strong tendency, however, for authority to usurp the place of reason. In penmanship, for example, the teacher often dictates the proper (3) The position of the body, instead of acquainting tendency of the child with the reasons for it. The rules asarp the for composition are usually dogmatically reason. presented, in spite of the fact that there are plain reasons back of most of them. If, for instance, a sentence did not begin with some large mark, such as a capital, and end with some other plainly seen mark, it would be difficult to distinguish one sentence from another, so as to read. Statements in geography were long based on authority, like those in grammar; in fact, only very recently has the causal idea become prominent in geography. High-school students of pl vsics very generally want to know what the teacher wishes them to see in an experiment before feeling sure what they do see; and college students of politics, rather than depend upon the evidence itself, are inclined to learn the political views of their professors as the means of finding out what they themselves think.

There are good reasons for this tendency to base conclusions upon authority. It takes much more knowledge of a subject and much greater skill in its presentation to make the reasons for facts clear. Furthermore, it requires a good degree of energy and moral courage on the part of teachers to decline the compliment that young people confer upon them in preferring to trust 
them rather than evidence; and it also requires a good degree of energy on the part of students to rely upon their own study of facts. It is not surprising, therefore, if the average teacher makes himself the main authority for the statements that he makes in class, and if the average student readily accepts his authority. That is the easier way to get through a day.

As the first step in combating this tendency, both teachers and students must decide how highly they (4) How this value a scientific method of arriving at contendency clusions. Heretofore our interest in conclubated. sions as valuable information has been so great that the method of reaching them has been neglected; it mattered little how much prejudice or blind acceptance of authority was connected with them, so long as they were understood and remembered. If such neglect has been wrong, and if a habit of basing opinions on carefully selected facts is approximately as important as knowledge itself, - as is probably true, then we have found sufficient motive for serious effort toward reform.

The next step is to make the words premises, evidence, proof, as prominent in study as the word conclusions. "In reasoning," says ex-President Eliot, "the selection of the premises is the all-important part of the process. . . . The main reason for the painfully slow progress of the human race is to be found in the inability of the great mass of people to establish correctly the premises of an argument. . . . Every school ought to give direct instruction in fact-determining and truth-seeking; and the difficulties of these processes ought to be plainly and incessantly pointed out."

"Aluontic Monthly, "'The School," November, 1903, p. 584. 
Some college studies, as physics, for instance, might be taught primarily for the sake of method rather than subject-matter, and all college subjects, so far as possible, should emphasize the value of the right method of study.

But scientifically trained college students, with their snap judgments in fields outside of their specialties, give convincing proof that emphasis on method in one or a few studies taken up so late in life cannot inculcate the general habit of mind desired. Such training must begin much earlier, must in fact extend throughout the whole period of study, as Dr. Eliot suggests. Teachers in the elementary school in particular must assume responsibility for developing a scientific habit of thinking, just as they assume responsibility for correct speech, and must insist upon the one in every subject as they do upon the other.

The tendency to dogmatize can be further overcome if disagreements of view are habitually referred for decision to large facts or principles. Suppose 5 . The rethat a dispute has arisen as to when phonics ferring of should be introduced in beginning reading, ments of and how prominent it should be made. A, view to large wishing to teach children to read as soon and principles. as rapidly as possible, would drill upon lists of phonetic words and upon sentences composed only of such words, no matter how artificial they might be. B, considering other things more important in beginning school life than learning to read, strongly opposes any extensive and systematic use of phonics. Reiteration of views, and even the customary proofs of success by trial, may avail nothing. But reiteration may lead to derogatory 
remarks, when each becomes impressed with the stubbornness and meanness of the other.

Suppose, however, that B, remembering that details of method are determined by large principles, runs back to his largest controlling idea in beginning reading, the need of live minds or of lively thought on the part of the children. Suppose that he shows that extensive use of phonics during the first year of school means the use of words without meaning, a tendency that is marked in prayers and greetings and that has to be actively combated throughout school and college life. Suppose that he shows, further, that the main progress of the best primers and readers in the last twenty years has been in opposition to this tendency and in the direction of interesting thought, and that good expression of thought rather than the mere pronouncing of words is the chief element in good reading.

A large principle thus brought to bear is likely to accomplish one of three things: (a) it may lead to full agreement; $(b)$ or it may itself be agreed upon, while the details are still objects of dispute. But in that case the large thought, having put the details in proper perspective, prevents unpleasant conflict by revealing their comparative littleness. Also, agreement on the large point convinces each disputant of the other's partial sanity, at least, and thus preserves harmony; (c) or, finally, the principle itself may become an object of dispute. Even then the largeness of the idea places the discussion on a high plane, and the disputants, im. pressed with the dignified, impersonal character of the thought, are disinclined to personalities.

This value of a principle is often illustrated in the 
work of criticising young teachers. Let the critic condemn with authority one feature of a recitation after another, making free use of the pronoun $I$, and the young teacher criticised is likely to glare at him in rising wrath. But let the critic omit the show of authority entirely, even the use of $I$, merely offering the reasons for certain objections, particularly some broad principle of method whose relation to the matter in hand is perfectly plain, and harmony is almost bound to prevail, no matter how complete the condemnation may be. Thus people will bear with one another, either agreeing or agreeing to disagree, so long as discussions center about principles; but without this condition intolerance and ill feeling easily manifest themselves.

Having granted the need of relying on reasons, and large ones, rather than on authority, the habit can be inculcated of delaying judgment until the evidence has been considered. It might laying of seem superfluous to add this suggestion, till the eridid it not frequently happen that people dence has get the cart before the horse in this manner. ${ }^{\text {sidered. }}$ For example, it is common for debaters to choose sides as soon as a question is agreed upon, and to do their studying afterward. Then, having committed themselves to one side, they study and argue in order to win rather than to get light. It being regarded as ridiculous for partisans to be on both sides of a question at once, - even though one's convictions often place one there, - they ignore strong opposing arguments, bolster up their own weak assertions by fluency of speech and a bold manner, and try to substitute 
witticisms for thought, when thought is lacking. While such efforts increase knowledge, they pit personality against personality in such a way that the ego rather than truth becomes the main object of interest, and on that account their influence as a whole is extremely injurious. That kind of discussion is not honest, and its spirit is far removed from that of the true scientist.

Young people should avoid taking sides, at least at the beginning of their study of a problem, and probably discussion should take the place of debating. At any rate, the single point, rather than the whole question, might form the unit of debate. They should be taught to argue on both sides of a question, according to belief, just as frank persons do in conversation, to recognize the strength of opposing arguments, and to confess their own weak points. Then they would be making truth their aim, rather than victory. Such discussions are much more typical of life than ordinary debates; and if the latter seem necessary as a preparation for some professions - which is deplorable, if true - one should wait to acquire such ability until professional training begins.

Aside from debates, people are often tempted to commit themselves too positively in regard to facts by 7. Avoidanoe too positive forms of speech. We so often of too posi- hear "I know" in place of "I suspect" or
tive forms of speech. "I surmise"; and the speaker, having committed himself almost before he knows it, repeats the assertion to make himself more sure, meanwhile wondering how sure he is.

Benjamin Franklin speaks in his autobiography of baving acquired the habit of expressing himself in terms 
of modest diffidence, "never using," he says, "when I advance anything that may possibly be disputed, the words certainly, undoubtedly, or any others that give the air of positiveness to an opinion; but rather say, ' $I$ conceive or apprehend a thing to be so-or-so'; 'It appears to me,' or 'I should not think it so-or-so, for suchand-such reasons'; or ' $I$ imagine it to be so'; or 'It is so, if I amnot mistaken.' This habit, I believe, has been of great advantage to me, when I have had occasion to inculcate my opinions, and persuade men into measures that $I$ have been from time to time engaged in promoting. And, as the chief ends of conversation are to inform or be informed, to please or persuade, I wish well-meaning and sensible men would not lessen their power of doing good by a positive, assuming manner, that seldom fails to disgust, tends to create opposition, and to defeat most of those purposes for which speech was given to us." 1

Franklin is here considering intemperate forms of speech from the point of view of others. But they have a corresponding bad effect on the speaker, making him more dogmatic the more he indulges in them, until he loses the power to be tolerant of other persons.

Discussion and conversation should be conscientiously utilized by the student for the practice of intellectual honesty, of sincerity with himself, for such sincerity lies at the very foundation of true scholarship.

1 Aubobiography, p. 21, of edition of Cassell \& Ca. 


\section{CHAPTER X}

PROVISION FOR INDIVIDUALITY, AS AN EIGHTH FACTOR IN STUDY

There was a time when people seemed to take pride in self-depreciation. Believing in total depravity, they The change were suspicious of all natural tendencies, and in appre-
ciation of the crushing out of strong desires seemed no the self. evil. Obedience to Another's will was the one supreme virtue, and the killing of human nature, the annihilation of self, was the condition of its attainment. ${ }^{1}$

But the watchwords of modem education - selfactivity, self-expression, self-development, self-reliance, self-control - indicate a very different attitude now. The emphasis here placed on self reeognizes it as the center of virtue; and the suffixes, activity, expression, etc., declare the unfolding of instincts and other native powers, up to the point of independence, to be a great desideratum in education. These watehwords signify that the constitution of an infant, like that of a young plant, fixes a certain goal within broad limits for it to reach, the narrower limits being left to be determined by social ideals. They signify further that this goal can be reached only by the unfolding of inner powers, and that the purpose of the educator, like that of the gardener, is not to create but merely to furnish the food and environment most favorable to growth. In brief, the object of education must be attained by quickening to the utmost, rather than by annihilating, the self.

' See John Stuart Mill, On Iiberty, Chapter III. 
This conception holds good, too, for every human being, in spite of the infinite variety of individuals. For, according to the doctrine of interest, which is a term intimately related to these other terms and equally emphasized with them, only that spiritual food can be expected to be truly assimilated by any person which appeals to his peculiar nature; all else fails of real nourishment, no matter how much drill may be given to it. Thus the sovereignty of every individual is recognized. Psychologically speaking, there are no saints among us to set the standard for others. Each person is worthy of exercising his own choice, of having his own way; indeed, he must exercise this privilege if he is to act rightly.

What respect we have come to have for ourselves! Have we, then, put off corruption and become perfect? And is the millennium at hand? Far from it. Causes of We have merely discovered the method by this change. which we can become good; and, stated briefly, it is that erery one must be true to himself, or must be himself. It is not strange that, in this age of scientific investigation, we have come to know more about our own natures than we did two hundred years ago. And the knowledge gained touches two great questions: first, the original character of the infant mind; and second, its method of advance.

As to the former, we are now convinced that the child is originally endowed with certain impulses and instincts, or with certain instinctive tendencies, such as fear, love, curiosity, imitation, pride, constructiveness, appreciation of beauty, and conversational power, ${ }^{1}$ and

'See James, Talks to Teachers, Chapter VII; also Dewey, School and Suciety. Chapter II. 
that these constitute the foundation or starting point for all educational endeavor. As to the latter, progress takes place by the unfolding of these instinctive tendencies, by their development rather than by their repression. Further than that, since everybody is unlike everybody else in his native impulses, and since his environment likewise varies, every person must expect to differ from all others, more or less, in knowledge, desires, and actions. Corruption may be as common as formerly, perhaps more so, requiring more vigorous restrictions than ever; but the proper way for any one to advance is to use the peculiar talents for good with which nature has endowed him, in the peculiar way fitting to himself. He may not do everything he likes; but whatever he does do must be an outgrowth of his own past, in harmony with himself and therefore an expression of himself, if it is to prove effective.

This truth is often illustrated in the government of children. A young teacher who attempts to govern a The value of class "in just the same way as the principal individuality does it," thus relying upon imitation, is composition. doomed to failure. Pupils quickly detect the lack of native force, of genuineness, in such a teacher, and lose respect on that account.

But the vital character of this thought is best illustrated in English composition. It has long been recognized that merit in that field is present to the extent that one gives expression to one's own ideas, and is lacking to the extent that the ideas are borrowed. Whatever is to be fresh and valuable must bear the peculiar stamp of the author presenting it.

The reason for this is that only through self-expres- 
sion is a natural product obtained. So long as I am consciously imitating another, or am unconsciously so warped by him as to ignore my own nature and experience, I am sounding a false note. What another thinks, no matter how good it may be, cannot properly represent me, and coming from me as mine, the want of harmony injures. I am in that case merely pretending, and the outcome is faulty because it is a sham. I might much better give expression to my own ideas, remembering Wendell Phillips's assertion that " any man who is thoroughly interested in himself is interesting to other people." Real interest in self (which is a very different thing from egotism) implies honesty with self and consequent freedom from subjection to another. Then naturalness, which borders closely on originality and is the first guarantee of excellence, is assured.

Naturalness is assured, too, in my expression of other people's ideas, provided these have become my own property by right of true assimilation. In that case they have received my own stamp, so that I am still offering something at first hand. The virility of even this kind of thought is well illustrated in the following composition by a twelve-year-old boy:-

The Chinese and Japanese may look alike in appearance; but they are not one bit alike. Once upon a time they both were the most civilized people in the world. Then Confucius came in and told them that they should learn no more and do exactly what their ancestors did. Both countries believed in this for a long time. Then the United States butted in and told them of their danger; they said that they were going backward instead of forward, and would be conquered by another nation if they did not pick up. The Chinese would 
not listen to this and said the United States had no right to interfere. But Japan thought there was some truth in this, and so the United States sent over machines, built factories, laid railroad tracks, etc. The result is that Japan is winning the war she is fighting with Russia.

English composicion is perhaps the best single test of the general healthfulness of school instruction, and it How compo- typifies life in general. The pretended appresition thus
typifies lifo ciation of an author, an affected manner, inin general. sincerity in the profession of friendship and religion, anything that admits a deceitful, artificial element is pernicious in composition as well as in life. Whatever is good must be true. In consequence, no matter how extensively persons differ from one another, the first essential to the highest efficiency of each is fidelity to his own nature.

We hear a great deal about self-made men, men who have wrested success from a stubborn world without the help of the schools. They are examples of those who are guided from within rather than from without. But every man, so far as he is a man, is self-made. He has had to use his own observation to see; his own reason and judgment to foresee; his own discrimination to decide; and his own firmness to stand by his decisions. ${ }^{1}$ His adaptation to his environment has been self-accomplished, and the first condition of its success has been a noble self-respect. Trust in self is a prerequisite to ability to do, - we must believe that we can, before we can, - and obedience to inner promptings is a necessary antecedent to such trust.

It was true wisdom that led Polonius to close his

1 See John Stuart Mill, On Liberty, Chapter III. 
blessing on Laertes with the advice, "This above all : To thine own self be true; and it must follow, as the night the day, thou canst not then be false to any man." Character itself is deeply involved. As Mill says: "A person whose desires and impulses are his own are the expression of his own nature, as it has been developed and modified by his own culture - is said to have character. One whose desires and impulses are not his own, has no character, no more than a steam engine has a character." 1

Accordingly, it behooves every one to accept himself as he is. No doubt every one at times becomes dissatisfied with himself even to the point of despair. Necessity of Feeling his own weakness, and seeing the accepting the many superior qualities of persons about him, he thinks how much more successful he might be if only he were some other person, and envy takes possession of him. But "there is a time in every man's education," says Emerson, "when he arrives at the conviction that envy is ignorance; that imitation is suicide; that he must take himself for better for worse as his portion; that, though the wide universe is full of good, no kernel of nourishing corn can come to him but through his toil bestowed on that plot of ground (himself) which is given to him to till." 2 And this conviction must not be accompanied with self-reproach. Any one who habitually feels ashamed of himself is shorn of power to do his proper work in the world. The nature and rightfulness of the desired contentment with self and of proper self-confidence are suggested by Emerson in the words: "What pretty oracles nature yields us on

1 Ibid. ${ }^{2}$ Emerson, essay on Self-reliance. 
this text in the face and behavior of children, babes, and even brutes. ... Their mind being whole, their eye is as yet unconquered, and when we look in their faces, we are disconcerted. Infancy conforms to nobody; all conform to it; so that one babe commonly makes four or five out of the adults who prattle and play to it. So God has armed youth and puberty and manhood no less with its own piquancy and charm, and made it enviable and gracious and its claims not to be put by, if it will stand by itself. . . . The nonchalance of boys who are sure of a dinner and would disdain, as much as a lord, to do or say aught to conciliate one, is the healthy attitude of human nature." 1

But are such unconquered, unconciliatory minds desirable where social coöperation is a necessity, as in Is suoh in- present society? Are not those persons pref-

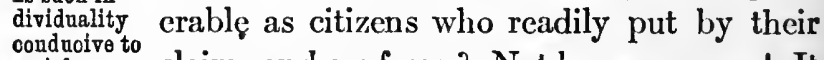
sooial cooperation? claims and conform? Not by any means! It might be that wisdom would declare the supposed claim unfounded, and that energy to combat it, rather than willingness to conform to it, is wanted. Though yielding is often a virtue, unintelligent conformity is weakness. Intelligent and vigorous reaction of the individual against all claims for conformity, sufficient to judge them, is a prerequisite even to actual conformity, and it is only a well-developed individual. ity that is capable of such reaction.

Even military discipline, which represents the extreme in its demand for slavish mass action, greatly values individual independence. Soldiers often become isolated from their superiors in the midst of combat, 
and are left to act on their own initiative, sometimes deciding the fate of battles by their resourcefulness. It is partly appreciation of the worth of individuality in all walks of life that has spurred the European nations to educate the masses in recent years.

Ordinary social life makes a constant demand for individual judgment and self-reliance. A high average of ability and character is required for the maintenance of our democratic society; but that average can be attained only when the persons who compose society individually attain that average, that is, when their individuality is highly developed.

Summarizing the preceding discussion, we see that the ideal man is not one who is afraid, ashamed, and servile, but one who belicves in himself and Why it is dares realize himself rather than imitate nocessary to others, one, in short, who lives naturally and theimporhonestly. He possesses a personality com- tance of inmanding enough to produce self-respect, and hero.

an individuality bold enough to mark his thoughts and actions as his own.

Why is it necessary to emphasize this matter so much, particularly with reference to young people? In our country, where the children are so often charged with overboldness, and where commercial individualism seriously threatens society, is there real danger that the intellectual self may be neglected and that individuality may consequently be lacking?

1. Vigor of

Remembering that method of study is our the reaction theme, let us first recall the degree of vigor proper stady. necessary in providing for the elements of study that have been named. Then let us consider some of the 
ways in which students show unnaturalness and a tendency toward self-suppression.

A person must stand somewhat firmly upon his own feet in order to set up for himself such specific aims, as guides for study, as have been urged in Chapter III. The supplementing of an author's statements is not so difficult, although one must be able to see around and beyond him, in order to realize what additions are advisable. The appreciation of relative worths, particularly the recognition of the organizing ideas in the treatment of a subject, is a task that requires a high degree of self-reliance. Judging of the soundness and general worth of thoughts is certainly not any easier. Any one can memorize; but to memorize in the proper way requires all the ability just referred to. The using of knowledge, involving the selection of the more promising part and its application until it becomes a part of the self and even habitual, is impossible without a high degree of mental vigor. Finally, the precautions to be taken in order to preserve a tolerant attitude presuppose a personality moved by purposes far higher than those of the average person. Altogether, therefore, proper study is impossible without a self that is energetic and firm. It should be noted, too, how little the mere quantity of knowledge that one has happened to collect counts. It is not so much learning as individuality that is required to meet these demands; on that account the child can study just as truly, within his sphere of experience, as can the adult.

Now let us consider the evidences of unnaturalness and of want of the boldness necessary for real study. In both school and college, when members of the class 
ignore their mates by addressing only the instructor, often speaking too low to be heard by others present, there is usually little complaint. Although each person is a direct loser, he seems recon- assert the ciled to such neglect.

Very many young people lack the courage 2. Failure to implest rights in class. to ask questions in order to understand a point; and eren when asked if they understand and if they do not wish to put some questions, they still are too timid to respond; not seldom they declare that they understand when they know that they do not. Teachers attending teachers' institutes are as bad as children in this respect. Such conduct is not due to any desire to deceive, but to self-depreciation; it is more agreeable to prevaricate than to assert one's self.

The mere desire to please a teacher influences pupils of all ages to watch the teacher's expressions and gestures and to answer what is wanted, rather than what is sincerely thought. In Sun- rience to day school, in particular, children can scarcely anthority. be got to give sincere answers; they are so eager to please that they say what they think they ought to think, rather than what they really think. Undue respect for professors often hes an overpowering influence on university students. The writer has known of several instances where students of good ability have almost lost the power to proceed with an argument, on the unexpected discovery that their view was opposed to that of some instructor.

The subservience to books is as striking as that to teachers. The history lesson of a certain class of eleven-year-old children contained the following para 
graph on the appearance of the Indians: "When the first white men came to our shores. they found the country inhabited by the people Columbus had named Indians. They had copper-colored skin, coarse, jet-black hair, high cheek bones, thick lips, small eyes, and no whiskers." The children had considerable difficulty in reproducing the substance of this paragraph, attempting it several times. The writer, who was observing the class, remembered, however, having seen an Indian exhibition only a few weeks before, which included Indian men, squaws, boys and girls, and even papooses, and which this same class had visited in a body. After three rather unsuccessful attempts to relate the contents of the paragraph, the class were reminded of their visit to the Indians, and were then asked to tell how they looked. Forgetting about the text, they had no diffculty in doing this, for they were speaking out of their own experience.

Subjects like geography and grammar likewise frequently contain facts that pupils have long known; yet in school there is such an undue respect for print that many children dare not subordinate such matter to their own experience, and for that reason they have the same difficulty with it as though it were new.

It is rare for even the college student to assert his independence of both teacher and book. One of the greatest surprises that the writer received in a two years' college course was produced in a rhetoric class. The students were ordinarily assigned about twenty pages of advance text per day, which was reproduced in the recitation. On one occasion a student who was 
malled upon did very well until he was interrupted by the professor in charge on account of an omitted topic. The professor gave the cue, but obtained no response; then, since the student usually knew his lesson, the professor exercised a special degree of patience and tried twice more to start him off. Failing, however, he impatiently asked, "Why didn't you tell about so and so" " "Why," replied the student, "I did remember something about that; but I did n't think that it was worth talking about." In the estimation of the entire class that man deserved a medal, and the writer still thinks so. There is subject-matter in most textbooks that students are called upon to memorize which they feel is not worth reproduction, and they are often right; but most college students are as still as mice when it comes to declaring the fact. Their timidity in purely intellectual matters is equaled only by their boldness in playing pranks that require mere physical courage.

Subservience to mere custom is as common as that to teacher and to print. If certain pictures or musical selections have come to be generally admired, few persons to whom they fail to appeal have the courage to acknowledge the fact. There is much pretended enjoyment in art galleries.

The rate of progress acquiesced in by students is often greater than fidelity to self will allow. The amount of text and the number of references assigned frequently leave no possible time for reflection, although reflection is the sole means by which the self can react on ideas so as truly to assimilate them. Not seldom both teachers and students are conscious of 
this fact and even lament it, yet they continue in the same course. The result is that the average student learns to disregard his own questions, doubts, and suggestions, and is smothered by his studies. Only the exceptional nature rebels, as in case of the rhetoric, and follows his own gait, even in opposition to the teacher.

In order to test the power of initiative of young people in study, the writer once selected a class of twenty 4. The ab- children, ranging from ten to twelve years of

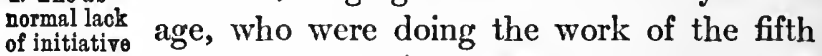
in olass. school year. They were only average pupils in home advantages and native ability. But the school to which they belonged, being the practice department of a training college for teachers, undoubtedly allowed a greater degree of freedom to the individual and possessed more merits than the orrinary public school. Nine of the children had attended this particular school from the beginning, and several of the others had gone there one or more years; and every one of the five different teachers that the class had had, had been a graduate of a state normal school, or of a teachers' college, or of both. Here, if anywhere, one might expect a good degree of independence on the part of the pupils. Also, the writer had been personally acquainted with the class from the beginning, so that they felt reasonably at home with him when he took charge of them in geography and history. After spending two thirty-minute periods with them on successive days, considering various review questions in geography, the writer, acting as teacher, assigned them the following lesson of map questions in the text-book:- 
Here is a relief map of the continent on which we live. What great highland do you find in the West? In the East? In what direction does each extend? Which is the broader and higher? Where is the lowest land between these two highlands? Trace the Mississippi River. Name some of ita largest tributaries, etc.

This lesson was to be studied in class aloud; that is, the writer was not to do any teaching or give any help; he was to assume as nearly as possible the attitude of a listener, doing nothing more than call upon some one now and then to "go on" or to "do what ought to be done next." The children were to do all that wasnecessary to dispose of the questions properly, even to the extent of correcting one another freely.

With this understanding a girl was called on to begin. She arose and read, "Here is a relief map of the continent on which we live. What great highland do you find in the West? In the East?" Then she stopped, and stood staring at the book. She may have needed to inquire the meaning of "relief"; or she may have been in doubt whether or not she should turn to the relief map opposite, which was small, or to the better map two pages further over; or to the wall map hanging, rolled up, in front of the class. But, although she was not noticeably embarrassed, she did none of these things. She waited to be told just what to do, and she waited patiently - until aid from the teacher arrived.

In response to the next question, "In what direction does each [highland] extend?" the two great highlands, the Rockies and the Appalachians, were described as parallel; and the pupil was passing to the 
next question without objections from any source, when the teacher again had to interfere.

The boy who was called upon for the third question, "Which is the broader and higher?" stepped to the wall map and pointed out the Rockies. But, as no one asked why they were supposed to be broader and higher, the teacher suggested that question himself. Some one gave the correct reason for considering them the broader; but by that time the entire class had forgotten that there was a second part to the question, and were passing on when they were reminded by the teacher of the omitted part.

In response to the fourth question, calling for the location of the lowest land between these two highlands, four or five stepped to the map in succession, showing wide disagreement. Yet no one asked any one else "Why?" or proposed any way of settling the dispute, or even evinced any responsibility for finding one. They would have proceeded to the next question had they not again been halted by the teacher.

In tracing the Mississippi River, only about one-half of it was pointed out; i.e., from Cairo southward. But no one entered complaint, and the next question was actually read before the teacher requested more accurate work. The girl called on to "name some of its largest tributaries" stood silent. Possibly the word tributaries puzzled her; but she lacked the force necessary to make a request for help. She seemed to be waiting for the teacher to ask her if she didn't need to ask some one else for the definition. So the teacher complied and the definition was given. But then all failed for a time to answer the original question, appar. 
ently because they could not break it into its two parts, first tracing the principal tributaries on the map, then finding the names attached to them.

These responses are representative of the writer's earlier experiences with these children. Although they were not frightened, and plainly understood that they were to go anywhere in the room, and were to do or say anything that was necessary, they almost invariably waited to be told when to step to the board; when an answer was wrong; when something had been overlooked or forgotten; when the pointer should be taken up or laid aside; and when they were through with a question.

Between three and four recitation periods of thirtyfive minutes each were consumed, before they were able to do all that was necessary in answering the extremely simple questions above, with a half-dozen more, without help. Their frequent smiles of chagrin, too, proved beyond question that they were fully in earnest in their efforts. This helplessness was not exhibited on the first few days either. It was their custom to wait for assistance and directions - even to sit down and it was a custom so well established that five weeks of daily work with them in history and geography, with the avowed object of breaking it up, only barely began a reform.

Other children, as a rule, would scarcely do better. But these are cases of children. Would not a class in a normal school or a college show greater capacity for leadership? Not often. Of course they possess greater mental power; but the subject-matter with which they are struggling is more difficult. Any teacher of such a 
class who unexpectedly eliminates himself from a recitation by silence, and who asks the students to provide a substitute from within themselves for his part of the work, is likely to feel disappointed over the result. Who will assert that such lack of initiative is natural ?

How docile young people are, after all, in intellectual matters! They lack the courage to resent neglect in 5. The evil class, to acknowledge that they do not undereffects of
such suppression. initiative and even independent power to think, when in the presence of teachers; and they ignore their own experience in favor of print. They are so bent on satisfying others that they suppress their own inner promptings. In doing this they seem to confuse moral with intellectual qualities, acting as though the sacrifice of self in study was equally virtuous with its sacrifice in a moral way. Yet listen to Emerson's warning:-

"Books" (and he might have said teachers) "are the best of things well used; abused, among the worst. What is the right use? They are for nothing but to inspire. I had better never see a book than to be warped by its attraction clean out of my own orbit, and made a satellite instead of a system. The one thing in the world, of value, is the active soul. This every man is entitled to; this every man contains within him, although in almost all men obstructed, and as yet unborn. . . U Undoubtedly there is a right way of reading, so it be sternly subordinated. Man Thinking must not be subdued by his instruments." 1

The evil in a young student's being "subdued by

1 The American Scholar. 
his instruments" is that he is made artificial and dependent, and thereby ceases to be a whole unit. The artificiality is often shomn in the voice. Many schools, owing to the restraint that their pupils are allowed to feel, are guilty of establishing a special recitation voice, distinguished from that ordinarily used in conversation by its different pitch, and often amusingly distinguished, too, when some interruption during recitation causes a question about outside or home matters to be answered in the natural way. Many educated adults have suffered so much in this respect that they cannot read in natural tones.

The dependence, further, is shown in any attempt to produce thought. When a student has formed the habit of collecting and valuing the ideas of others, rather than his own, the self becomes dwarfed from neglect and buried under the mass of borrowed thought. He may then pass good examinations, but he cannot think. Distrust of self has become so deep-rooted that he instinctively looks away from himself to books and friends for ideas; and anything that he produces cannot be good, because it is not a true expression of self. This is the class of people that Mill describes in the words, "They like in crowds; they exercise choice only among things commonly done; peculiarity of taste, eccentricity of conduct, are shunned equally with crimes; until, by dint of not following their own nature, they have no nature to follow; their human capacities are withered and starved; they become incapable of any strong wishes or native pleasures, and are generally without either opinions or feelings of home growth, or properly their own." ' Such people

I On Liberty. Chapter III. 
cannot perform the hard tasks required in study, because they have lost their native power to react on the ideas presented.

The evil is most serious with young children because of their youth. Many of them, while making good progress in the three R's, outgrow their tendency to ask questions and to raise objections, in other words lose their mental boldness or originality, by the time they have attended school four years. But all along, from the kindergarten to the college, there is almost a likelihood that the self will be undermined while acquiring knowledge, and that, in consequence, one will become permanently weakened while supposedly being educated. In this respect it is dangerous to attend a schuol of any grade.

"Familiar as the voice of the mind is to each," says Emerson, "the highest merit we ascribe to Moses, Why indi- Plato, and Milton is that they set at naught riduality is books and tradition, and spoke not what
so difficult to preserve so difficult men, but what they, thought." 1 It is evi-
to preserve
and develop. dently exceptional for one's thoughts and actions to be quite fully one's own. In matters of dress hosts of persons would rather be fashionable than comfortable; and in matters of the intellect subordination to others is even more common.

One great reason for this is that people do not know how to be true to themselves; they do not comprehend themselves well enough for that. "Know thyself " was a dictum of Socrates that should precede the command "Be true to thyself," because it is a prerequisite to it. But if it takes a literary genius to

1 Essay on Self-reliance. 
reveal our thoughts to us, as it often does, certainly the average person will not discover his own characteristics alone: Even with firm intentions he will merely grope about, and from blindness and want of skill will stifle a good portion of his own nature.

On the other hand, if he goes to school, whatever peculiarities he may possess are liable to suppression, through the teacher and the curriculum, the two chief agencies of the school. For the average elementary teacher is not greatly concerned about preserving and developing individuality, and the average high-school teacher or college professor still less. Indeed, many teachers are convinced that there is too much of it already, as shown in the discipline, and insist upon as much uniformity as possible, because it is less troublesome. When it comes to the curriculum, the commonly recognized purpose of instruction is acquisition of knowledge rather than development of self. But if a student sets out to amass as much information as possible, he is almost sure to be covered up by his collection; and, even if he proceeds slowly enough to admire and try to imitate the gcod that he finds in his spiritual inheritance and present environment, he is in no less danger of being mastered by his instruments. Thus it happens that while self-expression should be one of the great purposes of the The positive school, annihilation of self is a common out- $\frac{\text { oharaoter of }}{\text { provision for }}$ come. Individuality as a factor

It follows from the preceding that provision in stady. for individuality is a very positive factor in study, one requiring much time and energy and on which all the others that have been mentioned are dependent. A per- 
son must have the courage to assert his rights in intellectual matters, must believe in the worth of his own past, and must not allow his regard for othersto weaken his trust in self. All this requires a high degree of self-respect, which can be attained only by careful cultivation.

As he comes more and more in contact with the ideas, desires, deeds, and examples of other persons, and the demand for conformity grows more pressing, he must reserve special time and energy for studying his own powers and tastes and for discovering his own thoughts about the many subjects of study in which he engages. In the study of many a poem, for example, more time will be required to determine his own attitude toward it, to find himself in regard to it, than to understand its meaning.

Remembering that one purpose of education is development of the self, he must ever be on his guard against being warped out of shape by others, and must therefore offer a certain normal resistance to everything that is presented to him. To preserve and develop one's self thus normally, it is safe to say that any student should have as much esteem for himself, intellectually, as for others, and should spend at least as much time and energy upon himself in finding out what he himself thinks and feels, as upon others.

PRACTICAL SUgGestions FOR PRESERVING AND DEVEL OPING INDIVIDUALITY

The value of tolerance on the part of teachers, as discussed in the preceding chapter, is plainly seen in this connection. Unless a teacher's manncr toward a 
pupil indicates a high degree of respect, the pupil's respect for himself is in danger of being weakened. A sarcastic attitude is even worse than a dog- 1 . The rematic one; beyond doubt, the proper self- lation boesteem of many a young person has been ersand permanently undermined by his teacher's stadents. sharp tongue; sarcasm is the extreme of intolerance.

There should be a clearer understanding, too, about the function of teachers in general. Many instructors give the impression that educational institutions exist for their benefit, rather than for the good of their students; and from the start the latter are forced into the position of suppliants. If questions are asked, impatience is shown; and if objections to statements are raised, impertinence is charged. Such treatment tends to cow the average student and thus to limit his power to react upon ideas.

While teachers may be real authorities in subjectmatter, they can never be anything more than assistants in the self-development of their students. They should more openly assume this subordinate position, placing the primary responsibility upon the learner; they would then be less likely to subordinate the inner growth of the student, which it is their highest function to aid, to the mere acquisition of knowledge.

If, however, teachers practically compel subservience by an arrogant manner, or by the assignment of lessons much too long for one's normal rate of advance, or by the assignment of subject-matter that seems to have no possible value, what should the student do? Should he smother his own desires and opinions in the attempt to satisfy his teacher? Rarely, 
if ever; he will not grow inwardly by suppressing the self. On the contrary, when he feels himself in serious restraint, he should frankly state his grievances, and the teacher, even though a college professor, should receive and ponder such statements seriously, remembering that one reason he is paid a salary is that he shall exercise skill in adapting himself to the psychological condition of his students.

If these frank statements evoke no friendly response, then protest may be in place, and sometimes revolt, just as when political liberty is assailed. Of course, a good degree of patience and tolerance should always be exercised toward one's teacher; but there is need of more moral courage among young people to meet the disapproval of teachers and their punishments in the form of scoldings and low marks. Many a college student unresistingly submits to a sarcastic, dictatorial teacher when he ought to show resentment and stand on his rights. Resistance to teaching authority may be just as vital a part of study as the rejection of the conclusions of an author. Until such ideas are more generally practiced, a normal, vigorous self, which is the first factor in scholarship, is in danger. Intellectual liberty is not less important than political liberty, and often worth a fight. It is odd that much blood has been shed for the attainment of political and religious freedom, while the tyranny of mind over mind, which is exceedingly common in the class room, has scarcely been recognized as a serious evil. It can be accounted for only by the fact that both teachers and parents have been more interested in the quantity of knowledge acquired than in the inner growth of learners. 
Every person has many peculiarities that are important factors in his study and that should be noted by all concerned with great care. For example, aside from the desirable rate of advance for each person, which has already been mentioned, a tion of instudent may be eye-minded, or ear-minded, or dividuat motor-minded. That is, he may be peculiarly dependent upon his eyes, needing to see a statement in print rather than to hear it read, and inelined to visualize or image even the most abstract thought. Or he may learn best through the ear, wanting to hear statements read, rather than see them. Or he may be peculiarly dependent on motor activity, preferring to write his spelling lesson, rather than to see the words only or to spell them orally; such a person will need to gesticulate freely, to imitate movements and act out scenes, rather than see or hear only verbal descriptions. Some persons are naturally regular and systematic in their work, following a definite program each day and arranging facts as well as furniture in an orderly way. Others are pained by regularity and system, and find it impossible to reform themselves. They can work well only when they feel like it, and therefore by spurts. Some do their best thinking under the stimulus of discussion and opposition, others are disturbed by such conditions and can think best in private. Some are especially devoted to facts, being scientifically minded and interested in the objects about them. Others are idea-lovers, caring little for the concrete world of nature, but attracted to literature, history, and music. Others, still, are particularly strong in execution, rarely considering theory apart from practice. ${ }^{1}$

'See President Hadley's article in Harper's Magazine, June, 1905. 
Some of the peculiarities that we discover in our. selves are weaknesses that should be discouraged and combated to the utmost; others require more or less modification. But there is no choice concerning most of them; their sum constitutes our nature, and we must accept them. They are our original capital, our source of strength on which all increase of strength must be grafted. And we should become well acquainted with them, just as the engineer should know the properties of steam.

Full acquaintance is impossible, and even approximate knowledge of the extent of one's powers cannot be reached, until one has become deeply interested in some project and loaded with responsibility in regard to it. But by humbly and diligently observing one's better tendencies, and by giving full expression to them, one may attain a fair degree of self-knowledge. One of the special duties of teachers and parents is to come to the assistance of young people in such study, helping them to recognize their strong and weak points and to understand themselves without getting discouraged or excited. If we fail to enjoy a book or musical concert that arouses the enthusiasm of others, we may well admit the fact to ourselves, and perhaps to others, with neither pride nor shame, but as a fact. Such facts reveal us to ourselves, and should be noted with the consciousness that, if strength is not found in one direction, it is likely to be discovered in some other.

It is obvious from preceding statements 3. Responsibility for initiative. that both children and older students must become far more accustomed to taking the initiative during instruction, if they are to take it in 
private study. The way to prepare for leadership, whether of self or of others, is to undertake such leadership under wise guidance.

There are two degrees of responsibility in recitation that are somewhat common. Suppose, for example, that a class in manual training is to make a tile out of clay, to be placed under a coffee pot. After proposing this task the teacher (1) might further state that the tile must be six inches square and one-half inch thick; that it must have a level surface; that a ball of clay of a certain size will be needed in order to make a tile of the desired size; that it must be pressed into shape mainly by the use of the thumbs; that careful measuring will be necessary to secure the proper dimensions; that square corners can be obtained by placing some square-cornered object directly over the corners of the tile, for comparison; and that a level surface can best be obtained by sighting carefully across the surface, so as to detect any irregularities. After these and perhaps other instructions have been given by the teacher, the children may be directed to begin work.

Or, after the task has been proposed, the teacher (2) might simply ask the main questions that need to be considered, letting the pupils find the solutions for the same as far as possible. For example: How large should the tile be made? What should be its shape? What kind of surface must it have? How must the clay be worked into the desired shape? How make sure of the dimensions? Of square corners? Of a level surface?

The first plan shows practically the lecture method in operation. The teacher presents all of the ideas, and 
the children have the position of listeners or followers That method places the minimum degree of responsibility upon pupils, the responsibility for attention, and is quite common in the poorer schools and in colleges. The second plan allows the children to join actively with the teacher in producing the ideas involved in the solution of the problem. It shows the development method in operation, which places much more responsibility upon the class. But the teacher even here takes practically all of the initial steps. She is the one who breaks the large problem up into its parts; who determines the wording of the questions and the order in which they shall be considered. The children follow her cue; they are subject to her constant direction, and merely make response to her specific biddings. The reaching of new thought by them under such immediate stimulus and suggestion involves responsibility for thinking, to be sure, but very little responsibility for the initial thinking or for initiative. Neither of these methods, therefore, plainly develops the power of selfdirection.

Training in the exercise of initiative is provided, not when young people are following some other person's plan and answering some other person's questions, but when they are obliged to conceive their own plans and their own questions. Here is the crux of the whole matter. Some other method, therefore, is desirable, and it is not difficult to find. After the making of the tile has been proposed, the teacher might simply ask, "How will you plan this piece of work?" leaving the conception of the main questions, together with tho answers, as far as possible to the children. 
They would know that a certain size would need to be determined upon, fixed by the size of a coffee pot; that the shape would have to be considered, the round or square form being chosen according to personal preference and ease of making; that the thickness would be a factor, it being important that the tile be thin enough to be reasonably light, but thick enough not to break easily or to let heat through; that a level surface is desirable, both for the sake of beauty and utility; and that some way must be found for pressing the clay into shape. All of these ideas lie within their personal experience and therefore call only for common knowledge and common sense.

All or most of this part of the plan, including the correction of any misstatements, could be made by the children with little or no help from the teacher. Where their knowledge is more limited, however, she should come to their aid, either telling or developing, as the case required. For instance, she might possibly tell outright how much clay each would probably need, also how the clay should be pressed into shape; and develop the method of making sure of proper dimensions, of square corners (or of roundness) and of a level surface.

This task in manual training is typical of lessons in general. In their mastery there is always a procedure of some sort to be followed, and now and then, at least. this procedure lies in whole or in part so fully within the class experience that they should have the responsibility of mapping it out. Sometimes in the lower grades such work might occupy a whole recitation period; again, only a few minutes. As the experience increases, 
this responsibility should increase, so that the higher grades should often show children stating the main questions to be considered in their lessons, without help, just as they have long been in the habit of stating the main steps to be taken in individual problems in arithmetic without aid. In very many recitations children should have responsibility for rejecting some of the answers and for accepting others. The writer is acquainted with one cighth-year class in which not only all this is done, but the children frequently determine their own lesson assignments, reporting in class what home work was attempted the previous evening and how it was done. These reports are then subjected to general criticism and suggestion. If such practices become successfully established in the elementary school, they will have to be adopted higher up, for very shame if for no other reason.

Socrates was one of the most fertile thinkers that ever lived; yet he scarcely traveled beyond the walls of 4. Past ex- Athens, and was accused of always talking perience as about the most commonplace objects, such sonroe of as "brass founders and leather cutters and new ideas. (1) Mluntra- skin dressers." He clearly illustrates the fact tions.

that fertility of thought bears little relation to one's quantity of learning, but depends rather upon the use made of such very simple raw material as any ordinary person possesses.

The Children's Hour as discussed on pages 69-70 how how one's past may be used in the production of hought. The poem tells of an hour set aside by the family for play. The fact that we know this to be a very rare thing prompts the questions, " ||$^{\mathrm{N}}$ ?. 
tomary in this family, or did it happen only once?" The fact that many fathers would be bored by such an hour suggests the query, "Did this father really enjoy it ?" The fact that the custom is so uncommon raises the further inquiry, "Was there any special merit among these children that led to it?" Also, "Why is the custom not more common?" And, since some one must take the lead in establishing such an hour, the query follows, "Can children themselves accomplish anything in this direction?"

Thus facts that are well known lead to new ideas. No matter what we hear or read, or what topic is given to us to ponder, thoughts additional to those directly presented are likely to be reached by reference to past related experience. That one should look to past experience as an almost unlimited source of new thought is one of the most important truths for any person to bear in mind who is endeavoring to learn to think.

It is very common, however, for persons who are rich in experience touching some subject that they are studying to fail almost entirely to use it. This (2) Tho was once well illustrated by about twenty $\begin{gathered}\text { common } \\ \text { neglect of }\end{gathered}$ young women who were specializing in do- experience. mestic science. At their own suggestion, they prepared written plans for teaching how to bake sweet potatoes; the writer was to correct these and discuss them with the class. But after carefully examining all the papers and finding remarkably few facts included, he asked the class what was really necessary, after all, in the baking of sweet potatoes, beyond putting them, clean, into a hot oven and taking them out when done. He requested them to enumerate the facts that really needed to bo 
taught. After perhaps two minutes of meditation they sheepishly admitted that there was really very little to present on the topic, and that they had carefully written out plans only because "plans" were expected, and they wanted some practice.

Since it was subject-matter, rather than method, that was needed, the discussion was then directed to the facts involved in baking the potatoes. A dispute soon arose when one remarked, "You should never cut a sweet potato," others inquiring what should then be done with those that were partly unsound, and how potatoes of very different sizes could be baked together. Numerous other questions were considered, as follows:-

What is the best way to clean them? Is it best to allow them to lie long in water? Should the oven be very hot, or is a slow heat preferable? Should anything be done with them while baking? How can they be protected against burning? How much time is necessary for the baking? Or will it vary? If so, why? How tell when they are done? Is it necessary to take them out and strike them with the palm of the hand, breaking them slightly? How get them out without burning one's self?

Since one cookbook says that we want "dry and mealy" potatoes and another states that they should be "moist and sweet," which is right? Also, what different steps should be taken to secure each kind? Some persons parboil the potatoes before baking them. Is that desirable? What about the advisability of bak. ing them with butter, sugar, and salt? Are there other ways of baking them? What changes does the heat 
effect in the potato? Should they be served immedi. ately? Or, if guests are not prompt, is there any way of keeping them in good condition?

Most of these questions arose for the first time in the discussion, not having been referred to in any of the plans. Yet, no doubt, all the members of the class had baked sweet potatoes many times, had read cookbooks as often as novels, and - since they were not altogether young - had scores of times been called upon to eat potatoes that were not clean, or were unsound, or not done, or were tasteless, or burnt, or soggy, or cold. Therefore, probably not one of the questions was entirely new to any one of the students, so that the raw material for thought was present in abundance and even very close at hand.

Why, then, did they so neglect their past? Above all, why should two minutes of reflection on the subject mark their limit? For, having given to the (3) Reasons to themselves the signal for all stray ideas for guch on the baking of sweet potatoes to assemble, ${ }^{\text {negleot. }}$ their manner indicated no hope of further returns after the expiration of that brief period. A partial answer is that they did not know where to look for ideas. But an additional answer is that they did not know how to look to their past, and they accordingly lacked confidence. Indeed, they knew that they could not think, so what was the use of wasting more than two minutes for the sake of appearances?

It does require some knowledge and confidence to think out a subject in view of one's experience. When we are somewhat familiar with a subject, some ideas in regard to it may come very readily, so that the first 
few minutes of reflection may be easily spent and fairly rewarded. But the ability really to think is tested after this period. Then we must know how to overhaul our past and must have faith that we will get something from it. We must search our experience through and through, viewing it from one point and then another in the keen lookout for suggestions. And we must know that many of the best thoughts, probably most of them, do not come, like a flash, fully into being, but find their beginnings in dim feelings, in faint intuitions, that need to be encouraged and coaxed before they can be surely felt and defined.

The writer's experience in the observation of recitations with graduate students has often illustrated this fact. Not seldom a recitation has been observed that has apparently pleased most of the observers, but that has produced only an uncomfortable feeling on his part. At the close of the recitation he had no more definite ideas about its merits than his students; but he was conscious of this feeling of discomfort produced, and knew that if he followed it up he would probably arrive at some important thoughts. Occasionally his main points in an extended discussion of a recitation have been reached in this way. Usually he has found afterward that his students have had the same feeling as he: but they were scarcely conscious of the fact, and, even if conscious, they failed to realize its worth as a source of suggestion.

Thus vague premonitions furnish the clew to much of the best thought. Very often onc of the chief differences between a thinker and one who cannot think lies in the attention given to premonitory feelings of 
pleasure, discomfort, doubt, suspicion, etc.; the latter ignores such, while the former, when he lacks clear ideas, or all ideas, even shakes himself to discover how he feels, and patiently labors to define his feelings and trace them to their source.

But how dependent such study is upon self-confidence! Unless we have faith in the richness of our own experience, and belief that a careful inspection of it will be rewarded, we lack the (4) How $_{\text {condenoo in }}$ courage and patience necessary for success. the value of

How can such confidence be cultivated? may be deMainly by cultivating the habit of turning first to self when reflective thought is required. It is presupposed that we must consult the library and the world about us for raw facts of various kinds, for historical events, scientific data, views of men, descriptions, etc.; but when our own thought is wanted on a topic with which we are somewhat familiar, and on which we are supposed to have some ideas, let us form the habit of turning to ourselves first; to others as helps later. If other authorities are consulted first, there is danger that the first impressions, the first thoughts, of the student will never come to light; the ideas of others will hide these and become their substitutes, thereby engendering distrust in self. But by giving attention first to self, by giving it the first chance, its contributions can be recognized; that encourages it to grow and attain vigor, so that, when outside helps are later consulted, it can react upon them and maintain itself. Every young person should do enough thinking on a subject, before attempting to find what others think nbout it, to have something to oppose to these others, 
as a basis of judgment. That will keep the self upper most and cultivate the confidence desired.

If, on the contrary, we wait until we have found what others think, before attempting to find what we think, others will do our thinking for us, and we will ever be suffering from the timidity that Emerson laments in the words:-

A man should learn to detect and watch that gleam of light which flashes across his mind from within, more than the luster of the firmament of bards and sages. Yet he dismisses without notice his thought, because it is his. In every work of genius we recognize our own rejected thoughts; they come back to us with a certain alienated majesty. Great works of art have no more affecting lesson for us than this. They teach us to abide by our spontaneous impression with good-humored inflexibility then most when the whole cry of voices is on the other side. Else to-morrow a stranger will say with masterly good sense precisely what we have thought and felt all the time, and we shall be forced to take with shame our own opinion from another. ${ }^{1}$

- Emerson, essay on Self-reliance. 


\section{PART III CONCLUSIONS}





\section{CHAPTER XI}

FULI, MEANING OF STUDY: RELATION OF STUDY TO CHILDREN AND TO THE SCHOOL

True or logical study is not aimless mental activity or a passive reception of ideas only for the sake of having them. It is the vigorous application of the mind to a subject for the satisfaction of a felt need. The meaning Instead of being aimless, every portion of of atudy. effort put forth is an organic step toward the accomplishment of a specific purpose; instead of being passive, it requires the reaction of the self upon the ideas presented, until they are supplemented, organized, and tentatively judged, so that they are held well in memory. The study of a subject has not reached its end until the guiding purpose has been accomplished and the knowledge has been so assimilated that it has been used in a normal way and has become experience. And, finally, since the danger of submergence of self among so much foreign thought is so great, it is not complete - at least for young students - until precautions for the preservation of individuality have been included.

The common notion that study should consist of thinking is, therefore, quite right. In Hints for Home Reading (p. 51) Henry Ward Beecher says of himself: "Reading with me incites to reflection instantly. I cannot separate the origination of ideas from the reception of ideas; the consequence is, as I read I always begin to think in various directions, and 
that makes my reading slow; and that being the origin of it psychologically, it has grown into such a habit that, if I read a novel even, I read slowly." Later he advises (p. 95), "Never give more time to reading a book than to reflecting upon its contents." In criticism of the customary haste in reading, on the other hand, Mr. Gorschen declares: "Honestly, I must say, I believe that a vast number of readers do not allow what I may call the frenzied current of their eyes, as they read, to be stopped by even a moment of calm reflection or thought." 1 Real assimilation of ideas has to be slow; and while some reading, owing to the simplicity of subject-matter, should be as rapid as the eye can travel, the rate at which ground is usually covered is too great to make assimilation possible.

The eight factors of study that liave been treated are not to be regarded as separate stages of advance that must follow one another tandem fashion. The principal stages through which the learner passes are only four in number as outlined in Chapter VIII. Yet some of the eight factors necessarily follow others. For example, the conception of the specific aim should, if possible, come first, while memorizing should usually come late, partly if not wholly as the by-product of thinking; and the actual using of knowledge should come last. On the other hand, provision for a tentative attitude and for individuality should be made frequently throughout one's study. Several of these factors, therefore, may be in evidence in any one of the four chief stages of advance described.

1 Aspects of Modern Study, by Right Honorable G. J. Gorschen D.C.L., M.P., p. 39. 
We have seen that children possess the ability to undertake the kind of work required by each of the several factors of study. In fact, outside of The ability school, they are continually applying their of children minds in the meeting of specific needs, just stody. as adults are, thereby employing most, if not all, these factors. There is, accordingly, no fundamental difference between their study and that of adults, although the relative prominence of the various phases may vary somewhat; in other words, these factors of study are general principles like the principles of teaching, and likewise applicable to all ages. No assertion is here made that children know intuitively how to do this systematic kind of studying; they merely have the qualities of mind and the experience prerequisite to rational study, and are therefore in a position to receive instruction on the subject with profit.

Every one recognizes the fact that young people, as a rule, have not been learning to study properly alone. There are two reasons for this, which deserve very careful consideration. One is that the peoplebarg difference between studying with a teacher not been and studying alone has been overlooked. It stady prophas been assumed that the two were practically identical, so that the one was full preparation for the other, while in fact there is a very striking difference between them.

Consider what happens in class instruction, and then how independent study differs from it. When a young person sets to work to master a lesson with the aid of a teacher there is a question of how much two persons can accomplish together. One of the two 
is mature, more or less informed in general, more or less versed in the principles of study, and more or less skilled in their application. The 1. The dif- other is immature, and only under favorable
ference between stndy- circumstances fully willing to apply himself.
ing with a teacher and alone has been overAs they ordinarily work, their relation to looked.

each other is well defined. In case text has been assigned, the teacher asks various questions, pushes the pupil against difficulties, points out crucial thoughts, calls a halt here and there for review and drill, supplies motive for attention by reprimanding or praising or pummeling, as the case may be, and not seldom becomes flushed in the face from exertion. In the case of development instruction in which, without the help of a text, the thought is slowly unfolded by means of question and answer, the teacher is the recognized master of the discussion. She usually selects the general topic, breaks it into its parts, and then concentrates her abilities on her questions, endeavoring to make them short enough not to require too sustained attention, simple enough to be reasonably easy, and attractive enough to be sure bait. In short, she exerts herself to the utmost to conceive questions of just the right size and quality; and, if she is very skillful, her morsels of knowledge will prove so enticing that they will be swallowed and digested without pain, and perhaps without conscious effort. In case lecturing is the method followed, the teacher is still more plainly the sole producer of thought, it being the mission of the student to listen, comprehend, and retain.

In each of these cases the teacher is the acknowl. 
edged leader. Her personality, as represented by voice, gesture, and manner, is drawn upon for stimulus; she gives directions, puts the questions, and makes the corrections, or sees that they are made. If she is accounted a good teacher, she is probably more active than her pupils and grows tired first.

Now, suppose that the teacher drops out and leaves the young person to attack a similar lesson alone. How is the situation changed? The purpose in the former case was the assimilation of the facts in the lesson by the pupil. That is still the purpose. There is, therefore, no change in that respect.

The method employed in the former case may be assumed to be as fully in accord with the laws of the pupil's mind as the teacher could make it. In short, the topic under consideration had to be carefully broken into its parts, and various keen questions touching the meaning and value of each had to be conceived in order that they might be considered and answered. The same mind is still present to be ministered to, so that, so far as possible, substantially the same method must be followed. There is, therefore, no important change in this respect. The purpose and the method in general being the same, it is clear that the two situations duplicate each other to a large extent. The same quantity of work must be done, and in practically the same way.

But there is a very striking difference. When the two studied together, the teacher not only did a part of the work, but she was the leader; the pupil was a follower, doing only the subordinate part. Now, being alone, he must do the principal part, in addition to the 
other. He must divide his topic into parts, and conceive all the questions that are worthy of attention; in brief, he must determine the course of procedure himself, or take the initiative. Herein is found the great difference between studying with a teacher and studying alone, and it is a fundamental one. Capacity for selfdirection or initiation is not necessary in the usual class instruction; but it becomes indispensable the moment one undertakes independent study.

This capacity is not simply a matter of knowledge. One person may know much more than another about (1) The na- the factors involved in a proposed project, tare and im- and still be inferior to the other in ability portance of nitiative by to plan its execution. It is not simply a the pupil. matter of boldness, either, nor of energy, although both of these, as well as knowledge, are necessary elements. It signifies, in the main, rather a certain power of invention, or a resourcefulness in planning work, a resourcefulness that is sure to be exercised, however, only in case the other factors just mentioned are also present.

Power of initiative is the key to proper study. If different lessons were mastered in exactly the same manner, it might not be important. But that is not the case, for every new lesson brings a new situation. Experienced teachers know that one year of instruction in a certain study does not free them from the necessity of extensive preparation, if required to teach the same subject a second year. The discovery of this fact is one of the serious disappointments of young teachers. The same holds in study. Every new lesson, every new book, must be mastered in a 
way peculiar to itself; each affords a new test of resourcefulness. Thus the exercise of initiative is a constant and very important factor in all independent study.

Power of initiative might still prove no source of difficulty, if it were something that could be acquired mainly by imitation. But there is the rub; (2) Why the case of the geography class mentioned on power of page 258 shows conclusively that the natural cannot bo tendency of young people to imitate the ex- soquired ample of initiative set by their teachers gives tation. very little guarantee of the exercise of similar initiative on their part when studying alone.

And there are plain reasons for this. In the first place, there is the widest difference between seeing and doing, between theory and practice in general, so that one may observe an action and still fail utterly to duplicate it. That is very common. But, in addition, the power of initiative, being really the "ability to originate or start," calls for a good degree of originality and, therefore, lies largely outside the field of imitation. In the second place, the long-continued following of a leader, instead of fitting one to lead, may directly unfit one for that responsibility. In the case of the geoggraphy class it had been the leader who had determined how each lesson should be attacked; who had exercised resourcefulness in meeting unexpected obstacles; who had assumed responsibility for deciding what the crucial questions were, and when the answers were correct and complete; and who had supplied the energy that made things "go." Under these circumstances, could it be expected that these children, in their 
teacher's absence, would exhibit these same qualities? Hardly. One does not learn to make an independent plan, to show resourcefulness, to carry responsibility, and to supply motive for effort - in brief, to take the initiative - by having some one else perform these tasks for one. In other words, dependence is not the preparation for independence. Indeed, great skill on the part of a teacher in these respects almost precludes such skill on the part of pupils. If allowed prominence year after year, it so undermines self-reliance that one's helplessness when alone is greatly increased. The children of the geography class had had nearly five years of training in leaning on some one else, so that it was extremely difficult to make them stand alone. They were like common soldiers especially trained to obey their officers, yet expected to maintain their former efficiency when suddenly left without officers. They were even more helpless in the schoolroom, in the presence of a leader, than outside.

By overlooking the difference between studying with a leader and alone, therefore, the teacher overlooks initiative, and in consequence she not only fails to develop that power, but she may easily undermine it by accustoming pupils to depcndence upon her. Here is one of the reasons why young people have not been learning to study properly by themselves.

A second reason is that some of the factors of study themselves have long been neglected or overlooked by teachers. as was stated in a general way in Chapter $\mathbf{I}$ It is not customary, for example, for teachers to set up specific objects in their instruction, which shall furnish motive and he guides in study. Indeed, it is 
rare except among some primary teachers. While the supplementing of text is somewhat common in some subjects, such as literature, any clear notion as to what should be understood by thoroughness is rare indeed; and consequently 2. Some of the factors of study have the whole matter of relative values and of orer looked rganization is poorly comprehended. Chil- (1)Examples dren, and even older students, are not infrequently reprimanded for presuming to judge the merits of subject-matter, a fact that plainly indicates how little the importance of passing on the general worth of ideas is appreciated. Manual training and a few kindred branches recognize the actual using of ideas as their endpoint; but no one will assert that they are regarded as types of other subjects in that respect. Any one will admit that special provision for the development of a tentative attitude toward facts is very exceptional; and students are so commonly submerged by their studies, that there is hardly need to affirm that conscious provision for the preservation and development of individuality is rare. Memorizing is the only universally recognized factor in study; and the supplementing of the author ranks next to it. Whether, aside from these two, any or all of the other factors receive attention, depends upon the individual teacher; as a rule they are sadly neglected, or omitted outright from consideration.

This being true, it is uncommon for students to carry their study through the three or four stages necessary in the proper assimilation of knowledge (see p. 203), because these stages are accomplished only by doing the work involved in these several factors. Very little 
knowledge, for instance, is carried over into habit, the fourth stage. The four fundamental operations in arithmetic and a few facts in composition and grammar are shining exceptions. Very few teachers have ever even asked themselves what portions of their different subjects of instruction should result in habits; whatever habits become actually established, therefore, are a matter of accident rather than of intelligent planning by teachers. Every student reaches the third stage of assimilation with some of his knowledge; that is, he overhauls it until it is translated into his own experience. But what a small proportion of all that he learns becomes welded to him, by the warmth of his feeling for it, so that he forgets where it was obtained and feels it to be his own! Almost any college student can name whole courses that he pursued, to which he never warmed up appreciably.

How small this amount is, is suggested by the small quantity that is carried even through the second stage, where the pupil or student boldly subordinates both author and teacher to himself and asks what profit he is getting; where he casts aside as non-essential much of what is presented, and centers his attention on what seems of real value to him, to weigh and perhaps reorganize it. Many a student never consciously reaches this stage, and might be afraid to let his teacher know the fact if he did. Certainly many a teacher would regard any exercise of choice by the student, in the subject-matter assigned, as an act of impertinence. Evidently most study does not carry assimilation beyond the first stage, in which the crude materials of knowledge are merely collected. And this not because 
young people are lazy and disobedient, but because they are practically taught to stop there by their teachers. They tell the truth when, recalling practice, they almost universally declare that studying is mainly memorizing; and Helen Keller's complaint that she had to study so much that she did not have time to think, expresses a very common experience.

Even if there were no difficulty in regard to initiative, therefore, proper methods of study could not be acquired through imitation, because instruction does not set up a model of study that is worthy of imitation. Beyond doubt, the method of instruction would duplicate the method of study if each were right, and thus an example might be put before the student for him to follow. But there is no such example at present, and while students are upbraided for not studying properly, they are furnished no means of learning the right way.

The reason for this strange neglect of the factors in study is probably due principally to the exaggerated importance of the teacher. Believing in the maxim "As is the teacher, so is the school," we have (2) Why tho placed the center of gravity of the school in factors in the teacher. "The tendency of the (normal) been so the " neglected of training school," says President Millis, "is to teachers. make the teacher self-conscious, concerned about her own performance, about whether she did this or that in the approved way, whether her voice was properly modulated, whether she utilized illustrative and supplementary material in due proportion, whether she followed copy faithfully, whether she got standardized results. The tendency of supervision is to produce the same attitude of the teacher. The success of the 
teacher is graded on her scholarship, her culture, her standardized attainments, her questioning, her care of the property, her attitude toward the community and the system, her sympathy with the supervisor's notions - in short, her pedagogical ability, which is now made a large factor in determining her ration of bread and butter, is measured by her performance and her personal charms." 1 Books dealing with education show the same trend. There are hundreds of volumes on mcthod; but they almost invariably tell about what the teacher should do, that is, they center in the teacher, not in the pupil. No wonder that teachers come to regard themselves as "the whole thing," and sometimes act as though educational institutions existed principally for their benefit.

This exaggeration of the teacher's function has led the teacher habitually to picture the learner in the presence of a helper; and with that thought, it has hardly seemed necessary to ask whether or not the 'earner should set up specific aims as guiding motives in study; the teacher would furnish those herself in class, and perhaps project her influence outside overnight by threats if required. It has hardly seemed necessary to inquire how the learner would know when his work was finished, or to what extent he should pass judgment on thoughts presented, for her questions and other tests would insure proper thoroughness, and her presence would check unfitting boldness in judging. It has hardly seemed necessary to consider how far he should proceed in the mastery of a topic, or

${ }^{1}$ President W. A. Millis, Training Pupits in the Art of Study. The Educator-Journal, Oct., 1908. 
how he should avoid being dogmatic, for she would let him know when the endpoint was reached - if he did not stop too soon of his own accord - and she would reprove too positive an attitude. Finally, it has hardly seemed necessary to enumerate the various ways in which he might protect his individuality, because such protection has always been regarded as one of the teacher's prominent duties, and she would offer it as occasion demanded. Thus, with aid for the pupil always near at hand, the need of careful investigation into the problems of private study and how they should be met has not been felt by teachers to be pressing.

But the teacher herself has been at least something of a student while teaching; and she may have made an extensive study of the learning process as treated under apperception, attention, induction, and deduction, interest, etc. How, then, has she escaped a close acquaintance with the principal factors in study? The answer is that as a teacher she has always thought of herself as giving aid, and has never felt the need of examining into her own method of study. Why should she, if she has never been conscious of any particular weakness in that respect? In short, she has been too much absorbed in herself to analyze the problems of independent study to be undertaken by her pupils, and yet not enough absorbed in herself to investigate her own study. Her psychology and pedagogy have not been valueless by any means; but, lacking the imagination to picture her pupils at work alone, and the sympathy to feel their confusion at such times, she has not been prompted to make an examination of the requirements they should meet when separated from her. Like 
many persons in other fields, she has been too much interested in the results to consider the process itself. "She" in this case represents high-school and college teachers even more than those in the grades. This, at least in part, explains why the method of individual study has been so neglected.

The first change to be made, in order that young people may learn how to study, is to place the center Ohanges no0- of gravity of the school where it belongs - in essary before the learner. The great question of method, will learn then, becomes, How shall one learn? Not, how tostady. first of all, with the aid of the teacher, but alone. What are the main tasks that should be performed in private study, and how should they be ac1. Placing complished? These questions give the right the center of point of view by centering attention in the
gravity of gravity of
the school in pupil, and for that reason they are the first the learner. questions that teachers and books on method should consider. Every one will commend the insight of the mother who said to an instructor, "If you will teach my boy how to prepare his lessons, I will attend to his reciting." If lessons are properly prepared, the testing of knowledge will be simple.

The problem of independent study having reached some solution, how to come to the aid of the independent student, or how to impart knowledge, follows as a narrower and subordinate question. If the former has been adequately treated, the latter will introduce few new psychological points, because a full treatment of method of study will require a careful consideration of apperception, induction and deduction, interest, association of ideas, attention, etc. Above all, it will give a 
new conception of the meaning and scope of self-activity. Teaching will then call mainly for a review of such topics, although from a different and very important view-point.

Method of study will then become a large subject for regular instruction. Even in the kindergarten and the first years of school it will receive some atten- 2. Modifying tion, for that is the time when children begin the subjectto acquire good mental habits or to fall into recitation. pernicious ones. Without making so young pupils fully conscious that they are learning to study, the teacher will lead them to move their eyes rapidly over the printed page, so as to read simple stories quickly in silence, and with good expression orally. This is already done by good teachers. She will accustom them to responsibility for discovering the bearings of observations in nature-study, of stories, work in color, etc., on their home lives, and thus pave the way for collecting knowledge under guidance of definite aims. She will cultivate in them the power to fill out the author's picture, until situations are more vividly seen and felt than now. She will require them to think and talk more sharply by points, and to use judgment in neglecting really unimportant details, training their consciences to allow such neglect, if such training is needed. She will encourage them to pass judgment on the merits of facts that they learn, while influencing them not to feel too sure. She will see that they do whatever thinking is to be done on poems and other matter that is to be memorized before the memorizing itself is undertaken, so that the important habit of memorizing through thought, rather than without it, shall begin to 
be firmly fixed. She will lead them to understand that they are not through with the study of topics until the ideas have been used in some way, perhaps many times. And, particularly, she will put forth effort to keep them natural in whatever they do and say, reasonably contented with their abilities, and self-reliant. While most of such instruction will be incidental, a portion of many a recitation will be directly occupied in this way.

By the time the fifth year of school has been reached the principal facts concerning each of the prominent factors of study can be talked about freely, as so much definitely understood knowledge, and the children can be expected to apply them in their various studies. Many a whole recitation can be spent in supplementing authors' statements, in determining principal thoughts, and in doing many other things suggested in the preceding pages, the teacher directly emphasizing such things as essential parts of proper study, and requiring them in the preparation of lessons. Many a whole recitation, also, may be occupied in discussing how lessons have been prepared, the teacher not seldom presenting her own way in detail and allowing her pupils to compare theirs with it. Abstract theory about method of study will thus be avoided.

Perhaps, most of all, the teacher will fix upon the second stage of study (p. 204) as the crucial point in method, in which the children select what seems of real value to them and let the rest go. Of course they will often err, and then it will devolve upon the teacher to show the value of what they have rejected. If she cannot do that, either her mind or the curriculum will need to be improved. While this seems a grave respon- 
sibility to place upon pupils of the elementary school, it must be remembered that they should know how to study by the time they complete that course; and they cannot possibly learn how, without dealing boldly with values, - the values of facts in comparison with one another, or relative values, and their values to the self, or general values. We have long wanted young people to know how to study, without allowing them choice among ideas, that is, without placing them in the conditions that would permit it. The fact that during the later years of the elementary school children must choose almost daily outside of school between good and bad literature as presented in books, periodicals, and newspapers, and that they actually select and reject freely in their own reading, shows how normal it is to do such work in school, and how important it is to make it prominent.

Method of study will then have precedence over other aims of the school, even ranking above the acquisition of other knowledge. Possibly as much as one-fourth of all the school time might be devoted primarily to this problem, although within that period much subject-matter in the studies would also be mastered.

While children completing the curriculum of the elementary school might then be well enough acquainted with the general principles of study, in their practical applications, to stop the customary complaints of teachers and parents in that regard, method of study would still be far from mastered. For, besides the general principles, there are special principles peculiar to each branch of knowledge, just as there are both 
general and special methods of teaching. Proper study of arithmetic, for example, does not fully include the method of studying algebra, to say nothing of grammar; neither does the method in algebra duplicate that in geometry; nor the method in English, that in Latin; nor the method in Latin that in French. As each new branch is begun, therefore, two or three weeks might need to be spent primarily in considering how it should be studied, and now and then, later, an hour should be occupied in the same way.

Topics in learning to study that are too broad for the limits of any particular branch would need to be taught from time to time. For instance, the use of the table of contents, or of the index of a book, of the library catalogue, of encyclopedias and other reference works, should becomefamiliar in the elementary school, as well as some facts about taking and preserving notes. In high school and college further systematic instruction would be needed on the finding of articles and books treating of certain topics, on the keeping of notes, possibly to the extent of establishing a card catalogue for them, and on the general use of a library. Some attention to methods of study would be in place, therefore, even in college.

On the whole, the content of the regular school period would be considerably modified. Study periods, both supervised and independent, devoted either to method of study or to subject-matter, would be far more common; and, while the reproduction of facts would still be necessary, it need not be the dominant feature of the school; for improved methods of study, or better thinking, would render much of the mere 
lesting of the presence of facts, such as we now have, superfluous. Study periods, or, preferably, thinking periods, as the name in the regular school program, would then be recognized as more fitting than recitation; the latter is a belittling name.

Finally, in order that initiative, good judgment, and even skill, may be aquired in applying the principles of study, young people must do a much larger part of the work in class than has been customary. 3. Modifying President Millis's statements are again emi- the metbod nently sound, when he declares: "It is what tation. the pupil can do, not what the teacher can do, that counts. He may be fascinated by the brilliant performances of his teacher, he may be pulled and pushed about under a skillful cross-examination, he may manipulate apparatus, he may see the wheels go round and round, and come out of it all with little actual gain of power to do things for himself or for others. There is more than a little danger that we have carried the refinements of teaching to the extreme of defeating its proper ends. . . . A college professor of my acquaintance was criticised by a student for carrying the ball too much in class! No coach ever built up a winning team by carrying the ball himself. The pupil must be active. He must carry the ball. He must ask and answer questions. He must make as well as solve problems. He must be in the game himself, if he is to learn to play the game. He must be independently productive. He must learn to do things for himself, in a way which he has adopted for himself." 1

Children and older students, therefore, must become 
accustomed to taking the initiative and doing the other work of study in class, if they are to do these things outside.

One day when reading Hawthorne's story of The Gorgon's Head with a fourth-year class, the writer stopped at an interesting point and asked, "Do you ever stop to talk over what you read? Or do you always 'go on' and 'keep going on'?" "We always go right on," replied several. "We sometimes stop," said a few, among whom was Eddie. "Very well," said I, " let us stop here a moment to talk. What have you to say, Eddie?" "O, we don't talk; the teacher does the talking," said he, with a most nonchalant air. What likelihood was there that that class, after their four years of school training, would show a fair degree of independence in their study of literature, if their teacher were suddenly struck dumb?

It is a matter of rather frequent remark that children accustomed to lively participation in class discussion under a skillful teacher too often experience a disappointing relapse the moment the teacher absents herself. The peculiar stimulus being gone, they not only fail to rise to the occasion by conceiving such questions as she might ask; but even after the questions are put, they are overcome by a strange mental lassitude and make little response. The stimulus to work must come from within rather than from without, if one's state is to be healthy.

Furthermore, just as the children must do a larger part of the work in class, the teacher must do less. One follows as a consequence of the other. The oldfashioned country school neglected its pupils so much 
that knowledge was poorly digested. The modern school very naturally proposes to correct that evil. Accordingly, the "good teacher" of to-day lives very close to her children. In many a school she does not leave them to themselves five minutes in a whole day. With her keen eye she detects their very state of mind, and by the sharpest of questions reveals their slightest error. As a result, their knowledge is much more thorough than it used to be, more of it is acquired, and it is acquired with less effort.

But, meanwhile, new evils have crept in. The teacher, in spite of her better preparation, is working harder than ever, much too hard. She does more thinking in class than any one of her pupils, and more talking than all of them put together. At the same time, she is undermining their independence. The old-fashioned school, by leaving the pupil alone a good share of the time, threw him upon his own resources enough to develop a fair degree of self-reliance. It possessed the merit at least of not preventing the exercise of independence. The modern school, by providing a helper close at hand every moment, tends in the opposite direction. The gain on the whole is questionable.

The good of the old must be preserved while the added good of the new is realized. The wise teacher of the future, therefore, will do more for her children than lead them to learn rapidly and thoroughly; she will endeavor to develop their self-reliance and judgment in study and in other matters just as far as possible. For this end she will, more often than at present, plan to act merely as chairman of discussion, rather than as 
leader of it and an active participant in it. She will in. duce her pupils to study aloud before her, particularly to take such initial steps as lie plainly within their power. She will offer suggestions from time to time, but not to the extent of depriving them of responsibility for determining the main questions and answering them. The longer she instructs a class, the less talking she will do, because they, having grown more resourceful and independent, will be able to do it themselves, it being one of her objects to show them how they can get along without her. She will prove most useful when she is least needed. But her presence will still be necessary, for, while she will no longer have to prod them every moment by questions, her testing will always be important, and her greater maturity of knowledge will render her suggestions and criticisms always valuable.

The art of teaching will then consist not only in ability to present ideas but also in ability to keep still. That is by no means a small task. Under many circumstances it is not difficult to hold one's tongue. But when a teacher is confronted by a class in which every one has the duty of saying something, it is either painful or ridiculous if no one says anything. It is then that the poor teacher is obliged to talk much in order to "keep things going." The really good teacher is the one who understands the secret of delegating responsibility to her pupils, and not the least of her rewards is the fact that she is allowed to rest her voice.

The first condition to be met in regard to home study is to assign only such work as the pupils are known by 
the teacher to be able to do rightly, and without too great physical strain. With the attention to method of study that has been urged, this condition can be easily met. That means, however, that Home stady. many a topic cannot be assigned for the home as it is approached, for it will first require some consideration at school. Thus the home study of a lesson will very often follow rather than precede its study at school.

The assignment of lessons merely by pages is now often decried, and justly, because it leaves the child so utterly without a guide as to method. But, when method of study has been properly taught, such an assignment would often be fitting. The responsibility would then fall upon the pupil of determining what it was good for, of selecting and reorganizing the principal parts, etc.; but he could meet that responsibility because he would understand what things he was to do and would know how to do them.

Parents should not be expected to take a hand in teaching their children how to study, for that is altogether too large a task, and involves too much special preparation. If they observe that a child does not know how, they would better leave him alone, directing him to apply to his teacher for instruction. Parents are more bent upon obtaining results and getting rid of their children - so far as school work is concerned - than are teachers, so that the duties assigned to them should be few and of a simple character.

There are some important things for parents to do, however. They should take pains to provide proper physical surroundings for home study, including quiet, proper light and temperature. They should exert an 
influence in the direction of regular hours, of a short period of relaxation immediately before and after meals and before bedtime, and of some variety of occupation during the longer periods of study, so that fatigue may be avoided. In addition, they should stimulate their children by bringing pressure to bear on the lazy ones, by "hearing lessons" now and then, and, above all, by asking questions that call for a review of facts as well as for their use in conversation. They may give some help; but, if they do, they should by all means avoid falling into disputes about method. The child is right in preferring to do a thing in the teacher's way, for it is to the teacher that he is finally responsible; and parents ought to be broad enough to try to follow the teacher's plan. They can help their children most by showing concern for them, really inspecting their written work instead of merely pretending to, and otherwise manifesting genuine interest in their tasks.

Two questions remain to be considered, the first of which pertains to initiative. If independent study reAre children quires that one practically duplicate the work capable of
the initiative necessary for independent study? dren in the elementary school be expected to study alone, or can they even be trained to it? Much power of initiative is rare even among adults. Much of the instruction of teachers themselves is poor owing to a lack of independent thinking. What success, then, can come to children when they are sent off to study their lessons in private?

In reply, it is safe to say that they can be so trained, provided they have some native capacity for self-reliance that can be used as a basis for such training. And 
that theyhave such capacity can scarcely be questioned. In their choice and leadership of games and other play; in their plans for constructive work; in their serious tasks set by themselves at home; in their selection of topics for conversation and even in the turns that their remarks take, children plainly show power of initiative.

Intelligent parents recognize this fact, and they not infrequently take successful measures to cultivate this power. Kindergartners also recognize it. Indeed, they expect children who are little more than infants to propose suitable tasks, together with the method of their execution, in the kindergarten, and to carry the responsibility of leadership in the conversation of the "circle" and in the games. The resourcefulness of a ten-year-old boy was recently suggested in a certain class in composition. The subject that they were writing on was Mining in the Far West, and spelling was a serious obstacle for one youth, as it was for most of his mates. Finally, with apparent innocence, he asked his teacher if he might not describe his experiences as a miner in the miner's own dialect. On receiving her consent he gloried in his freedom by misspelling nearly every word that he used.

Evidently, latent power of self-direction is one of the "native tendencies" of childhood. The statement may be ventured, also, that while the field of experience of children is very different from that of adults, the exercise of initiative within that field is as common among children as it is among adults within their own field.

There is, therefore, a good basis in children for assuming the initiative. But it is only a basis. Unless this native tendency toward self-direction is carefully 
developed in connection with the studies in school, from year to year, it will of course prove inadequate to the demands of proper study. And that very often happens. In spite of the fact that schools exist for the sake of education, there is many a school whose pupils show a peculiar "school helplessness"; that is, they are capable of less initiative in connection with their school tasks than they commonly exhibit in the accomplishment of other tasks. In its quest for knowledge the school may thus easily prove inferior to the street and the average home in the development of this extremely valuable power.

On the other hand, if children's native capacity for taking initiative has been carefully developed, wellselected subjects of study need make no excessive demands upon them. The topics to be considered will be found so nearly within their experience that their ability to study alone will be taxed only to a normal degree. Children, therefore, can be expected to exercise the initiative that is necessary for independent study from year to year, provided their teachers from year to year do their duty in developing that power.

Finally, even though children be capable of learning to study alone, is there time for such instruction, parIs there ticularly if it is to be the primary object time for throughout possibly a quarter of the elebow to study? mentary-school time, and during a considerable time later? Is not the curriculum already full enough, indeed full to completion? While it is true that it has begun to be reduced by the selection of only surh matter as bears a plain relation to our lives, as can be understood by the learner, and as constitutes some 
part of a large topic, when such reduction has beec completed there may still remain twice as much as ought to be taught. Shall we, then, even while making these eliminations, make additions that may more than equal them?

The addition here proposed is not so alarming. For a long time some of our university departments of physics have aimed rather to teach the scientific method in laboratory investigations than to impurt a knowledge of the facts in physics; and some of our departments of practical politics have been more concerned about the method of investigating political problems than about the conclusions reached conceming them. In such cases the acceptance of proper method as the primary purpose has not precluded the acquisition of much subject-matter, for the method has been taught through the subject-matter. The same would hold in teaching proper method of study.

But, aside from that, attention to proper method of study will result in greatly reducing, rather than in increasing, the work of both teacher and pupil, and in two ways.

First, it will reduce the quantity of subject-matter. It is strange that, in spite of the hue and cry of teachers and superintendents against overcrowding in the ele- : mentary school, they are really the ones who make out the course of study, and there are no persons back of them requiring them to include a large amount. Beyond a minimum portion of the three R's, spelling, and geography, which are required by society, almost anything and everything could be omitted if they greatly desired it. But they have forced young people 
to study in much the same way as they themselves visit European countries, straining to get a bird's-eye view of everything, and settling on nothing long enough to know it intimately and to enjoy it deeply. They justify Herbert Spencer's remark to the effect that he would have known no more than a great many other persons, if he had read as many books as they had.

The difficulty has been that teachers, with the center of gravity of the school within themselves, have lacked a standard for determining their pupils' normal rate of advance. The curriculum that they have outlined has been merely the sum of those things that they have deemed good, that they would like to have the children know; and the children have been set to work to consume all these good things, just like gormands.

With the center of gravity in the child, however, and with the proper method of study in the lead, the learner's real power of assimilation becomes the standard for his rate of advance. And, since assimilation is a very slow process, including much discrimination among ideas as well as their use, comparatively few topics can be undertaken. Appreciation of proper study then makes extensive eliminations so evidently necessary that they become compulsory. So long as we did not look closely at the minds of children, and they seemed to thrive physically, we have lacked proof that they were surfeiting; attention to study reveals the fact too plainly for it to be ignored.

It is not merely the tcacher, either, that will be emboldened to cast aside subject-matter. 'The pupil himself, under the influence of specific purposes, a clear 
notion of thoroughness, and his own conception of values, will quickly pass over many of the facts that are assigned in his lessons. If he pays little attention to a full half of any school text that possesses literary merit, he will probably not be far in the wrong. For perspective is essential in all presentation of thought, and there are usually as many things in the background, necessary and yet to be ignored, as there are in the foreground.

Besides reducing the amount of matter to be studied, proper method of studying will further relieve both teacher and pupil from overwork by eliminating much friction in the process of study. The want of axle grease on a wagon does not increase the actual weight of a ton of coal, but it makes the pulling a lot harder; likewise, awkward methods of study do not increase the curriculum in fact, but they do in effect, by making progress slower and more taxing. There are hosts of young people who are willing and are trying to be studious, who do not know how. They, as well as the lazy ones, have to be dragged along by their teachers, and it is this dragging more than the thinking that exhausts them all. It is the discouragement resulting from this condition that drives many pupils out of school and many teachers into matrimony. While numerous things compete with it as a source of waste in education, unnecessary friction in method of study is probably the greatest source of waste; and it is as foolish to ignore the fact longer as it would be for a manufacturer to refuse to oil and repair his machinery.

There is no question, therefore, about the advisability of taking time to teach proper method of study. 


\section{2}

HOW TO STUDY

In spite of helpful reductions in the curriculum from other sources, we must look to proper method of study as the principal means by which work for both the teacher and the pupil will be made lighter, more effective, and more enjoyable. 


\section{INDEX}





\section{INDEX}

Ans. See Specific purposes. Angell, President James, on the use of libraries, 32.

Aristotle, on the value of expert knowledge, 147.

Arithmetic, in early processes of, facts vary little as to values, 88 ; value of drillin, 179, 180; habits in, that should be insisted upon, 212. See R's.

Art for art's sake, 198.

Assimilation of knowledge, a necessity, 193-203; stages in, 203-208; the time and labor necessary in, 209.

Associations, as a help in memorizing, 167-173; a remedy for cramming, 187.

Attention, proper study requires, 36,37 ; a help to memory, 176$178,185$.

Attitude toward knowledge. See Tentative attitude, and Fixed attitude.

Authorities, proper attitude of the student toward, 138-140. Authority, subordination of, to reason, 237-241; subservience to, in the class-room, $255-258$.

Bacon, Francis, on reading books, 112, 139; on conversation, 218. Baldwin, James, quoted, 171.

Beecher, H. W., on reading and thinking, 283, 284.
Bible text, supplemented by the minister, 61,62 ; by the layman, 62-65.

Books, Gibbon's method of using, 31; President Angell on the use of, 32; Noah Porter on the use of, 32 ; marking in, 107, 108; use in school, 108; Bacon on, 112, 139; the school handling of, too slow, 133; opposing statements in, 136-138; sympathetic attitude toward, 141,142 ; subservience to, 255257; Emerson on the use of, 262.

Browning, Robert, his My Last Duchess supplemented, 65-67.

Cat, discussion of the topic, 40 42.

Character, 251.

Children, their ability to study, 24; method of teaching then how to study, 25; their fitness to select specific purposes of study, 46-55; their need of specific purposes, 47-50; their present mental needs should be considered, 53; practical suggestions for teaching them to find specific aims, 55-60; their ability to supplement thought, 78, 79 ; their imagination, 78 ; their ability to imitate and think, 78; development in- 
struction of, 78, 79; character of their literature, 79; practical suggestions for teaching them to supplement thought, 80-84; their ability to group facts into points, 102-105; practical suggestions for teaching them to group related facts into points, 105-110; their ability to neglect unimportant details, 126128; practical suggestions for teaching them to neglect unimportant details, 128-134; their ability to judge values, 149158; practical suggestions for the development of independent judgment among, 158160 ; their ability to memorize by thinking, 182-184; practical suggestions for teaching them to memorize properly, 184-191 ; their capacity to include the use of knowledge as a factor in their study, 210-212; their desire to do something, 210; practical suggestions for teaching them to make the using of knowledge a part of their study, 212-219; how the matter of the tentative attitude concerns them, 230, 231 ; specific suggestions for cultivating a tentative attitude among them, 232-245; originally endowed with certain impulses and instincts, 247; their method of advance, 248; their ability to learn to study, 285; why they lave not been learning to study properly alone, 285-296; whether they are capable of the initiative neces- sary for independent study, 306-308.

Class-room, talk in, should take place under natural condi. tions, 215-218.

Comparisons, as an aid to memorizing, 171, 172.

Composition, English, value of individuality in, 248-250; how it typifies life in general, 250, 251.

Concentration, need of and method of securing, 185, 186.

Conscientiousness, 119, 124, 125. Cook, Joseph, on rapid reading, 117.

Cornman, Dr. O. P., on the value of drill in spelling, 179.

Cramming, 174, 186, 187.

Critical attitude toward authorities, 138-142.

Culture, what it is, 198-202.

Curriculum, commonly recognized purpose of, is acquisition of knowledge, 265.

Custom, subservience to, 257.

D'Aubigné, trustworthiness of the History of the Reformation, 136.

Debating, discussion should take the place of, 244 .

Degrees, whether normal schools should be allowed to give, 200 , 201.

Details, 122.

Development instruction, 78, 79, $103,106$.

Dewey, John, Studies in Logical Theory, 13 n.; Ethical Principles underlying Education 
quoted, 91 ; on what a thought is, 205; on the recitation, 217 .

Dickens, Charles, Gradgrind an example of narrowness, 235.

Discussion should take the place of debating, 244.

Dramatizing, type of reproducing thought, 82,83 .

Drill, prominence of, in memorizing, 178-181, 183, 190, 191.

Drummond, The Greatest Thing in the World, 93, 96.

Earhart, Dr. Lida B., her tests of methods of study, 4-6, 8 .

Education, efficiency a recently emphasized object of, 196; liberal, 199-202; development of self, one purpose of, 266.

Efficiency, object of education emphasized in recent years, 196.

Eliot, C. W., on reasoning, 240, 241.

Emerson, R. W., on self-reliance, $251,252,264,280$; on the use of books, 262.

Emotional life, to be fostered in children, 234-237.

End-point of study, indefiniteness of, 192, 193; importance of definiteness of, 193-195; accepted in mastery of the useful arts, 195; in the study of other subjects, 196-198; why the using of knowledge as, needs emphasis, 198-902.

Experience, the principal source of new ideas, 274-280; common neglect of, 275-277; reasons for neglect of, 277-279.
Factors in study, the, 15-24, 31280 ; the finding of specific purposes, 15, 16, 31-60; the supplementing of thought, 17 , 61-84; the organization of facts, 18, 85-134; the judging of the worth of statements, 19 , 135-160 ; memorizing, 20, 161191 ; the using of ideas, 20,21 , 192-219; the tentative attitude, 22, 220-245; provision for individuality, 23, 246-280; have been partly overlooked, 291296.

Facts, organization of, a factor in study, 18, 85-134; specific purposes as a basis for organization of, 39-42; different values of, and their grouping into points, 85-110; extent to which teachers treat them as equal, 85-87; the effect of treating them as equal, 87,88 ; as a rule, they vary greatly in value, 88 , 89; dependent upon one another for their worth, 89-91; sum of, does not equal the whole, 91, 92; the student's double task in the organization of, 98-100; precautions against inaccuracy in the grouping of, 100-102; ability of children to group them into points, 102-105; practical suggestions for teaching children to group them into points, 105-110; neglect of relatively unimportant, 110 134, see Neglect; have value as they relate to the leading ideas, 114; how recalled, 167. 
Feeling, remedy for static condition of ideas, 234-237.

Fiske, John, The Critical Period of American History, 57, 9496.

Fixed attitude toward knowledge, why undesirable, 220227.

Franklin, Benjamin, his habit of using terms of modest diffidence, 244,245 .

Froude, James Anthony, on facts and their grouping, 90.

Gibbon, Edward, his method of reading a new book, 31 .

Gorschen, G. J., on haste in reading, 284.

Greeks, ancient, their view of the use of knowledge, 198.

Grouping of facts into points, 85-110. See Points.

Habit, formation of, 206-208; easily formed by children, 212; special recognition of those facts that should be translated into, 212, 213.

Hawthorne, Nathaniel, Gorgon's Head quoted, 127.

Headings, 106, 108.

Holmes, O. W., on assuming a standard of judgment, 145.

Ilome life of the pupil, 219.

Home study, 304-306.

Huxley, T. H., on the supernatural, 226.

Ideas, the using of, a factor in study, 20, 21, 192-219; central, to be formed as early as possi- ble, 114, 115 ; central, must be kept in mind, 115-117; association of, 168-173; new, past experience as the principal source of, 274-280. See Facts, Knowledge.

Imagination in children, 78.

Improper methods of study, 3-11. Independence, combined with modesty, 156, 157, 159. See Judging etc., Judgment.

Individual characteristics, recognition of, 269, 270.

Individuality, provision for, $\mathbf{a}$ factor in study, 23, 246-280; to be preserved, 213-215; change of appreciation of self, 246,247 ; cause of the change, 247, 248; value of, in English composition, 248-250; necessity of accepting it as it is, 251, 252; whether it is conducive to social coöperation, 252, 253; why it is necessary to emphasize the importance of, 253264 ; why it is so difficult to preserve and develop, 264, 265 ; annihilation of, a common outcome of the school, 265; the positive character of provision for, as a factor in study, 265, 266; practical suggestions for preserving and developing, 266280.

Induction, spirit of, not opposed by hunting for the central idea of a book first, 118.

Initiative, lack of, 258-262; responsibility for, 270-274; the nature and importance of, 288; why it cannot be acquired 
through imitation, 289, 290; whether children are capable of it sufficiently for independent study, 306-308.

Interest, 37-39.

James, William, on the memory, 165-170, 177, 178; on habits, 207, 208; on old fogyism, 231 .

Jenks, J. W., Citizenship and the Schools, 229.

Judging of the worth of statements, a factor in study, 19, 135-160; pressing nature of the problem, 135-138; proper attitude of the student toward authorities, 138-140; necessity of this attitude in acceptance as well as in rejection of ideas, 140,141 ; in daily life, 142-146; greatness of each person's responsibility for, 146 ; the basis that every student has for, 147, 148; ability of children in, 149158; practical suggestions for its development among children, 158-160.

Judgment, independent, training toward should begin in the first year of school, 129; slowness in passing, 233, 234; the delaying of, till the evidence has been considered, 243, 244.

Kipling, Rudyard, his Seal Lullaby, 172, 175.

Knowledge, tentative attitude toward, a seventh factor in study, 29, 220-245, see Tentative attitude; organization of, 91-98; the using of, as an end- point, 192-203; stages in the assimilation of, 203-208; the time and labor necessary in real assimilation of, 209 ; children's capacity to include the use of, as a factor in their study, 210212; practical suggestions for teaching children to make the using of, a part of their study, 212-219; fixed attitude toward, 220-227; proper attitude toward, 227-229. See Ideas, Facts.

Koopman, on rapid reading, 117; on judging of worth of statements, 139; on studying history, 172.

Language, value of drill in, 180. Leading thoughts, the collecting of supports for, 109; the stating of, in close sequence, 109.

Liberaleducation. See Education.

Libraries, President Angell on the use of, 32 .

Literature, deals largely with ideals valuable as a guide to conduct, 197; possesses value for developing sympathy, 236. Longfellow, H. W., his The Children's Hour supplemented, 68-70.

Lowell, J. R., on concrete purposes, 37; on reading, 139.

Magazines, opposing statements in, 136.

Marginal, marks, 107, 108; headings, 108.

Marking of books, to indicate relative values, 107 . 
Materials, collection of, 203; selection and reorganization of the profitable portion of, 204; translation into experience, 205 ; formation of habit, 206208.

McMaster, his Child's History of the United States supplemented, $73,74$.

Memoriter method of reasoning in mathematics, 3,4 .

Memorizing, a factor in study, 20, 161-191; usual prominence of, 161 ; reasons for such prominence, 161-164; how this prominence may be reduced, 164-167; improved methods of, 167-173, 176-178; cramming, 174; should follow thinking, 174-176; the prominence of drill in, 178-181 ; by thinking, the ability of children in, 182184 ; by thinking, practical suggestions for teaching it to children, 184-191. See Memory.

Memory, importance of, 161; original quality of, cannot be improved, 165, 166; examples of improvement in, through closer attention and better method, 176-178. See Memorizing.

Methods of study, improper, 3$11,87-92$; teachers' and parents' complaints about, 6; among teachers, 6-8; literature dealing with, 9, 10; seriousness of improper, 11 ; training in, should begin early, 241; why young people have been using improper, 285-296; proper, 296-312.

Mill, John Stuart, on acquaintance with a variety of views, 232,233 ; on character, 251 ; on distrust of self, 263 .

Millis, W. A., on the teacher, 293, 294; on the work in class, 301. Milton, John, quoted, 140.

Mnemonic systems, 169.

Modesty, combined with independence, 156, 157, 159.

Morley, John, Aspects of Modern Study quoted, 31.

Motive power, 36-39.

Muscular method of learning history, 3, 4.

Naturalness, how assured, 249; evidences of lack of, 254-264.

Nature of study, 12-27.

Nature study, 39-42, 84.

Neglect, of relatively unimportant facts, 110-134; involved in relative values, 110 ; not allowable in the three R's and spelling, 111; why necessary in most subjects, 111-113; how safety and skill therein may be developed, 113-117; relation of, to thoroughness, 119-123; ability of children to practice, 126128; practical suggestions for teaching children to practice, 128-134.

Newman, John Henry, on the child's faculties, 149,150 ; on a liberal education, 199.

Newspapers, opposing statements in, 135, 136.

Normal schools, whether they 
should be allowed to give degrees, 200, 201.

Note-taking, 109.

Open-mindedness, 230, 232, 233.

Opposing statements, in books, etc., 135-138.

Organization of facts, a factor in study, 18, 85-134; specific purposes as a basis for, 39-42; the student's double task in, 98-100. See Facts.

Outlines, written, in development instruction, 106.

Orer-conscientiousness in teachers, 124.

Parents, duties of, in the studies of their children, 305,306 .

Parker, Col. F. W., cited, 227, 228.

Pestalozzi, story about, 157 .

Plato, his view of the use of knowledge, 198.

Points, the grouping of facts into. 85-110; precautions against inaccuracy in the grouping of facts into, 100-102; ability of children to group facts into. 102-105; practical suggestions for teaching children to group related facts into, 105-110. See Unit of progress.

Porter, Noah, on reading with a purpose, 32,33 ; on the proper attitude toward books, 142.

Positive forms of speech, to be avoided, 244, 245.

Priggishness, 156-158.

Principles, the referring of disagreements of view to, 241-243.
Prodigal Son, supplemented, 6264.

Purposes, specific, in reading and study, see Specific purposes; general, 34-36; specific, in life, 38.

Questions, 64, 69, 74, 75, 81, 82.

Ratzel, on learning the Koran, 163. Reaction required in proper study, vigor of, 253,254 .

Reading, with a purpose, 31-33; calls for little reflection at first, 83; rapid, 117, 118; varying rates to be encouraged, 131134. See R's.

Reason, subordination of authority to, 237-241.

Recitation, the name, 9, 301; should have emphasis on reflection rather than on reproduction, 81 ; how it should be conducted, 215-219; subjectmatter of, should be modified, 297-301; method of, should be modified, 301-306.

Repetition, prominence of, in memorizing $178-181 ; 183,190$, 191.

Reproducing thought, 82, 83.

Responsibility, of deciding what should be neglected, often to be left with the children, 128-130; that requires exercise of judgment, should be placed upon children, 158, 159; for initiation, 270-274.

Roentgen, story about, 156 .

Rousseau, J. J., trustworthiness of Emile, 137. 
R's, the three, danger of, to habits of reflection, 83, 84; extent to which values differ in, 88,89 ; facts of, not greatly dependent upon one another, 89; no neglect in, allowable, 111.

Ruskin, John, on getting at an author's meaning, 71, 72, 209 ; on marking books, 107, 108.

Sarcasm, not in place in the classroom, 267.

School, community life of, 219 .

Schoolishness, 124.

Scientific habit of thinking, 240, 241.

Self, the, change of appreciation of, 246, 247; cause of the change of appreciation of, 247, 248; as it appears in English composition, 248-250; necessity of accepting it as it is, 251 , 252; whether it is conducive to social coöperation, 252, 253; why it is necessary to emphasize the importance of, 253264 ; why it is so difficult to preserve and develop, 264, 265; annihilation of, a coinmon outcome of the school, 265; the positive character of provision for, as a factor in study, 265, 266; practical suggestions for preserving and developing, 266-280. See Individuality.

Self-assertion, lack of, in the class-room, 255.

Self-confidence, how it can be cultivated, $279,280$.

Self-made men, 250 .
Self-reliance among children, 157, 159.

Socrates, a fertile thinker, 274 . Soundness of statements, judging of the. See Judging, etc.

Specific purposes, the finding of, a factor in study, 15, 16, 31-60; the habit among eminent men of setting up, 31,32 ; examples of, 33; the character of, 34, 35: ways in which they are valu. able, 36-44; by whom and when they should be conceived, 45,46 ; fitness of children in the elementary school to select, $46-55$; needed by children, 4750 ; practical suggestions for teaching children to find, 5560.

Spelling, danger of, to habits of reflection, 83, 84; extent to which values differ in, 88, 89; words not greatly dependent upon one another, 89 ; no neglect in, allowable, 111; thoroughness as connected with, 120 ; associations in, 168, 169; value of drill in, 179 .

Spencer, Herbert, criticism of statement in Education, 136, 137.

Stone, Dr. C. W., on the value of drill in arithmetic, 179, 180.

Student, should plan to use his knowledge, 43; should find the relationships among the smaller portions of thought, 94; his double task in the organization of ideas, 98 ; must find the central idea, 115; must judge of ideas, 139; his basis for 
judging worth, 147, 148; should have definite conception of the end-point, 194; should remember that facility in the use of knowledge is the end of his study, 203; the prospect of applying knowledge a source of motive for, 211; relation between teacher and, 266-268; center of gravity of school should be placed in, 296. See Children.

Study, improper methods of, 311 ; individual examples of, 3 , 4; collective examples of, 4-6; teachers' and parents' complaints about methods, 6; method of, among teachers, 68 ; the prevailing definition of, 9; the literature dealing with method of, 9, 10; nature of, 12-27; how the demand for arises, 12,13 ; variety of response to the demand for, 14 ; factors in, 15-24, 31-280; definition and limitations of the term, 26,27 ; the end-point in, 192-203; for one's own benefit, 213-215; vigor of reaction required in, 253, 254; the meaning of, 283, 284; the ability of children to learn the process, 285; with a teacher and alone, difference between, 285-288; method of, a subject for regùlar instruction, 297301 ; whether there is time to teach the process, 308-312.

Study periods, 301 .

Subordination of authority to reason, 237-241.
Subservience to authority, 255258.

Supplementing of thought, a factor in study, 17, 61-84; in the Bible, 61-65; in other literature, 65-71; the necessity of, as stated by Ruskin, $\boldsymbol{7 1}, 72$; in text-books, 72-75; extent to which it should be carried, 75,76 ; reasons why authors leave room for it, 76,77 ; ability of children in the, 78, 79; practical suggestions for teaching children the, 80-84.

Suppression of individuality, 253266.

Suspended judgment, 228.

Sympathetic attitude toward books, 141, 142.

Sympathy, remedy for static condition of ideas, 234-237.

Teachers, their complaints about methods of study, 6; method of study among, 6-8; example to be set by, in suggesting specific aims, 56-60; extent to which they treat facts as equal in value, 85-87; example to be set by, in grouping facts into points, 105, 106; often overconscientious, 124, 125 ; should refer to kind of attention rather than the time spent in study, 185; their use of subsidiary books and of thought questions, 189 ; a potent factor in securing close attention, 190; largely their fault if children show no power to discriminate the values of facts, 214; man- 
ner in which they should conduct recitations, 215-219, 297-304; subservience to, 255; generally not greatly concerned about preserving and developing individuality, 265; relation between students and, 266268; their duty to help children to recognize their strong and weak points, 270 ; way in which they could put responsibility for initiative on the children, 271, 272; factors of study have been neglected by, 290-293; exaggerated importance of, 293-295; have thought of themselves as giving aid, 295; have lacked a standard for determining their pupils' normal rate of advance, 310 .

Tentative attitude, a factor in study, 22, 220-245; how the matter concerns children, 230 , 231; specific directions for cultivating, 232-245.

Text-books, the supplementing of, 72-75; importance of using, 80 ; kind to be preferred, 80,81 . Texts, 73; the use of several, 104; manner of using, 106110.
Thinking, of what constituted, 161 ; should precede memorizing, 174-176, 187-190; the process, 277-280.

Thinking periods, 9, 301 .

Thoroughness, a common conception of, 119, 120; the correct notion of, 120-123; qualitative, not quantitative, 121, 122; dangers in the two conceptions of, 123-125.

Trifles, the term sometimes unfortunately applied, 122.

Unit of progress, a common, 88; the proper, 92,93 ; the size of, $93,94$.

Use, breadth and meaning of the term, 202, 203.

Values of facts, different, 85-134; the judging of, 135-160.

Vigor of the reaction required in proper study, 253, 254.

Weed, Thurlow, how he improved his memory, 176, 177.

Worth of statements, judging of the. See Judging, etc.

Writing, calls for little reflection, 83. See R's. 


\section{.}




\section{RIVERSIDE \\ TEXTBOOKS IN EDUCATION}

General Educational Theory

PSYCHOLOGY FOR NORMAL SCHOOLS.

By L. A. Averilz, Massachusetts State Normal School, Worcester.

EXPERIMENTAL EDUCATION.

By F. N. Frerman, University of Chicago.

HOW CHILDREN LEARN.

By F. N. Frerman.

THE PSYCHOLOGY OF THE COMMON BRANCHES.

By F. N. FREEMAN.

DISCIPLINE AS A SCHOOL PROBLEM.

By A. C. Pzrky, Jr.

AN INTRODUCTION TO EDUCATIONAL SOCIOLOGY. By W. R. Sмrтн, Kansas State Normal School.

TRAINING FOR EFFECTIVE STUDY. By F. W. Thомяs, State Normal School, Fresno, California.

AN INTRODUCTION TO CHILD PSYCHOLOGY.

By C. W. WADDLE, Ph.D., Los Angeles State Normal Schoob

\section{History of Education}

THE HISTORY OF EDUCATION.

By E. P. CU BbrRLeY.

A BRIEF HISTORY OF EDUCATION.

BY E. P. CUBGERLEY.

READINGS IN THE HISTORY OF EDUCATION.

By E. P. Cubbrrzay.

PUBLIC EDUCATION IN THE UNITED STATES.

BY E. P. CUEERRLEY.

\section{Administration and Supervision of Schools}

HEALTHFUL SCHOOLS: HOW TO BUILD, EQUIP, AND MAIM TAIN THEM.

By MAY AYRzS, J. F. Williams, M.D., University of Cincinnati, and T. D. Wood, A.M., M.D., Teachers College, Columbia University.

PUBLIC SCHOOL ADMINISTRATION.

By E. P. Cugrzrlezy.

RURAL LIFE AND EDUCATION.

By E. P. Cuberkley.

HEALTH WORK IN THE SCHOOLS.

By E. B. Hong, M.D., and L. M. TrRman, Leland Stanford Junior Unlversity.

MEASURING THE RESULTS OF TEACHING.

By W.S. MONROE, University of Illinois. 
EDUCATIONAL TESTS AND MEASUREMENTS.

By W. S. Monror, J. C. DeVoss, Kansas State Normal School; and F. J.

KRLLY, University of Kansas.

THE SUPERVISION OF INSTRUCTION.

By H. W. NuTr, University of Kansas.

STATISTICAL METHODS APPLIED TO EDUCATION.

By H. O. RugG, University of Chicago.

CLASSROOM ORGANIZATION AND CONTROL.

By J. B. Srars, Leland Stanford Junior University.

A HANDBOOK FOR RURAL SCHOOL OFFICERS.

By N. D. Showaltre, Washington State Normal School.

THE HYGIENE OF THE SCHOOL CHILD.

By L. M. TERMAN.

THE MEASUREMENT OF INTELLIGENCE.

By L. M. TERMAN.

Test Material for the Measurement of Intelligence. Record Booklets for the Measurement of Intelligence.

THE INTELLIGENCE OF SCHOOL CHILDREN.

By L. M. Terman.

\section{Methods of Teaching}

TEACHING LITERATURE IN THE GRAMMAR GRADES AND HIGH SCHOOL.

Bу Емма M. Bolentus.

HOW TO TEACH THE FUNDAMENTAL SUBJECTS.

By C. N. Kentall and G. A. Mirick.

HOW TO TEACH THE SPECIAL SUBJECTS.

By C. N. Kendall and G. A. Mirick.

SILENT AND ORAL READING.

BY C. R. STONE.

THE TEACHING OF SCIENCE IN THE ELEMENTARY SCHOOL.

By G. H. Trafton, State Normal School, Mankato, Minnesota.

TEACHING IN RURAL SCHOOLS.

By T. J. WoortsR, University of Georgia.

\section{Secondary Education}

THE JUNIOR HIGH SCHOOL.

By Thos. H. Brigas, Columbia University.

THE TEACHING OF ENGLISH IN THE SECONDARY SCHOOL.

By Charles Swain Thomas.

PRINCIPLES OF SECONDARY EDUCATION.

BY Alexander INGLIS, Harvard University.

PROBLEMS OF SECONDARY EDUCATION.

By David Sngdden, Columbia University. 


\section{PRACTICAL NEW TEXTBOOKS}

\section{PRACTICAL BUSINESS ENGLISH.}

By Oscar C. Gallagher, Superintendent of Schools, Brookline, Mass., formerly Head Master, West Roxbury High School, Boston, and LEONARD B. Moulton, Department of English, High School of Commerce, Boston.

Practical Business English. tells how and what to write to conduct and promote business. Principles are presented clearly and definitely. Every exercise is so planned and analyzed that the pupil has a certain piece of work before him, with specific directions as to how to do it. Much of the material in the book is new and has not been treated in other books of similar character.

\section{LA CLASSE EN FRANÇAIS.}

By E. Gourio, Professor agrégé de l'Université de Paris, Chevalier de la Légion d'Honneur.

This book teaches pupils to read, speak, write, and think in French in a remarkably short time. It follows the direct method; that is, the entire book is written in French excepting translations of words and phrases, and the vocabulary at the end, f the book. $L a$ Classe en Français provides numerous examples, definitions, and pictures to explain the meaning of new words.

A Manual for Teachers - "The Direct Method of Teaching French" - is in preparation.

\section{SPANISH TAUGHT IN SPANISH.}

By Charles F. McHale, Instructor in Spanish in the National City Bank, New York.

The strong appeal of Spanish Taught in Spanish is that the pupil learns his lessons in Spanish right from the start. This method stim. ulates interest and thus enables the pupil to think in Spanish and to absorb the language with amazing rapidity.

\section{THE SCIENCE OF EVERYDAY LIFE.}

By EDGar F. VAN BUSKIRK, formerly in charge of General Science, DeWitt Clinton High School, New York City, and Edıтн L. SMith, Instructor, Geography Department, Boston Normal School.

This is the first science book to be built on a definite unifying principle. This basis is Everyday Needs. All the material is grouped under five units, which are subdivided in to projects.

(1) The Air and How We Use It. - (2) Water and How We Use It. - (3) Foods and How We Use Them. - (4) Protection - Homes and Clothing. - (5) The Work of the World.

The course bears a close relation to the familiar conditions of the pupil's life. The applicability of what he is studying is constantly impressed upon his mind.

\section{HOUGHTON MIFFLIN COMPANY}




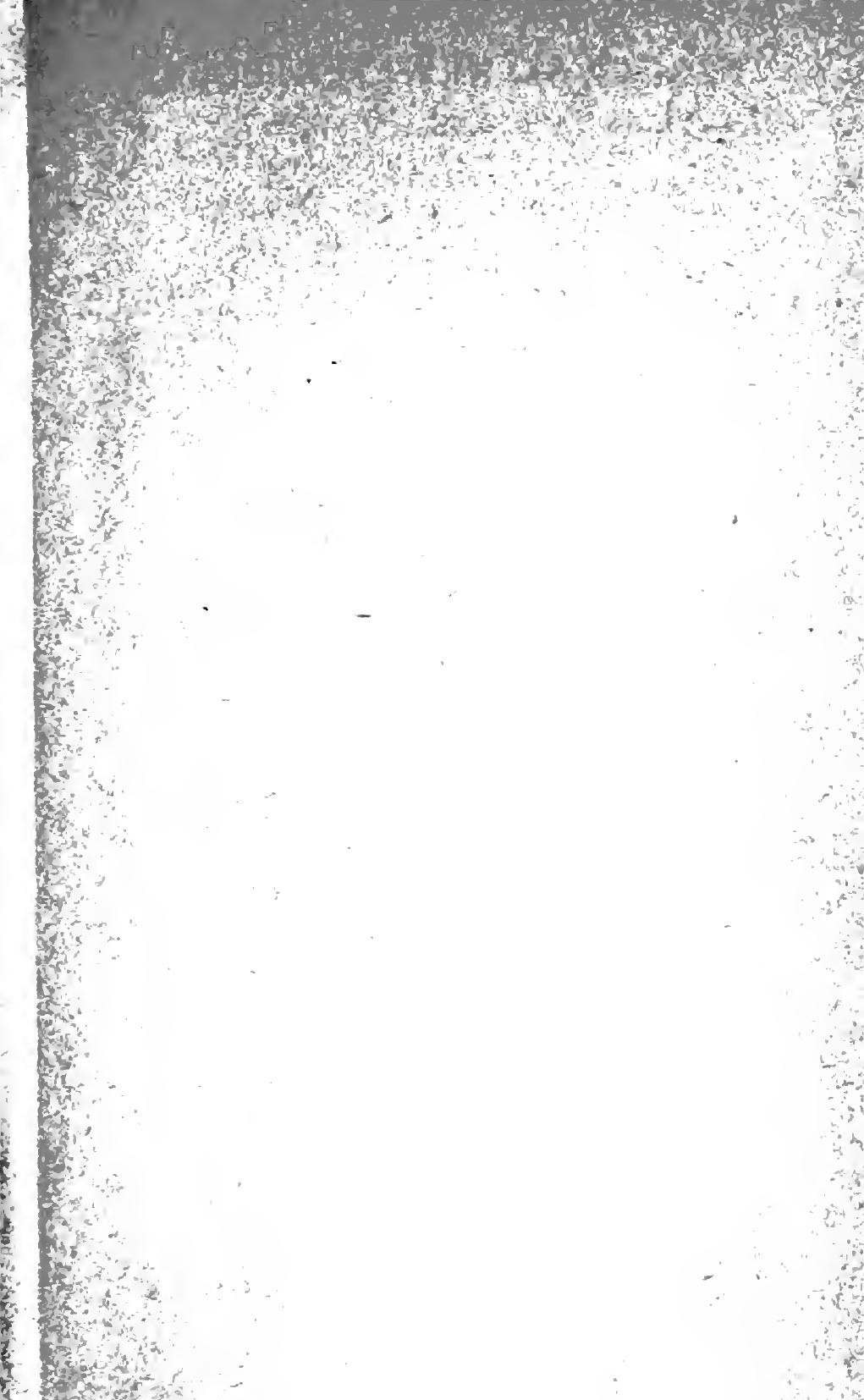



KK 5.6 .57

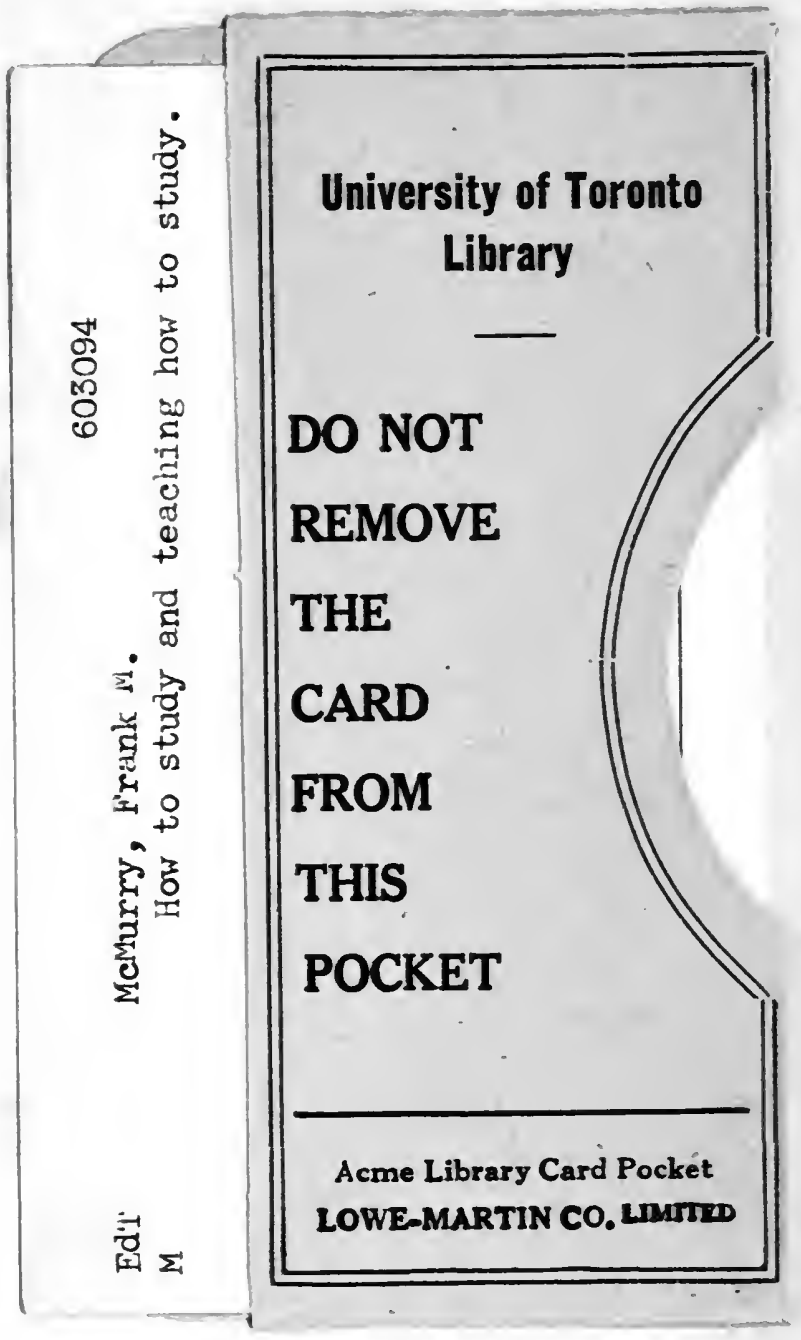


